\title{
Carbon dioxide and climate impulse response functions for the computation of greenhouse gas metrics: a multi-model analysis
}

\author{
F. Joos ${ }^{1,2}$, R. Roth ${ }^{1,2}$, J. S. Fuglestvedt ${ }^{3}$, G. P. Peters ${ }^{3}$, I. G. Enting ${ }^{4}$, W. von Bloh ${ }^{5}$, V. Brovkin ${ }^{6}$, E. J. Burke ${ }^{7}$, M. Eby ${ }^{8}$, \\ N. R. Edwards ${ }^{9}$, T. Friedrich ${ }^{10}$, T. L. Frölicher ${ }^{11,1}$, P. R. Halloran ${ }^{7}$, P. B. Holden ${ }^{9}$, C. Jones ${ }^{7}$, T. Kleinen ${ }^{6}$, \\ F. T. Mackenzie ${ }^{12}$, K. Matsumoto ${ }^{13}$, M. Meinshausen ${ }^{5,14}$, G.-K. Plattner ${ }^{1}$, A. Reisinger ${ }^{15}$, J. Segschneider ${ }^{6}$,

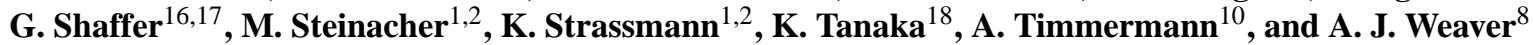 \\ ${ }^{1}$ Climate and Environmental Physics, Physics Institute, University of Bern, Bern, Switzerland \\ ${ }^{2}$ Oeschger Centre for Climate Change Research, University of Bern, Bern, Switzerland \\ ${ }^{3}$ Center for International Climate and Environmental Research - Oslo (CICERO), P.O. Box 1129 Blindern, 0318 Oslo, \\ Norway \\ ${ }^{4}$ MASCOS, 139 Barry St, The University of Melbourne, Vic 3010, Australia \\ ${ }^{5}$ Potsdam Institute for Climate Impact Research, P.O. Box 601203, 14412, Potsdam, Germany \\ ${ }^{6}$ Max Planck Institute for Meteorology, Bundesstr. 53, 20146 Hamburg, Germany \\ ${ }^{7}$ Met Office Hadley Centre, FitzRoy Road, Exeter, EX1 3PB, UK \\ ${ }^{8}$ School of Earth and Ocean Sciences, University of Victoria, Victoria, British Columbia, Canada \\ ${ }^{9}$ The Open University, Environment, Earth and Ecosystems, Milton Keynes, UK \\ ${ }^{10}$ International Pacific Research Center, School of Ocean and Earth Science and Technology, University of Hawaii, 1680 \\ East-West Rd. Honolulu, HI, USA \\ ${ }^{11}$ AOS Program, Princeton University, Princeton, NJ, USA \\ ${ }^{12}$ Department of Oceanography, School of Ocean and Earth Science and Technology, University of Hawaii, Honolulu, \\ Hawaii, 96822, USA \\ ${ }^{13}$ Department of Earth Sciences, University of Minnesota, Minneapolis, MN, USA \\ ${ }^{14}$ School of Earth Sciences, The University of Melbourne, VIC, Australia \\ ${ }^{15}$ New Zealand Agricultural Greenhouse Gas Research Centre, Palmerston North 4442, New Zealand \\ ${ }^{16}$ Department of Geophysics, University of Concepcion, Chile \\ ${ }^{17}$ Niels Bohr Institute, University of Copenhagen, Copenhagen, Denmark \\ ${ }^{18}$ Institute for Atmospheric and Climate Science, ETH Zurich, Zurich, Switzerland
}

Correspondence to: F. Joos (joos@climate.unibe.ch)

Received: 24 July 2012 - Published in Atmos. Chem. Phys. Discuss.: 9 August 2012 Revised: 25 January 2013 - Accepted: 11 February 2013 - Published: 8 March 2013

\begin{abstract}
The responses of carbon dioxide $\left(\mathrm{CO}_{2}\right)$ and other climate variables to an emission pulse of $\mathrm{CO}_{2}$ into the atmosphere are often used to compute the Global Warming Potential (GWP) and Global Temperature change Potential (GTP), to characterize the response timescales of Earth System models, and to build reduced-form models. In this carbon cycleclimate model intercomparison project, which spans the full model hierarchy, we quantify responses to emission pulses of different magnitudes injected under different conditions. The $\mathrm{CO}_{2}$ response shows the known rapid decline in the first
\end{abstract}

few decades followed by a millennium-scale tail. For a 100 Gt-C emission pulse added to a constant $\mathrm{CO}_{2}$ concentration of $389 \mathrm{ppm}, 25 \pm 9 \%$ is still found in the atmosphere after $1000 \mathrm{yr}$; the ocean has absorbed $59 \pm 12 \%$ and the land the remainder $(16 \pm 14 \%)$. The response in global mean surface air temperature is an increase by $0.20 \pm 0.12{ }^{\circ} \mathrm{C}$ within the first twenty years; thereafter and until year 1000, temperature decreases only slightly, whereas ocean heat content and sea level continue to rise. Our best estimate for the Absolute Global Warming Potential, given by the time-integrated 
response in $\mathrm{CO}_{2}$ at year 100 multiplied by its radiative efficiency, is $92.5 \times 10^{-15} \mathrm{yr} \mathrm{W} \mathrm{m}^{-2}$ per kg-CO $\mathrm{CO}_{2}$. This value very likely ( 5 to $95 \%$ confidence) lies within the range of ( 68 to 117$) \times 10^{-15} \mathrm{yr} \mathrm{W} \mathrm{m}^{-2}$ per $\mathrm{kg}-\mathrm{CO}_{2}$. Estimates for timeintegrated response in $\mathrm{CO}_{2}$ published in the IPCC First, Second, and Fourth Assessment and our multi-model best estimate all agree within $15 \%$ during the first $100 \mathrm{yr}$. The integrated $\mathrm{CO}_{2}$ response, normalized by the pulse size, is lower for pre-industrial conditions, compared to present day, and lower for smaller pulses than larger pulses. In contrast, the response in temperature, sea level and ocean heat content is less sensitive to these choices. Although, choices in pulse size, background concentration, and model lead to uncertainties, the most important and subjective choice to determine AGWP of $\mathrm{CO}_{2}$ and GWP is the time horizon.

\section{Introduction}

Emissions of different greenhouse gases (GHGs) and other agents that force the climate to change are often compared by simplified metrics in economic frameworks, emission trading and mitigation schemes, and climate policy assessments. The Global Warming Potential (GWP) introduced by the Intergovernmental Panel on Climate Change (IPCC) in 1990 (Shine et al., 1990), is the most widely used emission metric. GWPs are applied for emission reporting under the United Nations Framework Convention on Climate Change (UNFCCC, 2002) and in the emission basket approach of the legally-binding Kyoto Protocol (UNFCCC, 1998) to compare emissions of different GHGs and to compute the so called " $\mathrm{CO}_{2}$-equivalent" emissions. The initial Kyoto Protocol covered emissions of carbon dioxide $\left(\mathrm{CO}_{2}\right)$, methane $\left(\mathrm{CH}_{4}\right)$, nitrous oxide $\left(\mathrm{N}_{2} \mathrm{O}\right)$, sulphur hexafluoride $\left(\mathrm{SF}_{6}\right)$, hydrofluorocarbons (HCFs) and perfluorocarbons (PFCs) in the first commitment period (2008-2012). The Doha Amendment to the Kyoto Protocol covers emissions in a second commitment period of 2013-2020 and nitrogen trifluoride $\left(\mathrm{NF}_{3}\right)$ is added to the basket of greenhouse gases. The GWP compares the radiative forcing (Forster et al., 2007) integrated over a time period caused by the emission of $1 \mathrm{~kg}$ of an agent relative to the integrated forcing caused by the emissions of $1 \mathrm{~kg} \mathrm{CO}_{2}$. As $\mathrm{CO}_{2}$ is used as a reference gas in the GWP definition, any changes in the computation of the radiative influence of $\mathrm{CO}_{2}$ affect the GWP of any other agent.

The purpose of this study is to compute the response in atmospheric $\mathrm{CO}_{2}$, in ocean and land carbon, global mean surface air temperature, ocean heat uptake and sea level change to a pulse-like (i.e., instantaneous) emission of $\mathrm{CO}_{2}$ into the atmosphere. Best estimates for the mean and the 5 to $95 \%$ confidence range are provided for the Absolute Global Warming Potential (AGWP) and the Absolute Global Temperature change Potential (AGTP) introduced by Shine et al. (2005). We analyse the responses of fifteen carbon cycle- climate models, covering the full model hierarchy, and including two large ensembles of simulations by two of the models constrained with observations as well as an ensemble of runs of a box model substituting for a suite of more complex models. This allows us to address model-related uncertainties by investigating within-model and between-model differences. Uncertainties related to the size of the emission pulse, the atmospheric and climatic background conditions or the choice of the future scenario, and the carbon cycleclimate feedback are assessed in sensitivity simulations. Results are also compared to $\mathrm{CO}_{2}$ response functions as published in the IPCC First (FAR) (Shine et al., 1990), Second (SAR) (Schimel et al., 1996), and Fourth Assessment Report (AR4) (Forster et al., 2007).

A reevaluation of the $\mathrm{CO}_{2}$ response appears timely as (i) past GWP calculations applied results from a single model and (ii) the atmospheric and climatic conditions influencing the $\mathrm{CO}_{2}$ response continue to change with time. The GWP adopted for the first commitment period of the Kyoto protocol (2008-2012) (UNFCCC, 1997, 1998) and used for reporting under the UNFCCC (UNFCCC, 2002) are given by the SAR (Schimel et al., 1996) and based on the $\mathrm{CO}_{2}$ response of the Bern model (Bern-SAR), an early generation reduced-form carbon cycle model (Joos et al., 1996). Its behaviour was compared to other carbon cycle models in Enting et al. (1994) and it was found to be a middle of the range model. The GWP provided in the AR4 (Forster et al., 2007) relies on the $\mathrm{CO}_{2}$ response from the Bern2.5CC (here Bern2.5D-LPJ) Earth System Model of Intermediate Complexity (EMIC) (Plattner et al., 2008). More recently, the Conference of the Parties serving as the meeting of the Parties to the Kyoto Protocol decided (UNFCCC, 2011b, a) that the GWP from the AR4 should be used for the second commitment period of the Kyoto Protocol and the Conference also noted in its decision that metrics are still being assessed by IPCC in the context of its Fifth Assessment Report (AR5). A much broader set of models covering the whole model hierarchy from reduced-form models, to EMICs, to comprehensive Earth System Models (ESMs) are now available.

The redistribution of additional $\mathrm{CO}_{2}$ emissions among the major carbon reservoirs in the Earth System depends on previous emissions and on climate. In addition, radiative forcing of $\mathrm{CO}_{2}$ depends logarithmically on its own concentration. The response functions are calculated by modelling the response to a pulse emission added to a given concentration and climate state, but these background conditions have changed and will continue to change. For example, the concentration of atmospheric $\mathrm{CO}_{2}$ continued to increase from $354 \mathrm{ppm}$ in 1990 , to $378 \mathrm{ppm}$ at the time of the preparation of the IPCC AR4 report to $389 \mathrm{ppm}$ in 2010 (Conway and Tans, 2012). Such changes in the background concentration cause both the radiative forcing and the response function to change, but the changes partially cancel leading to smaller changes in the AGWP (Caldeira and Kasting, 1993; Reisinger et al., 2011). 
Additional uncertainties are of a fundamental nature as any metric to compare greenhouse gas emissions represents a crude simplification. Different forcing agents are distinct and have distinct impacts on climate and the Earth system. Differences include different atmospheric perturbation lifetimes ranging from weeks to many millennia, different regional and vertical distributions within the atmosphere and thus different influences on the energy fluxes within the atmosphere and to the Earth's surface, different indirect effects such as confounding impacts on the lifetimes of other GHGs (Prather and Hsu, 2010).

A complication is the complex and regionally and temporally distinct relationship between anthropogenic emissions, atmospheric abundances, radiative forcing, climate change and impacts and damages on socio-economic and natural systems. Other metrics have been proposed in addition to GWP such as global temperature change potential (GTP) (Shine et al., 2005; Fuglestvedt et al., 2010), the integrated temperature change potential (iGTP) (Peters et al., 2011; Azar and Johansson, 2012; Gillett and Matthews, 2010), the TEMPerature proxy index (TEMP) (Tanaka et al., 2009a), global damage potentials (GDP) (Kandlikar, 1995), global cost potentials (GCP) (Tol et al., 2012; Manne and Richels, 2001) and the Cost-Effective Temperature Potential (CETP) (Johansson, 2012). These metrics compare, for equal mass emissions of two GHGs, the global average surface air temperature change at a given point in time (GTP), the relative damages (GDP), or the ratio of the shadow price of a gas to the shadow price of $\mathrm{CO}_{2}$ when a given climate change target is achieved at least cost (GCP). TEMP is defined so that it provides a best fit to the temperature trajectory of a given period and CETP is based on an approximation of the GCP. Uncertainties generally increase along the cause-effect chain from emissions to impacts (Prather et al., 2009) and there is a trade-off for the selection of metrics between completeness and complexity versus simplicity and transparency, implying the necessity of subjective judgments (Fuglestvedt et al., 2003; Plattner et al., 2009; Tanaka et al., 2010).

While the GWP is a proxy for climate impacts, nonclimatic effects are not captured by the GWP or similar metrics. Air pollutants, such as ozone, aerosols, nitrogen oxides, carbon monoxide, or volatile organic compounds, influence human health and ecosystems directly. Anthropogenic $\mathrm{CO}_{2}$ emissions cause not only global warming, but also ocean acidification by the uptake of excess $\mathrm{CO}_{2}$ (Orr et al., 2005; Joos et al., 2011; Friedrich et al., 2012) - a threat to coral reefs, marine ecosystems, and related economic sectors (Gattuso et al., 2011).

The different perturbation timescales imply that near-term effects of short-lived agents must be compared with the persistent effects of long-lived agents if a metric is to be defined. Attempts involve the restriction to a distinct time horizon for the numerical evaluation of the metric (traditionally 20, 100 or $500 \mathrm{yr}$ for GWP) or the application of discounting rates, typically giving little weight to effects in the more distant fu- ture. In summary, any metric used to compare emissions of GHGs and other agents involves subjective choices and value judgments and represents a considerable simplification (e.g., Tanaka et al., 2010; Fuglestvedt et al., 2003; Boucher, 2012).

\section{Emission metrics and impulse response functions}

\subsection{Global warming potential}

The Global Warming Potential is based on the timeintegrated radiative forcing due to a pulse emission of a unit mass of gas at nominal time, $t=0$. It can be given as an Absolute Global Warming Potential for gas $x\left(\mathrm{AGWP}_{\mathrm{x}}\right)$ or as a dimensionless value by dividing the $\mathrm{AGWP}_{\mathrm{x}}$ by the AGWP of a reference gas, usually $\mathrm{CO}_{2}$. The GWP is thus defined as:

$\mathrm{GWP}_{\mathrm{x}}(\mathrm{TH})==\frac{\operatorname{AGWP}_{\mathrm{X}}(\mathrm{TH})}{\mathrm{AGWP}_{\mathrm{CO}_{2}}(\mathrm{TH})}$

and the AGWP by:

$\operatorname{AGWP}_{\mathrm{x}}(\mathrm{TH})=\int_{0}^{\mathrm{TH}} \mathrm{RF}_{\mathrm{x}}(t) \mathrm{d} t=\int_{0}^{\mathrm{TH}} A_{\mathrm{x}} \cdot \operatorname{IRF}_{\mathrm{x}}(t) \mathrm{d} t$,

where $\mathrm{RF}_{\mathrm{X}}(t)$ is the radiative forcing at time $t$ caused by the emission pulse released at time $t=0$. TH is the time horizon of choice over which the radiative forcing is integrated. For the GWP used by the UNFCCC and in the Kyoto Protocol, a time horizon TH of $100 \mathrm{yr}$ is applied, though this choice lacks a scientific basis (Shine et al., 1990).

Forster et al. (2007) (Table 2.14, p. 212) report the GWP of many gases and for different time horizons. A problem related to reporting GWP only is that each update in $\mathrm{AGWP}_{\mathrm{CO}_{2}}$ affects the reported GWP values of all other gases. This could be easily avoided by reporting Absolute Global Warming Potentials in addition to GWP.

The radiative forcing, $\mathrm{RF}_{\mathrm{x}}$, of gas $x$ can be written as the product of its radiative efficiency, $A_{\mathrm{x}}$, and the perturbation in its abundance or burden, $\mathrm{IRF}_{\mathrm{x}} . A_{\mathrm{x}}$ is defined as the radiative forcing per $\mathrm{kg}$ increase in atmospheric burden of gas $x$. $\operatorname{IRF}_{\mathrm{X}}(t)$ is the impulse response function (IRF) or Green's function. $I R F_{X}$ represents the time-dependent abundance of gas $x$ caused by the additional emission of one $\mathrm{kg}$ of gas $x$ at time 0 . In other words, the $\operatorname{IRF}_{\mathrm{X}}(t)$ is the fraction of the enhancement in concentration due to the added emission pulse remaining in the atmosphere at time $t$. For sufficiently small emissions and approximately constant background conditions the radiative efficiency, $A_{\mathrm{x}}$, can be approximated as time-invariant.

The radiative forcing by a perturbation in the atmospheric burden of $\mathrm{CO}_{2}, \Delta \mathrm{N}_{\mathrm{CO}_{2}}$, relative to a reference burden , $N_{\mathrm{CO}_{2}, 0}$, is parameterized following (Myhre et al., 1998):

$\mathrm{RF}_{\mathrm{CO}_{2}}\left(\Delta N_{\mathrm{CO}_{2}}\right)=5.35 \mathrm{Wm}{ }^{-2} \ln \left(\frac{N_{\mathrm{CO}_{2}, 0}+\Delta N_{\mathrm{CO}_{2}}}{N_{\mathrm{CO}_{2}, 0}}\right)$. 
This yields for small perturbations:

$\mathrm{RF}_{\mathrm{CO}_{2}}\left(\Delta \mathrm{CO}_{2}(t)\right)=5.35 \mathrm{Wm}-2 \frac{\Delta N_{\mathrm{CO}_{2}}}{N_{\mathrm{CO}_{2}, 0}}=A_{\mathrm{CO}_{2}} \cdot \Delta N_{\mathrm{CO}_{2}}$

for $\Delta \mathrm{N}_{\mathrm{CO}_{2}} \rightarrow 0$

Thus in the limit of a small perturbation, the radiative efficiency of $\mathrm{CO}_{2}$ is $5.35 \mathrm{~W} \mathrm{~m}^{-2}$ divided by the constant reference burden and is thus itself a constant and time-invariant.

It is convenient to describe the $\mathrm{IRF}_{\mathrm{x}}$ by exponential functions (Prather, 2007; Maier-Reimer and Hasselmann, 1987; Aamaas et al., 2012).

$\operatorname{IRF}_{\mathrm{x}}(t)=a_{\mathrm{x}, 0}+\sum_{i=1}^{n} a_{\mathrm{x}, i} \cdot \exp \left(\frac{-t}{\tau_{\mathrm{x}, i}}\right)$ for $t \geq 0$.

The unitless coefficients $a_{\mathrm{x}, i}$ represent a fraction that is associated with a certain nominal timescale $\tau_{\mathrm{x}, i}$ and their sum, including $a_{\mathrm{x}, 0}$, equals $1 . a_{\mathrm{x}, 0}$ is the fraction of emissions that remains permanently in the atmosphere. In turn the AGWP for gas $x$ is:

$$
\begin{aligned}
& \operatorname{AGWP}_{\mathrm{x}}(\mathrm{TH})=A_{\mathrm{x}} \cdot a_{\mathrm{x}, 0} \cdot \mathrm{TH} \\
& \quad+A_{\mathrm{x}} \sum_{i=1}^{n} a_{\mathrm{x}, i} \cdot \tau_{\mathrm{x}, i}\left(1-\exp \left(\frac{-\mathrm{TH}}{\tau_{\mathrm{x}, i}}\right)\right) .
\end{aligned}
$$

AGWP increases with increasing time horizon TH. It approaches a constant value for TH several times larger than the largest perturbation timescale of gas $x$ and if $a_{\mathrm{x}, 0}$ is equal zero. Then, the AGWP becomes the product of the "steady-state" life time of a perturbation, $\tau_{x, \mathrm{SS}}$, (Prather, 2007) and the radiative efficiency, i.e., $\mathrm{AGWP}_{\mathrm{x}}=A_{\mathrm{x}} \tau_{x}$,Ss. The steady-state perturbation lifetime is the weighted sum over all timescales $\left(\tau_{\mathrm{x}, \mathrm{SS}}=\Sigma a_{\mathrm{x}, i} \tau_{\mathrm{x}, i}\right)$. This implies that a change in the integration horizon from, for example, $100 \mathrm{yr}$ to $1000 \mathrm{yr}$ has no impact on the AGWP of gases with up to decadal perturbation timescales such as methane, but AGWP continues to increase with $\mathrm{TH}$ for long-lived gases such as $\mathrm{CO}_{2}, \mathrm{~N}_{2} \mathrm{O}$, or $\mathrm{SF}_{6}$. Consequently, the GWP of gases with a short life time generally decreases with increasing time horizon and the variation in GWP values with time horizon only reflects properties of the reference gas $\mathrm{CO}_{2}$. For instance, the GWP values for $\mathrm{CH}_{4}$, which has an adjustment time of approximately $12 \mathrm{yr}$, decrease with increasing time horizon (except for time horizons of a few years only), since GWP is defined with the (increasing) integrated $\mathrm{RF}$ of $\mathrm{CO}_{2}$ in the denominator. As TH increases past the adjustment time of $\mathrm{CH}_{4}$, the development in $\mathrm{GWP}_{\mathrm{CH}_{4}}$ with time horizon is purely controlled by the development in $\mathrm{AGWP}_{\mathrm{CO}_{2}}$ (Aamaas et al., 2012). For long-lived gases (e.g. $\mathrm{N}_{2} \mathrm{O}, \mathrm{SF}_{6}$ ) the development in GWP is controlled by both the increasing integrals of the radiative forcing by the long-lived gas and $\mathrm{CO}_{2}$. In conclusion, the GWP depends strongly on the behavior of the reference gas and sensitively on the (subjective) choice of the time horizon (see e.g., Shine, 2009).

Most GHGs are involved in complex chemical reactions in the atmosphere and are transported within the atmosphere. A local perturbation in one species invokes perturbations elsewhere on a range of timescales and often involving many other species. The chemistry-transport system can be linearized and represented with the help of eigenvalue decomposition following Prather, 2007. Then, it becomes clear that the perturbation timescales $\tau_{\mathrm{x}, i}$ represent the (negative inverse) eigenvalues characterizing the leading chemical modes of gas $x$.

$\mathrm{CO}_{2}$ is, unlike most other agents, not destroyed by chemical reactions in the atmosphere or deposited on the earth surface, but redistributed within the major carbon reservoirs atmosphere, ocean, land biosphere involving multiple timescales for exchange among and for overturning within these reservoirs. A substantial fraction of the initial perturbation by the emission pulse remains in the atmosphere and the ocean for millennia. This fraction is only removed by oceansediment interactions and interactions with the weathering and burial cycle of carbon involving timescales from many millennia to hundred thousand years (Archer et al., 2009).

The continuum of timescales involved in the redistribution of $\mathrm{CO}_{2}$ can be approximated in practice by a few timescales only. It is usually sufficient to consider three to four terms in the sum in Eq. (5). Then the coefficients $a_{\mathrm{CO}_{2}, i}$ and $\tau_{\mathrm{CO}_{2}, i}$ have no direct process-based meaning, but are fitting parameters chosen to represent a given model-based $\mathrm{IRF}_{\mathrm{CO}_{2}}$. The IRF of a model is normally computed by calculating the response to a pulse-like perturbation. In our case, the IRF for atmospheric $\mathrm{CO}_{2}$ is computed within the suite of carbon cycle-climate models by monitoring the simulated decrease of an initial atmospheric $\mathrm{CO}_{2}$ perturbation due to a pulselike $\mathrm{CO}_{2}$ release into the model atmosphere. Similarly, IRFs for surface temperature, ocean heat uptake, sea level rise or any other variable of interest are obtained by monitoring its simulated evolution after the initial perturbation.

The IRFs or Green's functions computed in this study are also useful to characterize the carbon cycle-climate models. The theoretical justification is that IRFs represent a complete characterization of the response of a linear system to an external perturbation. For $\mathrm{CO}_{2}$, the value of the IRF at any particular time is the fraction of the initially added carbon which is still found in the atmosphere. In a linear approximation, the change in atmospheric $\mathrm{CO}_{2}$ inventory at time $t$ can be represented as the sum of earlier anthropogenic emissions, $e$, at time $t^{\prime}$ multiplied by the fraction still remaining airborne after time $t-t^{\prime}, \operatorname{IRF}_{\mathrm{CO}_{2}}\left(t-t^{\prime}\right)$ :

$\mathrm{CO}_{2}(t)=\int_{t_{0}}^{t} e\left(t^{\prime}\right) \cdot \operatorname{IRF}_{\mathrm{CO}_{2}}\left(t-t^{\prime}\right) \mathrm{d} t^{\prime}+\mathrm{CO}_{2}\left(t_{0}\right)$,

where $\mathrm{CO}_{2}\left(t_{0}\right)$ is the atmospheric $\mathrm{CO}_{2}$ inventory at a time when the system was in (approximate) steady state. The IRF is thus a first-order approximation how excess anthropogenic carbon is removed from the atmosphere by a particular model. 
Non-linearities in the carbon cycle-climate system, however, limit the accuracy of the above equation substantially. The $\mathrm{IRF}_{\mathrm{CO}_{2}}$ is not an invariant function, but depends on the magnitude of the carbon emissions (Maier-Reimer and Hasselmann, 1987). Non-linearities arise from the non-linearity of the carbonate chemistry in the ocean, from changes in ocean circulation with global warming that affect the surfaceto-deep transport of excess anthropogenic $\mathrm{CO}_{2}$ as well as from other effects such as non-linear dependencies of terrestrial productivity or soil overturning rates on climate and atmospheric $\mathrm{CO}_{2}$. It has been shown that the atmospheric response, as simulated with a comprehensive model, is better approximated using oceanic and terrestrial impulse response functions that include major non-linearities of the carbon cycle (Joos et al., 1996; Meyer et al., 1999). In conclusion, the IRF and thus also the AGWP for $\mathrm{CO}_{2}$ depends on the details of the experimental setup (background concentration, pulse size) as well as on the characteristics of the carbon cycleclimate model used for its determination.

\subsection{Global temperature change potential}

The GWP has been critiqued from several angles (e.g., Shine, 2009; O'Neill, 2000) and an important critique is that the AGWP does not directly translate into a well-known climate response. The Global Temperature change Potential (GTP) was developed as an alternative (Shine et al., 2005). The Absolute Global Temperature change Potential (AGTP) is the change in global mean surface temperature, $\Delta T$, at time $\mathrm{TH}$ in response to a pulse emission, $e$, of one unit of agent $x$ at time $t=0$. It corresponds to $\mathrm{IRF}_{T, x}$, the impulse response of temperature, $T$, to a unit emission of agent $x$ :

$\operatorname{AGTP}_{\mathrm{x}}(\mathrm{TH})=\frac{\Delta T(\mathrm{TH})}{e_{\mathrm{X}}(t=0)}$.

The Global Temperature change Potential, $\mathrm{GTP}_{\mathrm{x}}$, is the AGTP of $x$ compared to that of $\mathrm{CO}_{2}$ :

$\operatorname{GTP}_{\mathrm{x}}(\mathrm{TH})=\frac{\operatorname{AGTP}_{\mathrm{x}}(\mathrm{TH})}{\operatorname{AGTP}_{\mathrm{CO}_{2}}(\mathrm{TH})}$

The AGTP is often written as convolution integral of the radiative forcing:

$\operatorname{AGTP}_{\mathrm{x}}(\mathrm{TH})=\int_{0}^{\mathrm{TH}} \mathrm{RF}_{\mathrm{x}}(t) \cdot R(\mathrm{TH}-t) \mathrm{d} t$,

where $R(t)$ is the temporally displaced response in $T$ to a $\delta$ function change in radiative forcing at time $t=0 . R$ is influenced by the uncertain properties of the global climate system such as the climate sensitivity, the heat capacity of the lower atmosphere-earth surface system, and by the rate of ocean heat uptake.

In most previous work (Fuglestevedt et al., 2010), the AGTP has been estimated from the convolution of the $\mathrm{RF}_{\mathrm{x}}$ with $R_{T}$ (Eq. 10), where the $\mathrm{RF}_{\mathrm{x}}$ and $R$ often come from different models that are likely not consistent in terms of ocean heat and carbon uptake (for example, the $\mathrm{RF}_{\mathrm{CO}_{2}}$ is from the Bern-SAR model and the $R$ is from HadCM3). It is also possible to estimate $\mathrm{AGTP}_{\mathrm{CO}_{2}}$ and $\mathrm{IRF}_{T, \mathrm{CO}_{2}}$ directly from a climate-carbon cycle model in response to a pulse emission. This is done in this study with the suite of carbon-cycle climate models. Apart from the box models, these models feature a consistent treatment of heat and carbon transport. Following similar logic, it is possible to derive similar expressions for the time-integrated GTP, ocean heat content, and sea level rise. Recent research has shown that the GWP and the time-integrated GTP are numerically similar over a range of time horizons, other than for very short lived species like black carbon (Peters et al., 2011; Azar and Johansson, 2012).

\section{Model description and experimental setup}

An open call was directed to the carbon cycle-climate modelling community to participate in this $\mathrm{IRF}_{\mathrm{CO}_{2}}$ intercomparison project (Joos et al., 2012). A common protocol defines model setup, requested simulations (Table 1), and output and it is given as a Supplement. The procedure corresponds to that for the calculation of the IRF $\mathrm{CO}_{2}$ for the IPCC SAR (Enting et al., 1994) and the IPCC AR4. In addition, output was also requested for the change in global mean surface air temperature as well as ocean heat content, and steric sea level rise. This allows us to derive the impulse response functions for temperature, ocean heat content and steric sea level rise to an emission pulse of $\mathrm{CO}_{2}$ and correspondingly the AGWP and AGTP for $\mathrm{CO}_{2}$ and similar metrics for ocean heat content and steric sea level rise.

Results from fifteen models were submitted (Tables 2 and 3) and these are briefly described and referenced in the Appendix A. The models include three comprehensive Earth System Models (HADGEM2-ES, MPI-ESM, NCAR CSM1.4), seven Earth System Models of Intermediate Complexity (EMICs), and four box-type models (ACC2, BernSAR, MAGICC, TOTEM). Many of these EMICs also participated in three model intercomparsion projects targeted to study the evolution of the climate and the carbon cycle over the historical period (Eby et al., 2012) and under different future scenarios (Zickfeld et al., 2012) and to explore the evolution of the North Atlantic Meridional Overturning Circulation scenarios (Weaver et al., 2012). The EMICs are of varying complexity and include either a 3-dimensional dynamic ocean (Bern3D-LPJ, GENIE, LOVECLIM, MESMO, Uvic-2.9), a 2-dimensional dynamic ocean (Bern2.5D-LPJ, Climber2.4-LPJmL), or a box-type ocean (DCESS). Nine models include a Dynamic Global Vegetation Model (HADGEM2-ES, MPI-ESM, Bern2.5LPJ, Bern3D-LPJ, Climber2.4-LPJmL, GENIE, LOVECLIM, MESMO, UVic-2.9), one model a spatially-resolved 
Table 1. Overview on main simulations. All simulations are started from a preindustrial state.

\begin{tabular}{|c|c|}
\hline Simulation & Model setup \\
\hline & PD100, standard impulse \\
\hline run 1 & $\begin{array}{l}\text { Atmospheric } \mathrm{CO}_{2} \text { prescribed to follow the historical evolution up to year } 2010 \\
\text { and kept at } 389 \mathrm{ppm} \text { thereafter. Compatible emissions are diagnosed. Non- } \mathrm{CO}_{2} \\
\text { and land use forcing constant after } 2010 \text {. }\end{array}$ \\
\hline run 2 & $\begin{array}{l}\text { Model is forced with diagnosed emissions from run } 1 \text { and atmospheric } \mathrm{CO}_{2} \text { is } \\
\text { computed. Other forcings as in run } 1 .\end{array}$ \\
\hline \multirow[t]{2}{*}{ run 3} & Setup as in run 2. An emission pulse of $100 \mathrm{GtC}$ is added in $2015 \mathrm{AD}$ \\
\hline & PI100 and PI5000 preindustrial impulses \\
\hline run 4 & Control simulation under preindustrial conditions and freely evolving $\mathrm{CO}_{2}$ \\
\hline run 5 & As run 4 . An emission pulse of $100 \mathrm{GtC}$ is added in year 10 \\
\hline run 6 & As run 4. An emission pulse of $5000 \mathrm{GtC}$ is added in year 10 \\
\hline
\end{tabular}

terrestrial carbon cycle with prescribed vegetation distribution (NCAR CSM1.4) and five models (ACC2, Bern-SAR, DCESS, MAGGIC6, TOTEM) a box-type biosphere with a simple logarithmic dependency of NPP on $\mathrm{CO}_{2}$. Land use and land use changes and their impacts on the carbon cycle and biophysical forcing are explicitly included as internal part of the model in five models (HADGEM2-ES, MPI-ESM, Bern3D-LPJ, GENIE, UVic-2.9). One model (Bern3D-LPJ, ensemble version) also includes a representation of peatlands and permafrost processes and corresponding carbon stocks (Tarnocai et al., 2009). The equilibrium climate sensitivity of the models ranges between 1.5 to $5.7^{\circ} \mathrm{C}$ for a nominal doubling of atmospheric $\mathrm{CO}_{2}$. Eight models include an oceansediment and weathering/burial module to address long-term (multi-millennial) carbon cycle changes. However, here we restrict the time horizon to $1000 \mathrm{yr}$ and do not provide results for the multi-millennial $\mathrm{CO}_{2}$ evolution. The models used to compute IRF $\mathrm{CO}_{2}$ for the SAR (Bern-SAR) and for the AR4 (Bern2.5-LPJ) as used by the UNFCCC are included for traceability of results.

The "standard" setup corresponds to a pulse input of $100 \mathrm{GtC}$ added to a constant background concentration of $389 \mathrm{ppm}$. The emission pulse is equivalent to a mean atmospheric change of $47.10 \mathrm{ppm}$ when using a unit conversion factor of $2.123 \mathrm{GtC} \mathrm{ppm}^{-1}$ (Enting et al., 1994). Recently, the factor to convert ppm into mol was slightly revised to $0.1765( \pm 5 \%) \mathrm{Pmol} \mathrm{ppm}^{-1}$ (Prather et al., 2012); this yields a conversion factor of $2.120 \mathrm{GtC} \mathrm{ppm}^{-1}$ $\left(0.1765 \mathrm{Pmol} \mathrm{ppm}^{-1} \times 12.01 \mathrm{gC} \mathrm{mol}^{-1}\right)$ when assuming that $\mathrm{CO}_{2}$ is distributed evenly in the atmosphere as done here. For current emissions, the increase in the stratosphere lags the tropospheric increase and a $1 \mathrm{ppm}$ change in the troposphere may corresponds to a mean atmospheric change that is about 1 to $2 \%$ lower. In the following these uncertainties of order $2 \%$ are neglected. Three simulations are performed to determine the "standard" IRF from individual models. An example figure showing results from these three simulations in terms of atmospheric $\mathrm{CO}_{2}$ can be found in the protocol added in the Supplement.

In run 1 , a model is forced with historical concentration up to a reference year (here $t_{\text {ref }}=2010$ ) and then concentration is kept fixed thereafter at a constant value (here $\mathrm{CO}_{2 \text {, ref }}=$ $389 \mathrm{ppm})$. A data file with the reconstructed distribution of atmospheric $\mathrm{CO}_{2}$ over the period 850 to 2010 AD was distributed to all groups. The model emissions, that are compatible with the prescribed $\mathrm{CO}_{2}$ evolution, are diagnosed from the simulated change in total carbon inventory (prescribed atmospheric change plus modelled ocean and terrestrial carbon uptake and any imbalance in the weathering/burial cycle).

In run 2, a model is forced with the diagnosed emissions obtained from run 1 with the same model. Run 2 serves for control purposes only and was not provided for the MPIESM and NCAR CSM1.4 model as CPU time was lacking. In run 3, the same forcing and setup as in run 2 is applied, but in addition $100 \mathrm{GtC}$ are added instantaneously to the atmosphere five years after the reference year (here in 2015.0). The normalised IRF is then approximately:

$$
\begin{gathered}
\mathrm{IRF}_{\mathrm{CO}_{2}}\left(t=t_{\text {model }}-2015.0\right)=\left(\mathrm{CO}_{2}\left(\mathrm{t}_{\text {model }}\right)-\mathrm{CO}_{2, \mathrm{ref}}\right) / \\
\left(100 \mathrm{GtC} / 2.123 \mathrm{GtCppm}^{-1}\right) \text { for } t_{\text {model }} \geq 2015
\end{gathered}
$$

The general advice in the protocol was to include non- $\mathrm{CO}_{2}$ forcing and land use area changes to the extent possible. Non- $\mathrm{CO}_{2}$ forcing as well as land use area are kept constant at 2010 level after 2010. While the total radiative forcing is kept constant in run 1 and 2 after 2010, the climate is evolving freely. The response to a $100 \mathrm{GtC}$ pulse obtained from run 1 to 3 for a present day (PD) background is also termed "PD100" and represents our standard case.

In addition to these standard experiments, groups were also asked to provide results for emissions pulses of $100 \mathrm{GtC}$ 
Table 2. Characterization of the climate models: physical components, $\Delta T_{2 x}$ denotes the equilibrium climate sensitivity for a nominal doubling of $\mathrm{CO}_{2} . \Delta T_{2 x}$ reported here for the Bern3D-LPJ, CLIMBER2, DCESS, LOVECLIM, MESMO1.0, UVic2.9 are those determined by doubling preindustrial $\mathrm{CO}_{2}$ in a simulation over $1000 \mathrm{yr}$ (Eby et al., 2012).

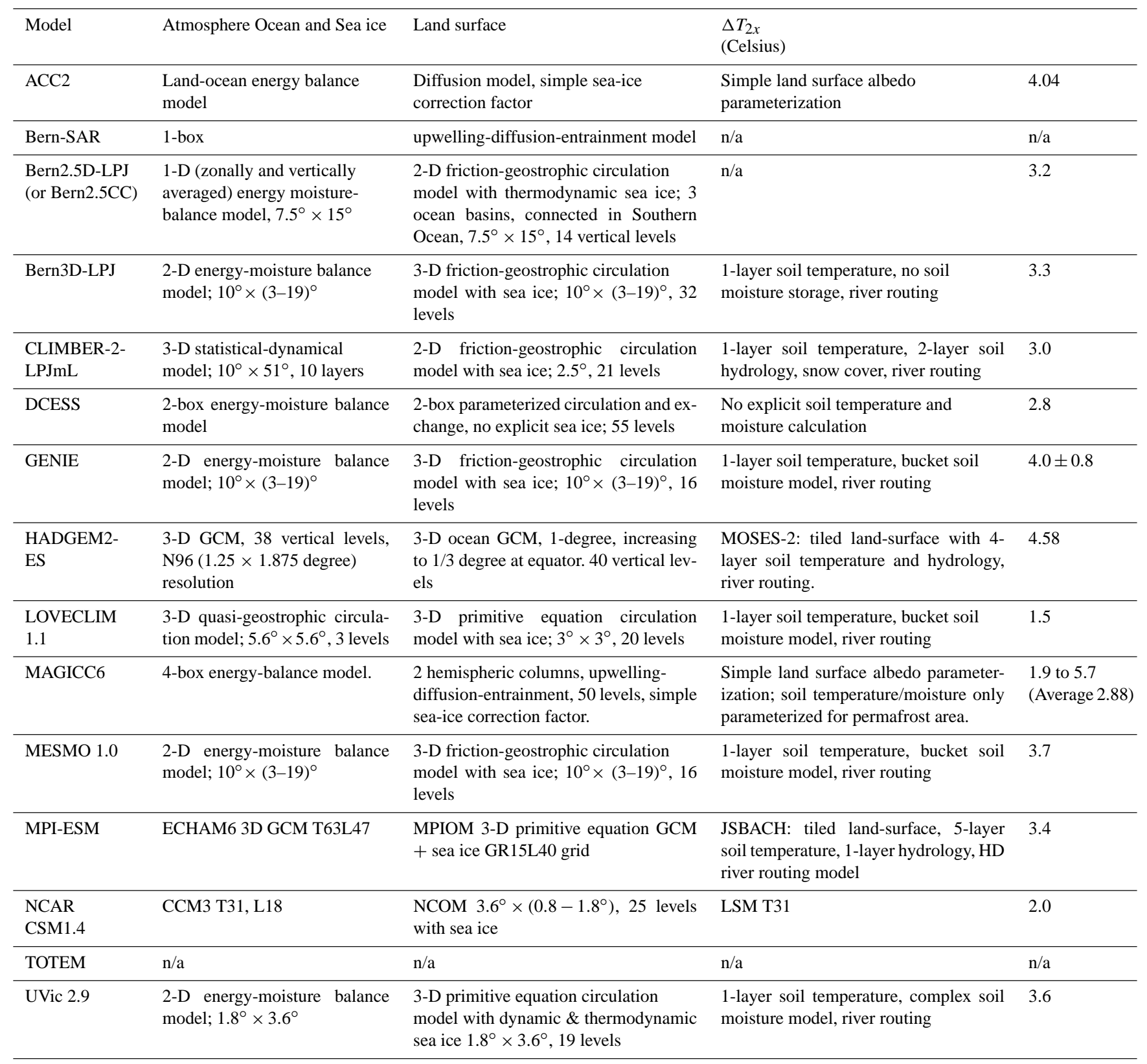

(run 5, case PI100) and $5000 \mathrm{GtC}$ (run 6, PI5000) added to a preindustrial (PI) background. A preindustrial control simulation with constant boundary conditions and freely evolving $\mathrm{CO}_{2}$ was also requested (run 4). $5000 \mathrm{GtC}$ is of the same order as available conventional (coal, oil, gas) fossil carbon resources and has been used in past pulse experiments (e.g., Archer et al., 2009; Eby et al., 2009). This experiment is thus indicative of the long-term consequences for burning all conventional fossil resources. The influence of different background $\mathrm{CO}_{2}$ concentrations is quantified by comparing the standard run with the $100 \mathrm{GtC}$ pulse added to the preindustrial $\mathrm{CO}_{2}$ concentration.

Sensitivity simulations with one model (Bern3D-LPJ, see figures in protocol in tbe Supplement) for PD100 suggest that the simulated response is insensitive to the inclusion of non$\mathrm{CO}_{2}$ forcing and whether the emissions pulse is released at the beginning of the year or distributed over one year. On the other hand, the simulated $\mathrm{IRF}_{\mathrm{CO}_{2}}$ is about 0.02 higher if anthropogenic land use is explicitly included compared to 
Table 3. Characterization of the carbon cycle models.

\begin{tabular}{|c|c|c|c|c|}
\hline Model & $\begin{array}{l}\text { Land } \\
\text { Carbon Cycle }\end{array}$ & $\begin{array}{l}\text { Land use (LU) } \\
\text { (LU area data and } \\
\text { anthropogenic LU classes }\end{array}$ & Marine Biogeochemistry \& Ecosystem & $\begin{array}{l}\text { Sediment/ } \\
\text { Weathering }\end{array}$ \\
\hline $\mathrm{ACC} 2$ & $\begin{array}{l}\text { 4-box, } \beta \text {-factor }\left(\mathrm{CO}_{2} \text { fertilization }\right) \text { and } \\
Q 10 \text { temperature sensitivity of soil res- } \\
\text { piration) }\end{array}$ & $\mathrm{n} / \mathrm{a}$ & $\begin{array}{l}\text { 4-box global atmosphere-ocean, } \\
\text { temperature-sensitive carbonate } \\
\text { chemistry }\end{array}$ & $\mathrm{n} / \mathrm{a}$ \\
\hline BernSAR & 4-box, $ß$-factor $\left(\mathrm{CO}_{2}\right.$ fertilization $)$ & $\mathrm{n} / \mathrm{a}$ & n/a (perturbation approach) & $\mathrm{n} / \mathrm{a}$ \\
\hline $\begin{array}{l}\text { Bern2.5D-LPJ } \\
\text { (or Bern2.5CC) }\end{array}$ & $\begin{array}{l}\text { Dynamic Vegetation Model, } 9 \text { Plant } \\
\text { Functional Types, multiple-litter/soil } \\
\text { pools, } 3.75^{\circ} \times 2.5^{\circ}\end{array}$ & $\mathrm{n} / \mathrm{a}$ & $\begin{array}{l}\text { Prognostic export production, } \mathrm{P}, \mathrm{DIC} \text {, } \\
\text { DOC, }(\mathrm{POC}), \mathrm{ALK}, \mathrm{O}_{2} \text {, no } \\
\text { ecosystem }\end{array}$ & $\mathrm{n} / \mathrm{a}$ \\
\hline Bern3D-LPJ & $\begin{array}{l}\text { Dynamic Vegetation Model, } 9 \text { Plant } \\
\text { Functional Types, multiple-litter/soil } \\
\text { pools, } 3.75^{\circ} \times 2.5^{\circ}\end{array}$ & $\begin{array}{l}\text { Hyde } 3.1 \\
3 \text { LU classes, products }\end{array}$ & $\begin{array}{l}\text { Prognostic export production, } \mathrm{P}, \mathrm{Fe}, \mathrm{Si} \text {, } \\
\text { DIC, DOC, POC ALK, } \mathrm{O}_{2} \text {, no } \\
\text { ecosystem }\end{array}$ & yes/diagnosed \\
\hline $\begin{array}{l}\text { CLIMBER2- } \\
\text { LPJmL }\end{array}$ & $\begin{array}{l}\text { Dynamic Vegetation Model } \\
9 \text { Plant Functional Types, } 12 \text { Crop } \\
\text { Functional Types, } 0.5^{\circ} \times 0.5^{\circ}\end{array}$ & $\begin{array}{l}\text { Landuse dataset 1700-2005 } \\
\text { (Portman et al., 2008; Fader et } \\
\text { al., 2010) }\end{array}$ & $\begin{array}{l}\text { Prognostic export production, P, DIC, } \\
\text { DOC, POC, ALK, O O }, \text { NPZD ecosys- } \\
\text { tem }\end{array}$ & yes/yes \\
\hline DCESS & $\begin{array}{l}\text { 4-box, } \beta \text {-factor }\left(\mathrm{CO}_{2} \text { fertilization }\right) \text { and } \\
Q 10 \text { temperature sensitivity of soil res- } \\
\text { piration }\end{array}$ & $\mathrm{n} / \mathrm{a}$ & $\begin{array}{l}\text { Prognostic export production, } \mathrm{P}, \mathrm{O}_{2} \text {, } \\
\text { POC } \\
\text { PIC, DIC and ALK, no ecosystem }\end{array}$ & yes/yes \\
\hline GENIE & $\begin{array}{l}\text { Efficient Numerical Terrestrial Scheme } \\
\text { (ENTS). } \\
1 \text { Plant Functional Type; } 10^{\circ} \times(3-19)^{\circ}\end{array}$ & $\begin{array}{l}\text { PMIP3 (800-1699), CMIP5 } \\
(1500-2005) 1 \text { LU class }\end{array}$ & $\begin{array}{l}\text { Prognostic export production, } \mathrm{P}, \mathrm{Fe}, \\
\text { DIC, DOC, POC, ALK, } \mathrm{O}_{2} \text {, no ecosys- } \\
\text { tem }\end{array}$ & yes/diagnosed \\
\hline $\begin{array}{l}\text { HADGEM2- } \\
\text { ES }\end{array}$ & $\begin{array}{l}\text { TRIFFID Dynamic global vegetation } \\
\text { model, with } 5 \text { PFTs. Half-hourly car- } \\
\text { bon fluxes from vegetation physiology } \\
\text { and soil respiration. 4-pool soil carbon } \\
\text { model. }\end{array}$ & $\begin{array}{l}\text { Hurtt et al. (2011) harmonized; } \\
\text { Anthropogenic agricultural } \\
\text { fraction }\end{array}$ & DiatHadOCC & $\mathrm{n} / \mathrm{a}$ \\
\hline LOVECLIM1.1 & $\begin{array}{l}\text { Dynamic Vegetation Model } \\
2 \text { Plant Functional Types; } 5.6^{\circ} \times 5.6^{\circ}\end{array}$ & $\mathrm{n} / \mathrm{a}$ & $\begin{array}{l}\text { Prognostic } \mathrm{P}, \mathrm{DIC}, \mathrm{POC}, \mathrm{DOC}, \mathrm{ALK} \\
\mathrm{O}_{2} \text {, export production/no ecosystem }\end{array}$ & preservation/no \\
\hline MAGICC6 & $\begin{array}{l}\text { 4-box global carbon cycle model, cal- } \\
\text { ibrated towards } 9 \text { C4MIP carbon cycle } \\
\text { model's pools and fluxes. }\end{array}$ & $\mathrm{n} / \mathrm{a}$ & n/a (perturbation approach) & $\mathrm{n} / \mathrm{a}$. \\
\hline MESMO 1.0 & $\begin{array}{l}\text { Efficient Numerical Terrestrial Scheme } \\
\text { (ENTS). } \\
1 \text { Plant Functional Type; } 10^{\circ} \times(3-19)^{\circ}\end{array}$ & $\mathrm{n} / \mathrm{a}$ & $\begin{array}{l}\text { Prognostic export production, } \mathrm{P}, \mathrm{Fe}, \mathrm{Si} \text {, } \\
\text { N, DIC, DOC,POC, ALK, no ecosys- } \\
\text { tem }\end{array}$ & $\mathrm{n} / \mathrm{a}$ \\
\hline MPI-ESM & $\begin{array}{l}\text { JSBACH:, } 3 \text { living, } 4 \text { litter, } 1 \text { slow soil } \\
\text { carbon pool, dynamical vegetation, } 12 \\
\text { PFTs }\end{array}$ & $\begin{array}{l}\text { Prescribed } 1994 \text { distribution of } \\
\text { agricultural land }\end{array}$ & $\begin{array}{l}\text { Full carbonate chemistry, NPZD type } \\
\text { ecosystem, } \mathrm{PO}_{4}, \mathrm{NO}_{3}, \mathrm{Fe} \text { colimitation } \\
\text { of biological production }\end{array}$ & yes/diagnosed \\
\hline $\begin{array}{l}\text { NCAR } \\
\text { CSM1.4 }\end{array}$ & CASA prescribed veg. distribution & $\mathrm{n} / \mathrm{a}$ & $\begin{array}{l}\text { Modified OCMIP-2 with prognostic ex- } \\
\text { port }\end{array}$ & $\mathrm{n} / \mathrm{a}$ \\
\hline TOTEM & $\begin{array}{l}\text { Global carbon-nitrogen-phosphorus cy- } \\
\text { cle model, explicit treatments of rivers, } \\
\text { erosion, fertilizer appl. }\end{array}$ & $\mathrm{n} / \mathrm{a}$ & $\begin{array}{l}\text { Global carbon-nitrogen-phosphorus cy- } \\
\text { cle model, explicit treatments of coastal } \\
\text { zone }\end{array}$ & $\begin{array}{l}\text { param./ } \\
\text { parameterized }\end{array}$ \\
\hline UVic 2.9 & $\begin{array}{l}\text { Dynamic Vegetation Model, } 5 \text { Plant } \\
\text { Functional Types, } 3.6^{\circ} \times 1.8^{\circ}, 3 \text { carbon } \\
\text { pools per PFT, } 1 \text { soil carbon pool }\end{array}$ & $\begin{array}{l}\text { Hyde } 3.1,2 \text { grass PFTs used for } \\
\text { agriculture, LUC carbon split } \\
\text { evenly to soil and atmosphere }\end{array}$ & $\begin{array}{l}\text { NPZD, } 2 \text { nutrient and } 2 \text { phytoplankon } \\
\text { classes, prognostic } \mathrm{PO}_{4}, \mathrm{NO}_{3}, \mathrm{O}_{2}, \text { DIC, } \\
\text { ALK, denitrification }\end{array}$ & yes/diagnosed \\
\hline
\end{tabular}

a simulation with natural vegetation only as less carbon is taken up on the converted land.

Three of the participating modeling groups delivered results from an ensemble of simulations. The GENIE group reported results from an ensemble with 69 members where model parameters where varied within uncertainties. The 69member ensemble was derived from a set of around 1500 simulations combined with a statistical modelling and fil- tering procedure applying eight preindustrial climatic constraints (Holden et al., 2013). The 69 member ensemble was reduced to 20 members by requiring a plausible present-day $\mathrm{CO}_{2}$ concentration in an emission-forced simulation over the industrial period and beyond. Here, median and $5 \%$ to $95 \%$ intervals from these 20 different model setups are reported.

The 69-member ensemble has an ensemble-averaged $\mathrm{CO}_{2}$ concentration of $404 \pm 50 \mathrm{ppm}$ (mean $\pm 1 \mathrm{sdv})$ at $2000 \mathrm{AD}$, 
compared to $370 \mathrm{ppm}$ measured at Mauna Loa. $\mathrm{CO}_{2}$ is on average lowered to $364 \pm 14 \mathrm{ppm}$ at $2000 \mathrm{AD}$ in the reduced set. The cases that give the better agreement with observed $\mathrm{CO}_{2}$ have the larger land uptake through the model's $\mathrm{CO}_{2}$ fertilization mechanism. Gross primary productivity in GENIE increases by $27 \pm 18 \%$ (mean $\pm 1 \mathrm{sdv}$ ) in the full set and by $39 \pm 17 \%$ in the reduced set for a doubling of the atmospheric $\mathrm{CO}_{2}$ concentration and considering fertilization only.

The MAGICC model version 6.3 has been run in 171 different parameter settings that emulate 19 AOGCMs and 9 coupled climate-carbon cycle models from the Coupled Model Intercomparison Project Three (CMIP3) and the Coupled Carbon Cycle Climate Model Intercomparison Project (C4MIP). The application of this model to simulate IRFs has been described in (Reisinger et al., 2010).

The Bern3D-LPJ model was run in 1069 different setups selected from a 5000-member ensemble following a Bayesian approach. Nineteen key model parameters are varied. These are related to terrestrial and ocean carbon and heat exchange, uncertainties in anthropogenic radiative forcing, and the transient and equilibrium climate sensitivity of the model. The 5000 member ensemble is constrained by a large set of observation-based data including estimates for surface air temperature change, ocean heat uptake, atmospheric $\mathrm{CO}_{2}$ change and ocean and land carbon uptake rates, seven physical and biogeochemical 3-D ocean tracer fields, and land carbon stocks and fluxes.

Additional sensitivity simulations were carried out with the standard setup of the Bern3D-LPJ model. These include a series of runs with emission pulses ranging from 10 to $10000 \mathrm{GtC}$ added to a preindustrial background. These simulations are used to demonstrate the dependency of the IRF on the magnitude of emissions. The model was also run in a mode where climate was kept constant for emission pulses of 100 and $5000 \mathrm{GtC}$. These simulations allow us to quantify the impact of carbon-cycle climate feedbacks on the $\mathrm{IRF}_{\mathrm{CO}_{2}}$ within the Bern3D-LPJ model.

The pulse size of $100 \mathrm{GtC}$ applied in the standard simulation (run 3) is larger than the pulse size of $10 \mathrm{GtC}$ applied to determine the $\mathrm{IRF}_{\mathrm{CO}_{2}}$ in the Bern-SAR model for the SAR and the pulse of $40 \mathrm{GtC}$ applied in the Bern2.5D-LPJ for the AR4. The choice of the larger pulse size is to improve signalto-noise ratio in the simulated response. The simple BernSAR model does not feature any internal variability and so a small pulse size still permits us to compute its response reliably. In contrast, the Bern2.5D-LPJ used in the AR4 and even more the ESM used in this study feature considerable internal variability in atmospheric $\mathrm{CO}_{2}$ and climate that would mask the response to a small emission pulse.

Model output was smoothed to remove short-term variability using a spline-fit method (Enting, 1987). A cut-off period is chosen as input parameter to the spline routine such that the amplitude of a sine wave with this period is attenuated by $50 \%$. The results from run 3 are subtracted from the control run (run 2; run 1 for MPI-ESM and NCAR CSM1.4). The resulting response is smoothed using cut-off periods of $4,20,50,250$, and $500 \mathrm{yr}$ for the periods from year 0 to 10 , from year 10 to 50, from year 50 to 100 , from year 100 to 300 and year 300 to 1000 , respectively. The response of all models to the $100 \mathrm{GtC}$ pulse added to a $389 \mathrm{ppm}$ background was smoothed in this way for consistency. This treatment has virtually no effect on results from box-models and from EMICs with small or absent internal variability and on the integrated $\mathrm{IRF}_{\mathrm{CO}_{2}}$ that is used to compute the AGWP and GWP.

The multi-model mean $\mathrm{IRF}_{\mathrm{CO}_{2}}$ and responses in other quantities are fitted by a sum of exponentials:

$\operatorname{IRF}(t)=a_{0}+\sum_{i=1}^{3} a_{i} \cdot \exp \left(\frac{-t}{\tau_{i}}\right)$ for $0 \leq t \leq 1000 \mathrm{yr}$

For $\mathrm{IRF}_{\mathrm{CO}_{2}}$ the conditions is applied that the sum of the coefficients $a_{i}$ equals 1 and for the other variables (e.g., surface air temperature, ocean heat content, steric sea level rise) that the sum equals zero. We suggest to use numerical values as obtained by these fits for the multi-model mean in future studies. Note that the fits only apply for the period from 0 to $1000 \mathrm{yr}$. We use the values from the fits as our best estimates.

The responses as simulated by individual models were also fitted using Eq. (11). The coefficients $\left(a_{i}, \tau_{i}\right)$ are tabulated in the Supplement for all models and for the responses in $\mathrm{CO}_{2}$. Results of the fits are compared with the model output in a complementary figure in the Supplement.

\section{Results}

\subsection{Impulse response functions and absolute global warming potentials for $\mathrm{CO}_{2}$}

The evolution of the $\mathrm{IRF}_{\mathrm{CO}_{2}}$ (Fig. 1a) shows a rapid decrease in the first few years after the emission pulse and then a continued but slow decline. It reaches a fraction of $0.60 \pm 0.14$ ( \pm two sdv) at year 20 and $0.41 \pm 0.13$ at year hundred. In other words, while $40 \%$ of the initial atmospheric $\mathrm{CO}_{2}$ perturbation is on model-average removed from the atmosphere within $20 \mathrm{yr}$, it takes additional $80 \mathrm{yr}$ to mitigate the next $19 \%$ of the perturbation. At year 1000, more than $25 \%$ $( \pm 9 \%)$ of the perturbation is still airborne. This evolution is consistent with earlier model results (Maier-Reimer and Hasselmann, 1987; Cao et al., 2009; Siegenthaler and Joos, 1992; Sarmiento et al., 1992; Enting et al., 1994; Archer et al., 2009; Eby et al., 2009). It is also consistent with our understanding of the carbon cycle as two-way transfers of carbon between reservoirs with different timescales (Prentice et al., 2001; Denman et al., 2007; Oeschger et al., 1975; Broecker et al., 1980).

The time-integrated $\mathrm{IRF}_{\mathrm{CO}_{2}}$ (Fig. 1b), and thus $\mathrm{AGWP}_{\mathrm{CO}_{2}}$, increases continuously with time and there is no sign of approaching a steady state value at year 1000 . The time-integrated $\mathrm{IRF}_{\mathrm{CO}_{2}}$ for the individual models is 
Table 4. Time-integrated airborne fraction for different time horizons in units of years and corresponding uncertainty ranges. Multiplication with $1.77 \times 10^{-15} \mathrm{~W} \mathrm{~m}^{-2} \mathrm{~kg}-\mathrm{CO}_{2}^{-1}$ yields the Absolute Global Warming Potential (AGWP) for $\mathrm{CO}_{2}$. Values in parentheses for the Bern3DLPJ, GENIE, and MAGICC6 ensembles represent median and $5 \%$ to $95 \%$ confidence range. The median for each of these models is included in the multi-model mean; reference setup of the Bern3D-LPJ is not included. The errors of the multi-model mean represent \pm two standard deviations. Our best estimate for the mean is the value from the fit to the multi-model mean and the best estimate for the 5 to $95 \%$ confidence range is the average range from the different methods centered at the mean.

\begin{tabular}{|c|c|c|c|c|c|}
\hline Time Horizon & $20 \mathrm{yr}$ & $50 \mathrm{yr}$ & $100 \mathrm{yr}$ & $500 \mathrm{yr}$ & $1000 \mathrm{yr}$ \\
\hline & \multicolumn{5}{|c|}{ Time-integrated $\mathrm{IRF}_{\mathrm{CO}_{2}}(\mathrm{yr})$} \\
\hline NCAR CSM1.4 & 13.8 & 27.8 & 46.6 & $\mathrm{n} / \mathrm{a}$ & $\mathrm{n} / \mathrm{a}$ \\
\hline HadGEM2-ES & 14.7 & 30.9 & 53.3 & $\mathrm{n} / \mathrm{a}$ & $\mathrm{n} / \mathrm{a}$ \\
\hline MPI-ESM & 14.5 & 29.2 & 48.8 & $\mathrm{n} / \mathrm{a}$ & $\mathrm{n} / \mathrm{a}$ \\
\hline Bern3D-LPJ (reference) & 15.4 & 34.3 & 61.9 & 241 & 417 \\
\hline \multirow[t]{2}{*}{ Bern3D-LPJ ensemble } & 15.1 & 32.7 & 57.6 & 205 & $\mathrm{n} / \mathrm{a}$ \\
\hline & $(14.0-16.0)$ & $(28.9-36.0)$ & $(48.9-65.6)$ & $(160-265)$ & $\mathrm{n} / \mathrm{a}$ \\
\hline Bern2.5D-LPJ & 13.9 & 29.7 & 51.1 & 163 & 283 \\
\hline CLIMBER2-LPJ & 13.0 & 26.8 & 49.2 & 181 & 306 \\
\hline DCESS & 14.6 & 31.8 & 56.3 & 199 & 329 \\
\hline \multirow[t]{2}{*}{ GENIE ensemble } & 13.6 & 28.9 & 50.5 & 173 & $\mathrm{n} / \mathrm{a}$ \\
\hline & $(10.9-17.6)$ & $(21.7-41.4)$ & $(38.3-77.9)$ & $(143.68-271)$ & $\mathrm{n} / \mathrm{a}$ \\
\hline LOVECLIM & 13.5 & 27.9 & 45.3 & 170 & 280 \\
\hline MESMO & 15.1 & 33.6 & 61.1 & 238 & 410 \\
\hline UVic2.9 & 13.7 & 29.5 & 53.0 & 209 & 376 \\
\hline $\mathrm{ACC} 2$ & 13.7 & 27.9 & 46.5 & 151 & 252 \\
\hline Bern-SAR & 14.0 & 29.0 & 48.9 & 161 & 270 \\
\hline \multirow[t]{2}{*}{ MAGICC6 ensemble } & 14.0 & 29.6 & 51.8 & 199 & $\mathrm{n} / \mathrm{a}$ \\
\hline & $(12.0-16.1)$ & $(23.6-35.7)$ & $(40.0-64.2)$ & $(148-233)$ & $\mathrm{n} / \mathrm{a}$ \\
\hline TOTEM2 & 16.9 & 38.3 & 66.6 & 180 & 281 \\
\hline \multirow[t]{2}{*}{ multi-model mean } & $14.3 \pm 1.8$ & $30.2 \pm 5.7$ & $52.4 \pm 11.3$ & $186 \pm 48$ & $308 \pm 94$ \\
\hline & \multicolumn{5}{|c|}{ Uncertainty ranges (yr) } \\
\hline multi-model range & 3.6 & 11.3 & 22.6 & 96 & 189 \\
\hline Bern3D-LPJ & 2.1 & 7.2 & 16.7 & 105 & $\mathrm{n} / \mathrm{a}$ \\
\hline GENIE & 6.7 & 19.8 & 39.5 & 128 & 172 \\
\hline MAGICC6 & 4.1 & 12.1 & 24.2 & 85 & $\mathrm{n} / \mathrm{a}$ \\
\hline Linear Progamming & $\mathrm{n} / \mathrm{a}$ & $\mathrm{n} / \mathrm{a}$ & 24.0 & $\mathrm{n} / \mathrm{a}$ & $\mathrm{n} / \mathrm{a}$ \\
\hline Average of ranges & 4.1 & 12.6 & 25.8 & 103 & 180 \\
\hline \multirow[t]{2}{*}{ in $\%$ of multi-model mean } & 28.8 & 41.6 & 49.1 & 56 & 58 \\
\hline & \multicolumn{5}{|c|}{ Best estimates for time-integrated $\mathrm{IRF}_{\mathrm{CO}_{2}}(\mathrm{yr})$} \\
\hline mean & 14.2 & 30.3 & 52.4 & 184 & 310 \\
\hline \multirow[t]{2}{*}{$5-95 \%$ confidence range } & $(12.2-16.3)$ & $(24.0-36.6)$ & $(39.5-65.2)$ & $(132-235)$ & $(220-400)$ \\
\hline & \multicolumn{5}{|c|}{ Best estimates for AGWP of $\mathrm{CO}_{2}\left(10^{-15} \mathrm{yr} \mathrm{W} \mathrm{m}^{-2}{\left.\mathrm{~kg}-\mathrm{CO}_{2}^{-1}\right)}^{-1}\right.$} \\
\hline mean & 25.2 & 53.5 & 92.5 & 324 & 548 \\
\hline $5-95 \%$ confidence range & $(20.7-29.6)$ & $(41.1-65.8)$ & $(67.9-117)$ & $(228-421)$ & $(380-716)$ \\
\hline
\end{tabular}

tabulated in Table 4. The multi-model mean increases from $14.3 \pm 1.8 \mathrm{yr}$ (mean $\pm 2 \mathrm{sdv}$ ) at year 20 , to $30.2 \pm 5.7$ at year 50 , to $52.4 \pm 11.3$ at year 100 , to $186 \pm 48$ at year 500 , and to $308 \pm 94$ at year 1000 .

The multi-model mean $\mathrm{IRF}_{\mathrm{CO}_{2}}$ over the first $1000 \mathrm{yr}$ is fitted by a sum of exponentials and the coefficients for $\mathrm{IRF}_{\mathrm{CO}_{2}}$ and for other responses are given in Table 5. We note that the time-integrated $\mathrm{IRF}_{\mathrm{CO}_{2}}$ as calculated with this fit is the same for a time horizon of $100 \mathrm{yr}$ and slightly different for the time horizons of 20,50,500, and $1000 \mathrm{yr}$ than those the multi-model mean values (the values from the fit are: $14.2 \mathrm{yr}$, $30.3 \mathrm{yr}, 52.4 \mathrm{yr}, 184 \mathrm{yr}, 310 \mathrm{yr}$ ). We use these values from the fit as our best estimates in Table 4 .

Uncertainty ranges across models and from model ensembles: there are uncertainties in the $\mathrm{IRF}_{\mathrm{CO}_{2}}$ and the $A G W P_{C_{2}}$. The range in integrated $\mathrm{IRF}_{\mathrm{CO}_{2}}$ across all models 
Table 5. Coefficients to fit multi-model mean responses to a pulse emission of $100 \mathrm{GtC}$ following Equation 11 in the main text and for $0<t<1000 \mathrm{yr}$. The mean relative error of the fit is given in percent. The error is calculated from annual values as the average of the absolute differences between fit $(f)$ and multi-model mean $(m)$ divided by the multi-model mean $\left(1 / N \sum(m-f) / m\right)$. Multiplication by $\left(12 /\left(100 \times 44 \times 10^{12}\right)\right)$ yields the change per kg- $\mathrm{CO}_{2}$ for ocean and land carbon storage, surface air temperature (SAT), time-integrated SAT (iSAT), steric sea level rise (SSLR), and ocean heat content (OHC). The timescales $\tau_{i}$ are given in years and units of $a_{i}$ are indicated in parentheses in the first column.

\begin{tabular}{lrrrrrrrr}
\hline & rel. error & $a_{0}$ & $a_{1}$ & $a_{2}$ & $a_{3}$ & $\tau_{1}$ & $\tau_{2}$ & $\tau_{3}$ \\
\hline $\mathrm{IRF}_{\mathrm{CO}_{2}}$ & 0.6 & 0.2173 & 0.2240 & 0.2824 & 0.2763 & 394.4 & 36.54 & 4.304 \\
Ocean $(\mathrm{GtC})$ & 0.6 & 60.29 & -26.48 & -17.45 & -16.35 & 390.5 & 100.5 & 4.551 \\
Land $(\mathrm{GtC})$ & 1.3 & 17.07 & 332.1 & -334.1 & -15.09 & 74.76 & 70.31 & 6.139 \\
$\mathrm{SAT}\left({ }^{\circ} \mathrm{C}\right)$ & 1.8 & 0.1383 & 0.05789 & -0.06729 & -0.1289 & 264.0 & 5.818 & 0.8062 \\
iSAT $\left({ }^{\circ} \mathrm{C}\right.$ yr $)$ & 1.8 & 3934 & -4432 & 777.7 & -280.0 & 16080 & 2294 & 1144 \\
$\mathrm{SSLR}(\mathrm{cm})$ & 1.5 & 5.259 & -3.789 & -0.9351 & -0.5350 & 581.7 & 75.71 & 5.963 \\
$\mathrm{OHC}\left(10^{22} \mathrm{~J}\right)$ & 1.0 & 42.63 & -32.86 & -6.589 & -3.182 & 420.4 & 54.82 & 6.340 \\
\hline
\end{tabular}

is 40 to $65 \mathrm{yr}$ at year hundred. This is comparable to the 5$95 \%$ interval ranging from 40 to $64 \mathrm{yr}$ for the MAGICC6 ensemble that emulates a number of carbon-climate models. The 5-95\% confidence interval for the Bern3D-LPJ ensemble, constrained with a broad set of observations, is 49 to $66 \mathrm{yr}$ at year 100 and somewhat smaller than the model range. The ensemble interval from the GENIE model is larger than the other ranges at year 100; the time-dependence of this ensemble was constrained only by preindustrial to modern $\mathrm{CO}_{2}$ change. At year 20 and 50, the situation with regard to uncertainties ranges is qualitatively similar as for year 100. However, the 5-95\% confidence range for the MAGICC6 ensemble is smaller than the range across all models at year 500, whereas the width of the confidence range is larger than that of the model range for the observation-constrained Bern3D-LPJ and GENIE ensembles. This may suggest that observational-constraints as applied in the Bern3D-LPJ narrow the uncertainty range for a time horizon of up to $100 \mathrm{yr}$.

An alternative, linear programming approach: an alternative approach is to constrain the uncertainty in $\mathrm{IRF}_{\mathrm{CO}_{2}}$ by assuming a linear carbon system and constraining the $\mathrm{IRF}_{\mathrm{CO}_{2}}$ with estimates of the 20th century airborne fraction of $\mathrm{CO}_{2}$. If we consider the uncertainty in the integrated response, then clearly if $\mathrm{IRF}_{\mathrm{CO}_{2}}$ lies between 0 and 1, the integral to time $\mathrm{TH}$ will lie between 0 and $\mathrm{TH}$, regardless of the form of the function $\mathrm{IRF}_{\mathrm{CO}_{2}}$. However not all functions have physically reasonable behaviour and not all functions will be consistent with the 20th century pattern of emissions and concentrations. Including such considerations can narrow the range of possible values of the integrated response. Finding the maximum and minimum possible values of the integral (and the functions that give these extrema) is a problem in mathematical optimisation that can be analysed using the calculus of variations. If the constraints are linear, then the discretised form of the optimisation can be expressed as a problem in linear programming for which well-established computational techniques are available (Press et al., 1986). Such an approach to analysing the carbon cycle response was introduced earlier (Enting and Mansbridge, 1987).

For the present study we consider functions with $\mathrm{IRF}_{\mathrm{CO}_{2}}$ $(t=0)=1, \operatorname{IRF}_{\mathrm{CO}_{2}}(t) \geq 0, \mathrm{~d} / \mathrm{d} t \operatorname{IRF}_{\mathrm{CO}_{2}}(t) \leq 0$, and $\mathrm{d}^{2} / \mathrm{d} t^{2}$ $\operatorname{IRF}_{\mathrm{CO}_{2}}(t) \geq 0$, and which give behavior consistent with observations for the 20th century. This last condition is expressed in terms of the 20th century cumulative airborne fraction $\gamma$. If we take $\gamma$ as known precisely then we find that for $\mathrm{TH}=100 \mathrm{yr}$, the integrated response is constrained to lie in the range 39.7 to $52.4 \mathrm{yr}$. The implication is that regardless of the model structure, no linear model that exhibits the dissipative behaviour expressed by the constraints on the derivatives, can have an integrated response that lies outside this range. This range of $13 \mathrm{yr}$ is thus an upper bound on the amount of uncertainty that can arise from differences in model structure (and termed "structural uncertainty", Enting et al., 2012).

If, however, it is acknowledged that the 20th century cumulative airborne fraction is not known precisely, mainly because of uncertainties in land-use emissions (Stocker et al., 2011), then a wider class of response functions and a wider range of integrals is possible. Constraining the airborne fraction to lie in the range $0.5 \pm 0.05$ gives the range 33.6 to $57.6 \mathrm{yr}$ for possible values of the integral for $\mathrm{TH}=100 \mathrm{yr}$. This expanded range of uncertainty is a combination of the "structural uncertainty" described above, and a "calibration uncertainty" arising from uncertainties in the calibration data (Enting et al., 2012).

Since we are primarily concerned with the range rather than the specific value, the 20th century constraint has been approximated in terms of carbon emissions that grew exponentially over $150 \mathrm{yr}$ with a timescale of $50 \mathrm{yr}$ (emissions are proportional to $\exp (t /(50 \mathrm{yr})))$. This is a truncation of the expression for the airborne fraction in terms of the Laplace transform of the response (Enting, 1990). In principle, the same approach can be used for $\mathrm{TH}=20 \mathrm{yr}$ but because the $20 \mathrm{yr}$ timescale is less representative of $20 \mathrm{th}$ 


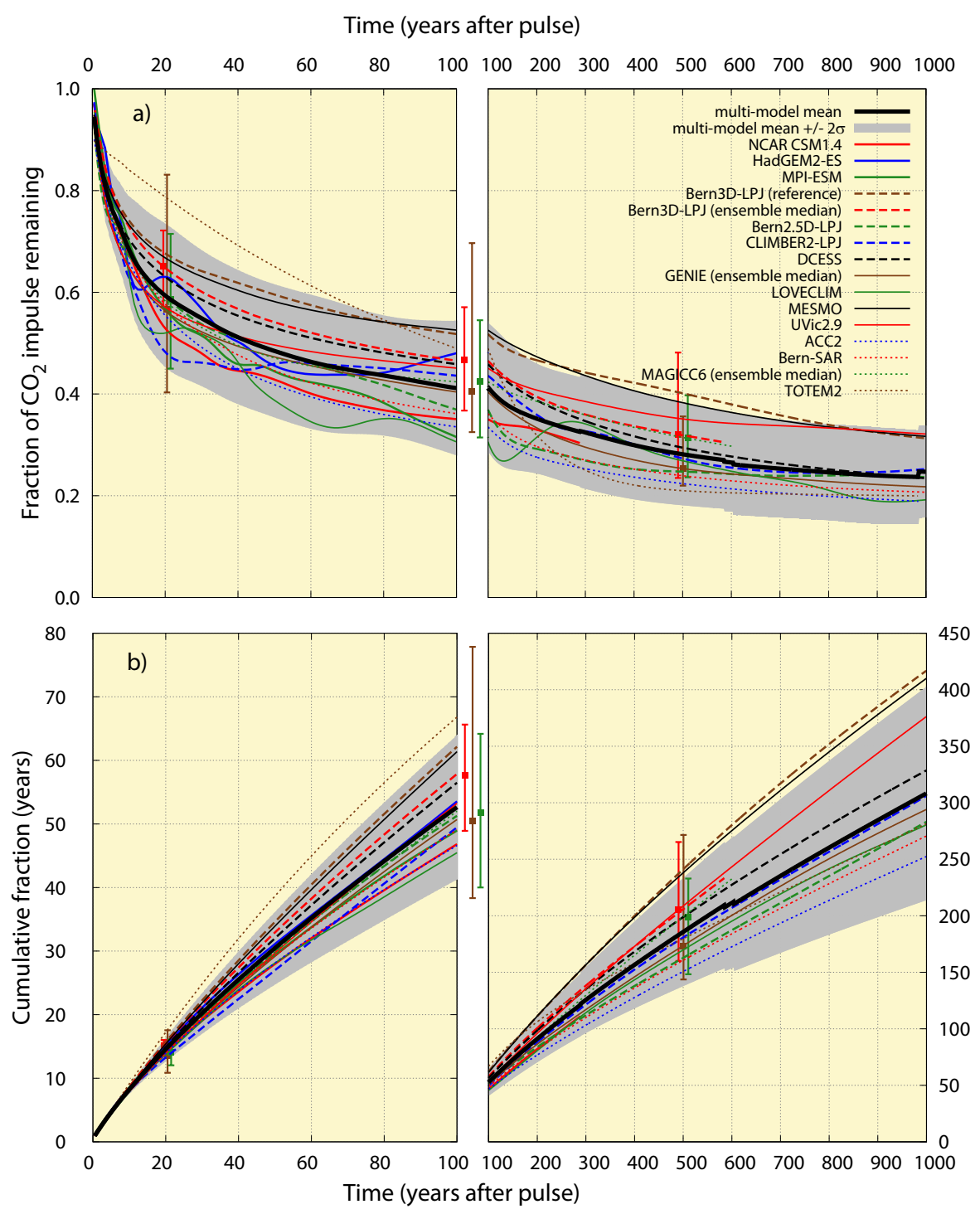

Fig. 1. (a) The evolution of the impulse response function for $\mathrm{CO}_{2}, \mathrm{IRF}_{\mathrm{CO}_{2}}$, for an emission pulse of $100 \mathrm{GtC}$ added to an atmospheric background concentration of $389 \mathrm{ppm}$ (PD100) for a range of Earth System Models (thick solid), EMICs (dashed and thin solid), and reduced-form models (dotted). The multi-model mean, computed by giving each available model equal weight, and the corresponding \pm two standard deviation range is shown by the black solid line and the grey shading. Note that not all models were run to year 1000 and thus the number of models included in the average changes with time. For three models, Bern3D-LPJ (red), GENIE (brown) and MAGICC (green), an ensemble of simulations is available and the ensemble median and 5 to $95 \%$ confidence intervals are given by error bars for year 20,100 , and 500. Only the ensemble medians are included in the multi-model mean and range. (b) Same as (a) but for the time-integrated $\mathrm{IRF}_{\mathrm{CO}_{2}}$.

century changes, the "calibration" constraint does little to constrain the range of uncertainty for the integral.

$5-95 \%$ confidence range: in conclusion, different approaches to estimate the uncertainty in the integrated $\mathrm{IRF}_{\mathrm{CO}_{2}}$ for a time horizon of $100 \mathrm{yr}$ yield comparable results. Taken together, these approaches yield an average uncertainty range of $26 \mathrm{yr}$ or of $49 \%$ for the 100-yr integrated response (Table 4). We assume that this average range represents approximately a $5-95 \%$ confidence range and that it is symmetrically distributed around the multi-model mean to arrive at our best estimates for the mean and 5-95\% confidence range for the time-integrated $\mathrm{IRF}_{\mathrm{CO}_{2}}$.

The MAGICC and Bern3D-LPJ ensemble ranges are roughly symmetrically distributed around the median for time horizons of 20,50 , and $100 \mathrm{yr}$ and skewed, but in different directions, for $500 \mathrm{yr}$. These results tend to support the assumption that the uncertainty range is symmetric around the best estimate, though the ensemble range from the GENIE model is skewed towards high values. 
Absolute Global Warming Potential: multiplying the time-integrated $\mathrm{IRF}_{\mathrm{CO}_{2}}$ with the radiative efficiency of $\mathrm{CO}_{2}, A_{\mathrm{CO}_{2}}$, yields the Absolute Global Warming Potential, AGWP $\mathrm{CO}_{2}$. Here, $A_{\mathrm{CO}_{2}}$ is computed for an atmospheric background of $389 \mathrm{ppm}$ and in the limit of a small perturbation by using the derivative of the simplified radiative forcing expression of (Myhre et al., 1998) (Eqs. 3 and 4 and converting ppm into $\left.\mathrm{kg}-\mathrm{CO}_{2}\right): A_{\mathrm{CO}_{2}}=5.35 \mathrm{~W} \mathrm{~m}^{-2}$ $(389 \mathrm{ppm})^{-1} \times\left(2.123 \times 10^{12} \mathrm{~kg}-\mathrm{Cppm}^{-1}\right)^{-1} \times(12 \mathrm{~kg}-$ $\left.\mathrm{C} / 44 \mathrm{~kg}-\mathrm{CO}_{2}\right)=1.77 \times 10^{-15} \mathrm{~W} \mathrm{~m}^{-2} \mathrm{~kg}-\mathrm{CO}_{2}^{-1}$.

The uncertainty in the radiative efficiency of $\mathrm{CO}_{2}$ is given as $\pm 10 \%$ in the IPCC TAR and AR4 (90\% confidence interval; see page 140 of Forster et al., 2007) and guided by the spread in published estimates. An uncertainty of $\pm 10 \%$ translates to an uncertainty range of $20 \%$. The overall uncertainty in $\mathrm{AGWP}_{\mathrm{CO}_{2}}$ is only slightly larger than that for $\mathrm{IRF}_{\mathrm{CO}_{2}}$ as the uncertainty in $A_{\mathrm{CO}_{2}}$ is much smaller than that of the time integrated $\mathrm{IRF}_{\mathrm{CO}_{2}}$. Assuming quadratic error propagation, the uncertainty range in $\mathrm{AGWP}_{\mathrm{CO}_{2}}(\mathrm{TH}=100 \mathrm{yr})$ is $53 \%\left(\sqrt{ }\left(0.49^{2}+0.2^{2}\right)=0.53\right)$ compared to $49 \%$ of the integrated $\mathrm{IRF}_{\mathrm{CO}_{2}}$ (Table 4). Our best estimate for the $\mathrm{AGWP}_{\mathrm{CO}_{2}}$ is a mean value of $92.5 \times 10^{-15} \mathrm{yrW} \mathrm{m}^{-2}{\mathrm{~kg}-\mathrm{CO}_{2}^{-1}}^{-}$and a $5-95 \%$ confidence range of (68 to 117$) \times 10^{-15} \mathrm{yr} \mathrm{W} \mathrm{m}^{-2} \mathrm{~kg}^{-\mathrm{CO}_{2}^{-1}}$ for a time horizon of $100 \mathrm{yr}$. In IPCC uncertainty language (Solomon et al., 2007), it is very likely that the AGWP $\mathrm{CO}_{2}$ for a time horizon of $100 \mathrm{yr}$ is within a range of (68 to

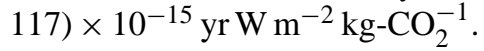

\subsection{Response in surface air temperature and AGTP, ocean heat uptake and steric sea level rise}

The response in radiative forcing to the $100 \mathrm{GtC}$ pulse (equivalent to $47.1 \mathrm{ppm}$ ) corresponds to a step increase by $0.61 \mathrm{~W} \mathrm{~m}^{-2}$ at year 0 , followed by a decrease to $0.26 \mathrm{~W} \mathrm{~m}^{-2}$ at year 100 and to $0.16 \mathrm{~W} \mathrm{~m}^{-2}$ at year 1000 . These values are computed from the multi-model mean $\mathrm{IRF}_{\mathrm{CO}_{2}}$ with the help of Eq. (3) and for a reference mixing ratio of $389 \mathrm{ppm}\left(\mathrm{RF}(t)=5.35 \mathrm{~W} \mathrm{~m}^{-2} \ln ((389 \mathrm{ppm}+\right.$ $\left.\left.\mathrm{IRF}_{\mathrm{CO}_{2}}(t) \times 47.1 \mathrm{ppm}\right) / 389 \mathrm{ppm}\right)$ ). What magnitude in the SAT response is to be expected from this forcing? The equilibrium response in global mean surface air temperature (SAT) to these forcing values are $0.49{ }^{\circ} \mathrm{C}$ (year 0), $0.21^{\circ} \mathrm{C}$ (year 100) and $0.13^{\circ} \mathrm{C}$ (year 1000) when assuming for illustrative purposes a typical mid-range climate sensitivity of $3{ }^{\circ} \mathrm{C}$ for a nominal doubling of $\mathrm{CO}_{2}$.

The multi-model mean response in SAT to the $100 \mathrm{GtC}$ pulse emission (Fig. 2a, Tables 6 and 7) is an increase by $0.20 \pm 0.12{ }^{\circ} \mathrm{C}$ within the first $20 \mathrm{yr}$. Afterwards, SAT remains almost constant until year 100. This evolution is a consequence of the delayed response in SAT to the initial increase in radiative forcing as it takes time to heat the surface layers of the ocean with its large heat capacity and heat exchange with the deep ocean. After year 100, SAT is generally closer to steady state with the simulated radiative forcing and

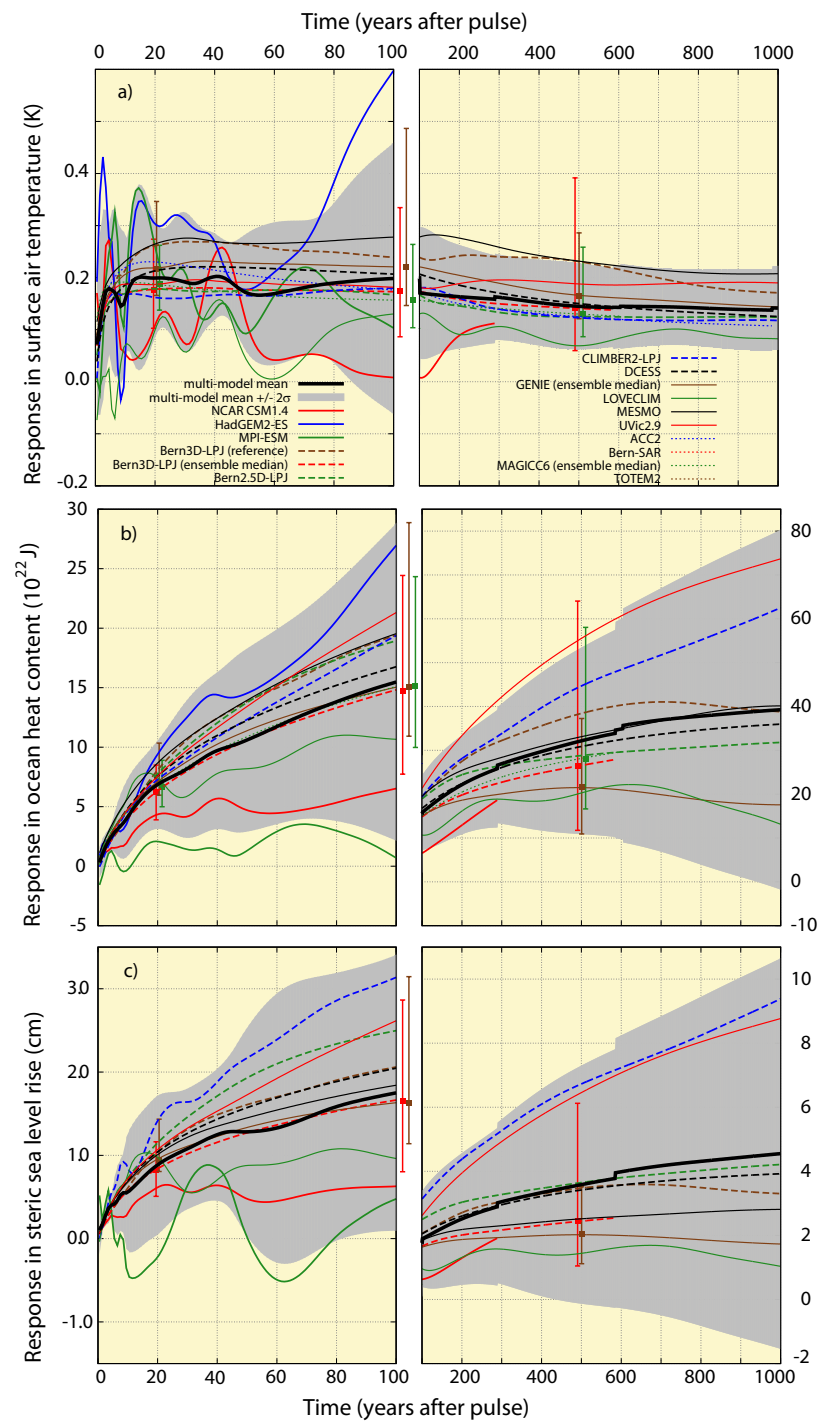

Fig. 2. As Fig. 1 but for the perturbation in global mean surface air temperature (a), in ocean heat content (b), and in steric sea level rise (c). Results are for a $\mathrm{CO}_{2}$ emission pulse of $100 \mathrm{GtC}$ added to a current $\mathrm{CO}_{2}$ concentration of $389 \mathrm{ppm}$ (PD100). We note that the signal-to-noise ratio is small for the models that feature a dynamic atmosphere (HadGEM2-ES, MPI-ESM, NCAR-CSM1.4, and LOVECLIM) and the plotted evolutions for these models represent both the forced response and a contribution from the models' internal (unforced) climate variability. Small abrupt changes in the multi-model mean and confidence range arise from a change in the number of model simulations; different groups run their model over different periods, pending on CPU availability.

decreases slowly to $0.14 \pm 0.08^{\circ} \mathrm{C}$ by year 1000 . Our best estimates for the mean and 5 to $95 \%$ uncertainty ranges in SAT changes and AGTP for $\mathrm{CO}_{2}$ are tabulated for a range of time horizons in Table 6. For a time horizon of $100 \mathrm{yr}$, AGTP of $\mathrm{CO}_{2}$ is $0.49 \times 10^{-15}{ }^{\circ} \mathrm{C}$ per $\mathrm{kg}-\mathrm{CO}_{2}$ and the estimated 5 to $95 \%$ confidence range is $(0.05$ to 0.92$) \times 10^{-15}{ }^{\circ} \mathrm{C}$ per $\mathrm{kg}$ $\mathrm{CO}_{2}$. 
Fuglestvedt et al. (2010) applied the analytical response functions for $\mathrm{CO}_{2}$ as given in the AR4 and the analytical response function for temperature to a change in radiative forcing $(R)$ by Boucher and Reddy (2008) to estimate $\mathrm{AGTP}_{\mathrm{CO}_{2}}$ to $0.68,0.58$ and $0.51 \times 10^{-15}{ }^{\circ} \mathrm{C}$ per kg$\mathrm{CO}_{2}$ for time horizons of 20,100 , and $500 \mathrm{yr}$ respectively. These values are higher than our best estimates of 0.52, 0.49 and $0.40 \times 10^{-15}{ }^{\circ} \mathrm{C}$ per $\mathrm{kg}-\mathrm{CO}_{2}$, but well within the 5 to $95 \%$ confidence range (Table 6). The different values are explained by the difference in temperature responses and less due to the differences in $\mathrm{IRF}_{\mathrm{CO}_{2}}$.

The response in SAT is fairly smooth in most EMICs and box models and the response in SAT is well defined in these models. However, the models that feature a dynamic atmosphere (HadGEM2-ES, MPI-ESM, NCAR CSM1.4, LOVECLIM) show strong interannual-to-decadal variability in SAT of several tenths of a degree Celsius both in the control and in the pulse simulation. We note that the three Earth System Models were run over the first $100 \mathrm{yr}$ only. This internal variability of the more comprehensive models makes the extraction of the response in SAT challenging for these models and a well-defined separation of the forced response from the models' internal variability is not achieved when relying on single simulations. For example HadGEM2-ES shows a positive variation in annual SAT values of several tenths of a degree Celsius towards the end of the simulation in the standard pulse experiment. This yields a difference in SAT of about $0.4^{\circ} \mathrm{C}$ between the smoothed HadGEM2-ES response and the multi-model mean response near year 100 (Fig. 2). This indicates that it is difficult to extract the temperature response for use in GTP from comprehensive models when they are forced with a pulse of modest size as applied here. Excluding the four models with dynamic atmosphere from the averaging has a relatively small effect on the multimodel mean SAT and deviations are well within the uncertainty range.

The response in ocean heat content $(\mathrm{OHC})$ and steric sea level rise (SSLR) is on multi-century timescales (Fig. 2b, c, Table 8). The responses in these quantities are in general much smoother than for SAT as they mainly reflect the time-integrated, cumulative perturbation in air-sea heat fluxes. Multi-model SSLR is $1.8 \pm 1.7 \mathrm{~cm}( \pm 2 \mathrm{sdv})$ at year 100 and $4.6 \pm 6.1 \mathrm{~cm}$ at year 1000 in response to the $100 \mathrm{GtC}$ pulse. The median in SSLR response in the Bern3D-LPJ ensemble is close to the multi-model mean at year 100 , while the 5 to $95 \%$ confidence interval ranges from 0.7 to $2.8 \mathrm{~cm}$ and is thus smaller than the multi-model range.

The multi-model response in $\mathrm{OHC}$ for the $100 \mathrm{GtC}$ pulse reaches $15 \pm 13 \times 10^{22} \mathrm{~J}$ by year 100 and $40 \pm 41 \times 10^{22} \mathrm{~J}$ by year 1000 . The upper and lower extreme cases in the multi-model ensemble are the ESMs: the MPI-ESM and NCAR CSM1.4 on the low side and the HadGEM2-ES on the high side. This indicates that the responses in globally aggregated values do not depend on the type of model, e.g., ESM versus EMIC. The 5 to $95 \%$ interval in OHC of the MAG-

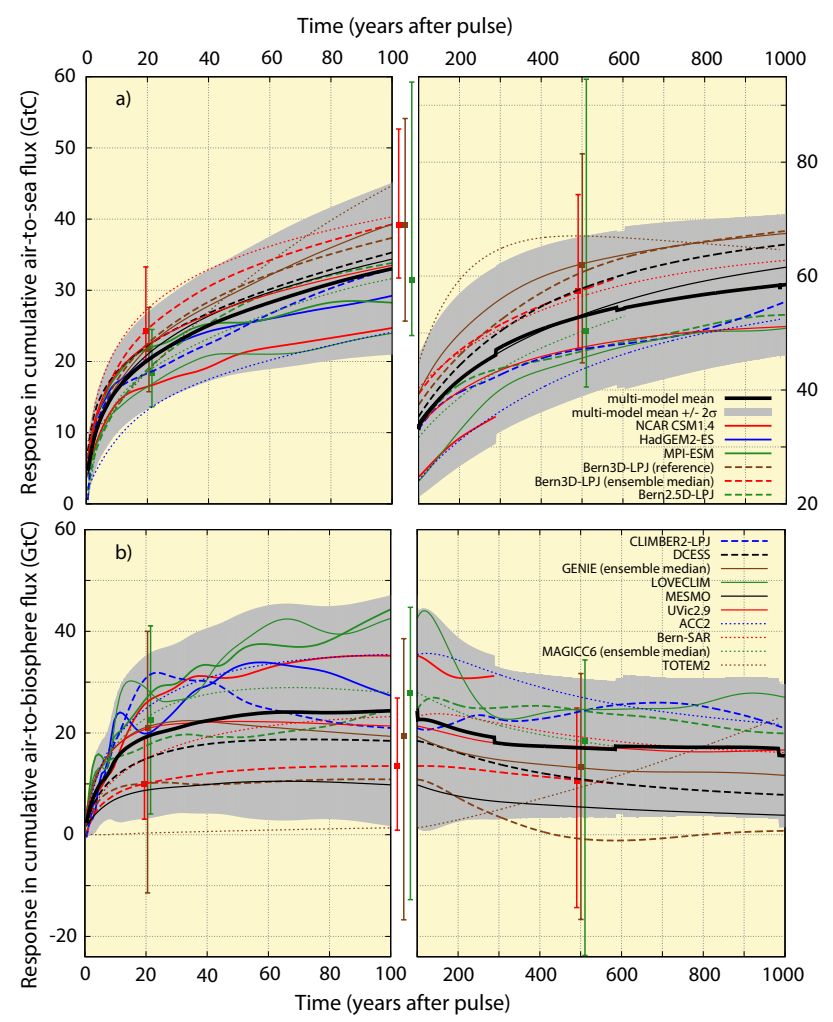

Fig. 3. As Fig. 1, but for the time-integrated perturbation in airto-sea (a) and air-to-land biosphere carbon fluxes (b). Results are for a $\mathrm{CO}_{2}$ emission pulse of $100 \mathrm{GtC}$ added to a present day $\mathrm{CO}_{2}$ concentration of $389 \mathrm{ppm}$ (PD100).

ICC ensemble and of the observation-constrained Bern3DLPJ ensemble is smaller at year 100 and comparable to the model range at year 500 .

In conclusion, AGTP of $\mathrm{CO}_{2}$ varies much less than AGWP for time horizons between 20 and $1000 \mathrm{yr}$. However, relative uncertainties (e.g., in percent of the mean value) in the estimates of AGTP are much larger than those for AGWP, as also inferred with a box model ensemble by Reisinger et al. (2010), and relative uncertainties in the response in ocean heat content and steric sea level rise are also larger than for AGWP.

\subsection{Response in ocean and land carbon}

The carbon that is removed from the atmosphere is taken up by the ocean and the land biosphere (Fig. 3). In the first decade, both the ocean and the land contribute substantially to removing the atmospheric carbon perturbation. Land and ocean absorb on multi-model mean close to $20 \mathrm{GtC}$ during the first $20 \mathrm{yr}$ after the emission. The ocean continues to absorb carbon from the atmosphere and the multi-model perturbation in the ocean carbon inventory is $20 \pm 7 \mathrm{GtC}$ by year $20,33 \pm 12 \mathrm{GtC}$ by year 100 and $59 \pm 12 \mathrm{GtC}$ by year 1000. In other words, $59 \%$ of the emission pulse (multi- 
Table 6. Response in global mean surface air temperature to an emission pulse of $100 \mathrm{GtC}$ added to an atmospheric concentration of 389 ppm.

\begin{tabular}{|c|c|c|c|c|c|}
\hline Time Horizon & $20 \mathrm{yr}$ & $50 \mathrm{yr}$ & $100 \mathrm{yr}$ & $500 \mathrm{yr}$ & $1000 \mathrm{yr}$ \\
\hline & \multicolumn{5}{|c|}{ temperature response $\left({ }^{\circ} \mathrm{C}\right)$} \\
\hline NCAR CSM1.4 & 0.10 & 0.14 & 0.01 & $\mathrm{n} / \mathrm{a}$ & $\mathrm{n} / \mathrm{a}$ \\
\hline HadGEM2-ES & 0.31 & 0.18 & 0.59 & $\mathrm{n} / \mathrm{a}$ & $\mathrm{n} / \mathrm{a}$ \\
\hline MPI-ESM & 0.27 & 0.09 & 0.10 & $\mathrm{n} / \mathrm{a}$ & $\mathrm{n} / \mathrm{a}$ \\
\hline Bern3D-LPJ (reference) & 0.26 & 0.26 & 0.24 & 0.23 & 0.17 \\
\hline \multirow[t]{2}{*}{ Bern3D-LPJ ensemble } & 0.18 & 0.18 & 0.17 & 0.14 & $\mathrm{n} / \mathrm{a}$ \\
\hline & $(0.10-0.27)$ & $(0.10-0.30)$ & $(0.09-0.33)$ & $(0.06-0.39)$ & $\mathrm{n} / \mathrm{a}$ \\
\hline Bern2.5D-LPJ & 0.18 & 0.17 & 0.17 & 0.13 & 0.13 \\
\hline CLIMBER2-LPJ & 0.16 & 0.17 & 0.18 & 0.12 & 0.11 \\
\hline DCESS & 0.21 & 0.22 & 0.21 & 0.15 & 0.12 \\
\hline \multirow[t]{2}{*}{ GENIE ensemble } & 0.22 & 0.23 & 0.22 & 0.16 & $\mathrm{n} / \mathrm{a}$ \\
\hline & $(0.17-0.35)$ & $(0.17-0.46)$ & $(0.15-0.49)$ & $(0.12-0.29)$ & $\mathrm{n} / \mathrm{a}$ \\
\hline LOVECLIM & 0.09 & 0.06 & 0.13 & 0.07 & 0.08 \\
\hline MESMO & 0.26 & 0.27 & 0.28 & 0.23 & 0.2 \\
\hline UVic2.9 & 0.19 & 0.19 & 0.18 & 0.19 & 0.19 \\
\hline $\mathrm{ACC} 2$ & 0.23 & 0.21 & 0.18 & 0.12 & $\mathrm{n} / \mathrm{a}$ \\
\hline Bern-SAR & $\mathrm{n} / \mathrm{a}$ & $\mathrm{n} / \mathrm{a}$ & $\mathrm{n} / \mathrm{a}$ & $\mathrm{n} / \mathrm{a}$ & $\mathrm{n} / \mathrm{a}$ \\
\hline \multirow[t]{2}{*}{ MAGICC6 ensemble } & 0.19 & 0.17 & 0.16 & 0.13 & $\mathrm{n} / \mathrm{a}$ \\
\hline & $(0.14-0.26)$ & $(0.12-0.27)$ & $(0.10-0.26)$ & $(0.09-0.26)$ & $\mathrm{n} / \mathrm{a}$ \\
\hline TOTEM2 & $\mathrm{n} / \mathrm{a}$ & $\mathrm{n} / \mathrm{a}$ & $\mathrm{n} / \mathrm{a}$ & $\mathrm{n} / \mathrm{a}$ & $\mathrm{n} / \mathrm{a}$ \\
\hline \multirow[t]{2}{*}{ multi-model mean } & $0.20 \pm 0.12$ & $0.17 \pm 0.11$ & $0.20 \pm 0.26$ & $0.14 \pm 0.08$ & $0.14 \pm 0.08$ \\
\hline & \multicolumn{5}{|c|}{ Uncertainty ranges $\left({ }^{\circ} \mathrm{C}\right)$} \\
\hline Multi-model range & 0.24 & 0.21 & 0.52 & 0.17 & 0.16 \\
\hline Bern3D-LPJ & 0.17 & 0.21 & 0.25 & 0.33 & $\mathrm{n} / \mathrm{a}$ \\
\hline GENIE & 0.18 & 0.28 & 0.34 & 0.16 & 0.13 \\
\hline MAGICC6 & 0.12 & 0.15 & 0.16 & 0.17 & $\mathrm{n} / \mathrm{a}$ \\
\hline Average of ranges & 0.18 & 0.21 & 0.32 & 0.21 & 0.14 \\
\hline \multirow[t]{2}{*}{ in $\%$ of multi-model mean } & 90 & 123 & 160 & 144 & 101 \\
\hline & \multicolumn{5}{|c|}{ Best estimates for temperature response $\left({ }^{\circ} \mathrm{C}\right)$} \\
\hline mean & 0.19 & 0.19 & 0.18 & 0.15 & 0.14 \\
\hline \multirow[t]{2}{*}{ 5-95\% confidence range } & $(0.10-0.28)$ & $(0.09-0.30)$ & $(0.02-0.34)$ & $(0.05-0.26)$ & $(0.07-0.21)$ \\
\hline & \multicolumn{5}{|c|}{ Best estimates for AGTP of $\mathrm{CO}_{2}\left(10^{-15}{ }^{\circ} \mathrm{C} \mathrm{kg} \mathrm{CO}_{2}^{-1}\right)$} \\
\hline mean & 0.52 & 0.51 & 0.49 & 0.40 & 0.38 \\
\hline $5-95 \%$ confidence range & $0.27-0.76$ & $0.24-0.81$ & $0.05-0.92$ & $0.13-0.70$ & $0.19-0.57$ \\
\hline
\end{tabular}

model average) has been transferred to the ocean by year 1000 (Fig. 3a)

In contrast, the land perturbation remains fairly constant after a few decades up to year 100 and decreases thereafter in most models. On multi-model average, the land has sequestered $19 \pm 16 \mathrm{GtC}$ by year $20,23 \pm 20 \mathrm{GtC}$ by year 100 and $16 \pm 14 \mathrm{GtC}$ by year 1000 . It is interesting to note that the three ensembles include also cases where the land loses carbon to the atmosphere in response to the $100 \mathrm{GtC}$ emission pulse (Fig. 3b). In these model realizations, the climate change resulting from an emission pulse forces a carbon loss from land ecosystems that is larger than the positive impacts of elevated atmospheric $\mathrm{CO}_{2}$. This loss is likely predomi- nantly driven by accelerated turnover of soil and litter carbon in response to warming (Joos et al., 2001).

The response in ocean carbon inventory to an emission pulse is relatively well understood. Ocean uptake is mainly driven by physico-chemical processes and uptake rates are governed by the quantitatively well-understood carbonate chemistry in surface waters and by the rates of surface-todeep transport. The latter are constrained by the distribution of transient tracers such as CFCs and bomb-produced radiocarbon in the thermocline (Key et al., 2004). In early generation carbon cycle models such as the Bern-SAR model only these physico-chemical processes were included. This first-order response is modified by other processes such as ocean warming and changes in ocean circulation and 
Table 7. Response in time-integrated global mean surface air temperature to an emission pulse of $100 \mathrm{GtC}$ added to an atmospheric concentration of $389 \mathrm{ppm}$.

\begin{tabular}{|c|c|c|c|c|c|}
\hline Time Horizon & $20 \mathrm{yr}$ & $50 \mathrm{yr}$ & $100 \mathrm{yr}$ & $500 \mathrm{yr}$ & $1000 \mathrm{yr}$ \\
\hline & \multicolumn{5}{|c|}{ time-integrated temperature response $\left({ }^{\circ} \mathrm{C} \mathrm{yr}\right)$} \\
\hline NCAR CSM1.4 & 2.53 & 7.36 & 10.6 & $\mathrm{n} / \mathrm{a}$ & $\mathrm{n} / \mathrm{a}$ \\
\hline HadGEM2-ES & 4.24 & 12.4 & 30.3 & $\mathrm{n} / \mathrm{a}$ & $\mathrm{n} / \mathrm{a}$ \\
\hline MPI-ESM & 3.83 & 8.84 & 19.1 & $\mathrm{n} / \mathrm{a}$ & $\mathrm{n} / \mathrm{a}$ \\
\hline Bern3D-LPJ (reference) & 4.11 & 12.1 & 24.5 & 121 & 219 \\
\hline \multirow[t]{2}{*}{ Bern3D-LPJ ensemble } & 3.20 & 8.61 & 17.3 & 79.7 & $\mathrm{n} / \mathrm{a}$ \\
\hline & $(2.1-4.6)$ & $(5.1-13.5)$ & $(9.5-29.3)$ & $(38-175)$ & $\mathrm{n} / \mathrm{a}$ \\
\hline Bern2.5D-LPJ & 3.15 & 8.40 & 17.1 & 71.0 & 133 \\
\hline CLIMBER2-LPJ & 3.05 & 7.96 & 16.5 & 74.2 & 134 \\
\hline DCESS & 3.38 & 9.96 & 20.6 & 89.8 & 158 \\
\hline \multirow[t]{2}{*}{ GENIE ensemble } & 3.77 & 10.54 & 21.6 & 96.6 & $\mathrm{n} / \mathrm{a}$ \\
\hline & $(3.0-5.2)$ & $(8.2-17.5)$ & $(17-42)$ & $(76-195)$ & $\mathrm{n} / \mathrm{a}$ \\
\hline LOVECLIM & 0.22 & 3.46 & 7.83 & 36.8 & 80.8 \\
\hline MESMO & 4.41 & 12.5 & 26.0 & 129 & 236 \\
\hline UVic2.9 & 3.40 & 9.17 & 18.5 & 94.8 & 189 \\
\hline $\mathrm{ACC} 2$ & 3.99 & 10.55 & 20.0 & 76.9 & $\mathrm{n} / \mathrm{a}$ \\
\hline Bern-SAR & $\mathrm{n} / \mathrm{a}$ & $\mathrm{n} / \mathrm{a}$ & $\mathrm{n} / \mathrm{a}$ & $\mathrm{n} / \mathrm{a}$ & $\mathrm{n} / \mathrm{a}$ \\
\hline \multirow[t]{2}{*}{ MAGICC6 ensemble } & 3.64 & 8.96 & 17.2 & 74.4 & $\mathrm{n} / \mathrm{a}$ \\
\hline & $(2.7-4.7)$ & $(6.6-12.7)$ & $(12-26)$ & $(49-129)$ & $\mathrm{n} / \mathrm{a}$ \\
\hline TOTEM2 & $\mathrm{n} / \mathrm{a}$ & $\mathrm{n} / \mathrm{a}$ & $\mathrm{n} / \mathrm{a}$ & $\mathrm{n} / \mathrm{a}$ & $\mathrm{n} / \mathrm{a}$ \\
\hline \multirow[t]{2}{*}{ multi-model mean } & $3.29 \pm 2.03$ & $9.13 \pm 4.45$ & $18.7 \pm 11.1$ & $82.2 \pm 44.5$ & $158 \pm 91$ \\
\hline & \multicolumn{5}{|c|}{ Uncertainty ranges $\left({ }^{\circ} \mathrm{C}\right.$ yr $)$} \\
\hline Multi-model range & 4.06 & 8.9 & 22.1 & 89.1 & 182 \\
\hline Bern3D-LPJ & 2.52 & 8.34 & 19.8 & 137 & $\mathrm{n} / \mathrm{a}$ \\
\hline GENIE & 2.13 & 9.27 & 24.7 & 119 & 184 \\
\hline MAGICC6 & 2.00 & 6.11 & 14.4 & 80.4 & $\mathrm{n} / \mathrm{a}$ \\
\hline Average of ranges & 2.68 & 8.16 & 20.3 & 106 & 183 \\
\hline \multirow[t]{2}{*}{ in $\%$ of multi-model mean } & 81.4 & 89.3 & 108 & 130 & 116 \\
\hline & \multicolumn{5}{|c|}{ Best estimates for time-integrated temperature response $\left({ }^{\circ} \mathrm{C} \mathrm{yr}\right)$} \\
\hline mean & 3.31 & 8.67 & 17.4 & 82.2 & 155 \\
\hline \multirow[t]{2}{*}{$5-95 \%$ confidence range } & $(2.0-4.7)$ & $(4.6-12.7)$ & $(7.3-27.6)$ & $(29-135)$ & $(64-247)$ \\
\hline & \multicolumn{5}{|c|}{ Best estimates for time-integrated AGTP of $\mathrm{CO}_{2}\left(10^{-15}{ }^{\circ} \mathrm{C} \mathrm{yr} \mathrm{kg}-\mathrm{CO}_{2}^{-1}\right)$} \\
\hline mean & 9.03 & 23.6 & 47.6 & 224 & 424 \\
\hline $5-95 \%$ confidence range & $5.37-12.7$ & $12.5-34.8$ & $20.0-75.2$ & $79.0-369$ & $174-673$ \\
\hline
\end{tabular}

Table 8. Response in ocean heat content and steric sea level rise to an emission pulse of $100 \mathrm{GtC}$ added to an atmospheric concentration of $389 \mathrm{ppm}$. Multiplication by $\left(12 /\left(100 \times 44 \times 10^{12}\right)\right)$ yields the change per $\mathrm{kg}-\mathrm{CO}_{2}$.

\begin{tabular}{lrrrrr}
\hline Time Horizon & $20 \mathrm{yr}$ & $50 \mathrm{yr}$ & $100 \mathrm{yr}$ & $500 \mathrm{yr}$ & $1000 \mathrm{yr}$ \\
\hline \multicolumn{5}{c}{ Best estimates for steric sea level rise (cm) } \\
\hline mean & 0.86 & 1.30 & 1.82 & 3.65 & 4.58 \\
$5-95 \%$ confidence range & $(0.37-1.35)$ & $(0.45-2.14)$ & $(0.59-3.05)$ & $(1.17-6.14)$ & $(0.98-8.17)$ \\
\hline \multicolumn{7}{c}{ Best estimates for ocean heat content change (10 } \\
\hline mean & 6.59 & 10.8 & 15.7 & 32.6 & 39.6 \\
\hline
\end{tabular}


marine biogeochemistry (Plattner et al., 2001; Sarmiento et al., 1998; Joos et al., 1999).

The response of the land biosphere carbon inventory is associated with considerable uncertainties. It is currently not clear whether the land will continue to act as a strong carbon sink or whether climate change will lead to a loss of land carbon that overwhelms the potentially positive influence of elevated atmospheric $\mathrm{CO}_{2}$ and nitrogen input on net primary productivity and carbon stocks. This limited understanding is reflected in the large uncertainty range. We estimate the 5 to $95 \%$ confidence range for the response in land carbon inventory to $45 \mathrm{GtC}$ at year 100 . For comparison, the corresponding uncertainty range for the ocean inventory is $29 \mathrm{GtC}$.

In conclusion, carbon uptake by the land biosphere is about equally important for the evolution of $\mathrm{IRF}_{\mathrm{CO}_{2}}$ as uptake by the ocean during the first two decades after the release. Subsequently, the ocean becomes the dominant carbon sink. The uncertainty range of the terrestrial and oceanic carbon inventories remain substantial over the $1000 \mathrm{yr}$ analysis period.

\subsection{Influence of background conditions, pulse size, and carbon cycle-climate feedback}

\subsubsection{Background conditions}

The response in atmospheric $\mathrm{CO}_{2}$ and cumulative air-tosea and air-to-land carbon fluxes depends sensitively on the background conditions (Fig. 4). Ten out of fifteen models were also used to run the simulations where a $100 \mathrm{GtC}$ emission pulse is added to preindustrial (PI) in addition to present day (PD) conditions. For these models, the time integrated $\mathrm{IRF}_{\mathrm{CO}_{2}}$ at year 100 ranges between 34 and $47 \mathrm{yr}$ for the PI100 case and between 45 and $62 \mathrm{yr}$ for the PD100 case. The lower $\mathrm{CO}_{2}$ perturbation for PI100 is generally due to a higher uptake by both the ocean and the land biosphere and is consistently lower for PI than PD conditions for all individual models.

The responses in SAT, OHC, and SSLR are similar for PI100 and PD100. This is due to two compensating effects (Caldeira and Kasting, 1993; Wuebbles et al., 1995; Reisinger et al., 2011). The time-integrated $\mathrm{CO}_{2}$ response decreases by roughly $23 \%$ from PD to PI conditions. On the other hand, the radiative forcing per unit change in atmospheric $\mathrm{CO}_{2}$ increases by $39 \%$ from PD to PI conditions. The range in time-integrated forcing at year 100 is then almost identical (32 to $43 \mathrm{yr} \mathrm{W} \mathrm{m}^{-2}$ for PI100 versus 29 to $40 \mathrm{yr} \mathrm{W} \mathrm{m}^{-2}$ for PD100).

The ocean uptake capacity regulated by the carbonate chemistry decreases with increasing $\mathrm{CO}_{2}$ and warmer climate conditions are generally associated with a lower solubility of $\mathrm{CO}_{2}$ and a more sluggish surface-to-deep transport (Joos et al., 1999; Roy et al., 2011). As expected, the model range in cumulative air-to-sea flux is smaller for PD (24 to $40 \mathrm{GtC}$ ) than for PI ( 32 to $47 \mathrm{GtC}$ ) conditions and at year 100. The ocean carbon uptake is consistently lower for PD than PI conditions in all models during the first hundred years. In the long-run, the time-integrated ocean uptake becomes larger for PD100 than PI100 in the Bern3D-LPJ model. This is likely related to the large difference in the land carbon responses ( $\sim 26 \mathrm{GtC}$ at year 500$)$ between the PI100 and PD100 cases in this model.

The land carbon uptake in the model depends on factors such as the spatio-temporal evolution of net primary productivity (NPP) under changing $\mathrm{CO}_{2}$ and climate and the change in soil and litter carbon turnover rates with changing climate conditions. It is beyond the scope of this paper to discuss the processes affecting land carbon stocks in detail for the range of models. The response in land carbon inventory to changes in $\mathrm{CO}_{2}$ and climate is complex and regionally distinct. Generally, the models react with an increase in NPP to increasing atmospheric $\mathrm{CO}_{2}$. Temperature and precipitation changes can have both positive and negative effects on NPP, while most models assume that soil and litter turnover rates increase approximately exponentially with increasing temperatures.

The response in land carbon inventory at year 100 ranges between 21 and $36 \mathrm{GtC}$ for PI100 compared to 10 to $42 \mathrm{GtC}$ for PD100. The model spread is thus considerably smaller for the PI100 than for the PD100 case. The response is not consistent among models. LOVECLIM shows a higher land carbon uptake under PD than PI conditions, NCAR CSM1.4 and DCESS show similar changes, whereas most models simulate a reduced land uptake for PD100 compared to PI100.

The response for temporally varying background conditions is in addition explored with one model (Bern3D-LPJ) for illustrative purposes. Emissions of $\mathrm{CO}_{2}$ and non- $\mathrm{CO}_{2}$ agents are prescribed to follow those from the Representative Concentration Pathways RCP2.6, RCP4.5, RCP6.0 and RCP8.5 in the control setup. The same procedure was applied to determine the IRF as in the standard setup. However, forcing $\left(\mathrm{CO}_{2}\right.$, non- $\mathrm{CO}_{2}$, aerosoles, landuse area) was extended based on the RCPs until year 2300 as described in Zickfeld et al. (2012). After year 2300, the forcing is extended until year 3010 by using 2300 values. The pulse was released in year 2010 instead of 2015 as in the 389 ppm background scenario. The evolution of $\mathrm{IRF}_{\mathrm{CO}_{2}}$ (Fig. 5a) is relatively similar between the standard case (389 ppm background) and RCP2.6, but very different for the three other RCP cases. $\mathrm{IRF}_{\mathrm{CO}_{2}}$ decreases in all cases to about $70 \%$ in the first two decades after the pulse. Then, it continues to decrease for the standard and the RCP2.6 cases, whereas $\mathrm{IRF}_{\mathrm{CO}_{2}}$ increases again in the other cases as atmospheric $\mathrm{CO}_{2}$ and global warming continues to rise in these scenarios. For RCP8.5, the pulse fraction remaining airborne is still well above $80 \%$ at year 1000. The time-integrated $\mathrm{IRF}_{\mathrm{CO}_{2}}$ evaluated at year 100 is $62 \mathrm{yr}$ for the $389 \mathrm{ppm}$ background and 66, 68, 69 and $75 \mathrm{yr}$ for RCP2.6, RCP4.5, RCP6.0, and RCP8.5, respectively. The resulting perturbation in radiative forcing is evaluated as difference in forcing between the control without pulse and the 

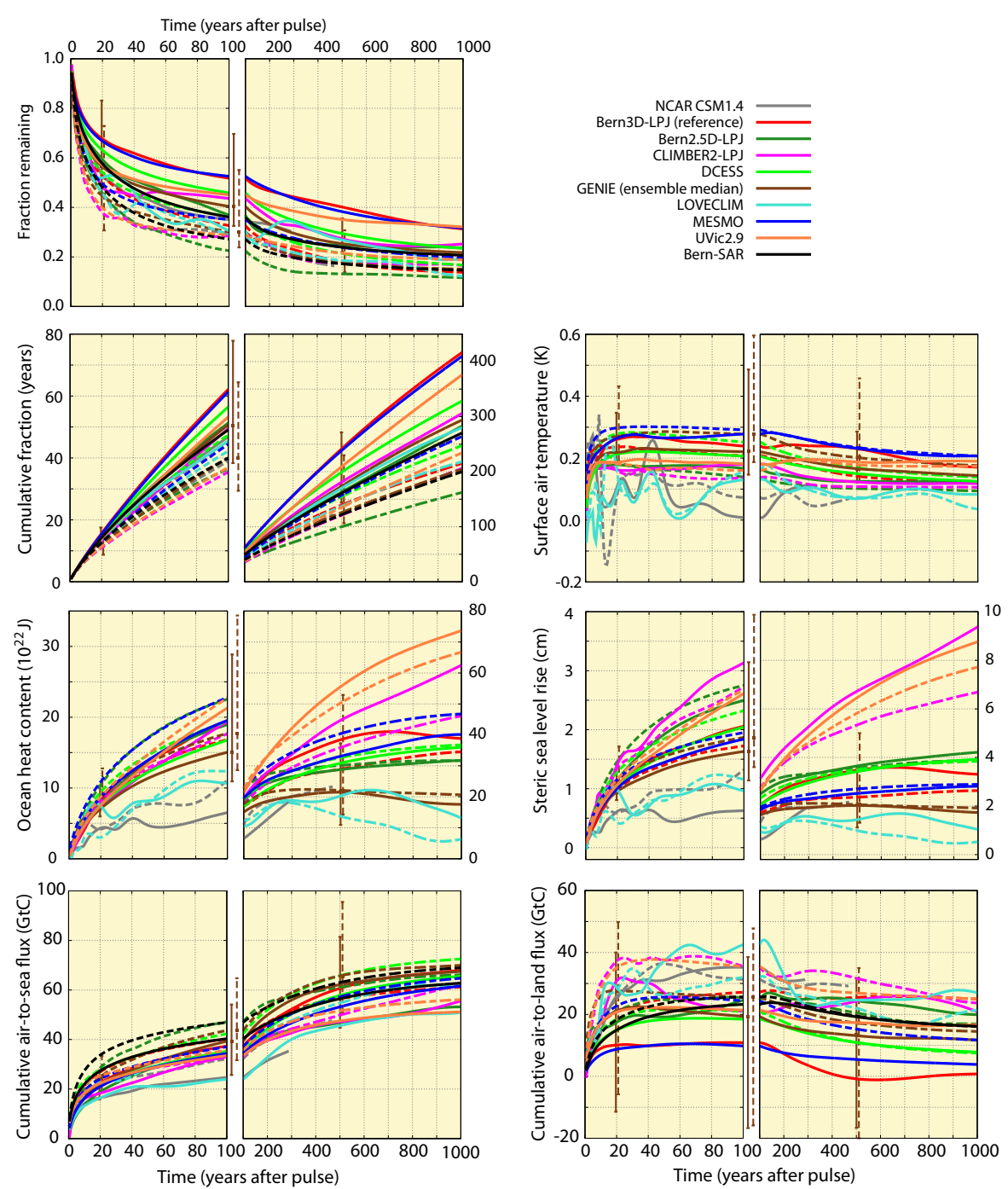

Fig. 4. Influence of the background conditions on the climate-carbon cycle response to a pulse emission of $100 \mathrm{GtC}$ into the atmosphere. Solid lines are for current conditions $\left(\mathrm{CO}_{2, \text { ref }}=389 \mathrm{ppm}, \mathrm{PD} 100\right)$ and dashed lines for preindustrial conditions $\left(\mathrm{CO}_{2, \text { ref }} \sim 280 \mathrm{ppm}\right.$, PI100).

corresponding pulse run and using the non-linear Eq. (3). AGWP range between 105 and $85 \times 10^{-15} \mathrm{yrW} \mathrm{m}^{-2} \mathrm{~kg}$ $\mathrm{CO}_{2}^{-1}$ for the five cases and at year 100. The RCP8.5 case, although featuring the largest time-integrated $\mathrm{IRF}_{\mathrm{CO}_{2}}$, has the smallest AGWP of the five cases as the radiative efficiency decreases with higher $\mathrm{CO}_{2}$ concentration.

\subsubsection{Pulse size}

We next turn to the case where $5000 \mathrm{GtC}$ were released into the atmosphere (PI5000) (Fig. 6). The $5000 \mathrm{GtC}$ pulse run was carried out with 10 models. With this higher input, a considerably greater proportion of $\mathrm{CO}_{2}$ remains in the atmosphere, compared to the release of $100 \mathrm{GtC}$ (PI100). For the PI5000 simulation, the integral of $\mathrm{IRF}_{\mathrm{CO}_{2}}$ through to year 100 is about double that from the PI100 simulation. In other words, the time integrated $\mathrm{IRF}_{\mathrm{CO}_{2}}$ depends sensitively on the pulse size. In particular the ocean uptake of carbon per unit carbon emitted is substantially smaller for the PI5000 than PI100 case.

As for pulse sizes of $100 \mathrm{GtC}$, the SAT increases rapidly within the first two decades after the pulse and remains high for the centuries to follow, while ocean heat content and steric sea level rise increase more gradually. The simulated SAT at year 100 per unit carbon emission is roughly $40 \%$ smaller in the PI5000 than the PI100 case $\left(0.05\right.$ to $1.7^{\circ} \mathrm{C}$ versus 0.08 to $0.3^{\circ} \mathrm{C}$ per $100 \mathrm{GtC}$ ). Similarly, the responses in ocean heat content and steric sea level rise are smaller per unit emission for the larger pulse. This smaller climate response per unit emission is a consequence of the smaller time-integrated forcing per unit emissions for larger pulses. The time-integrated radiative forcing at year 100 is smaller by $39 \%$ for PI5000 than for PI100. The decrease in radiative 

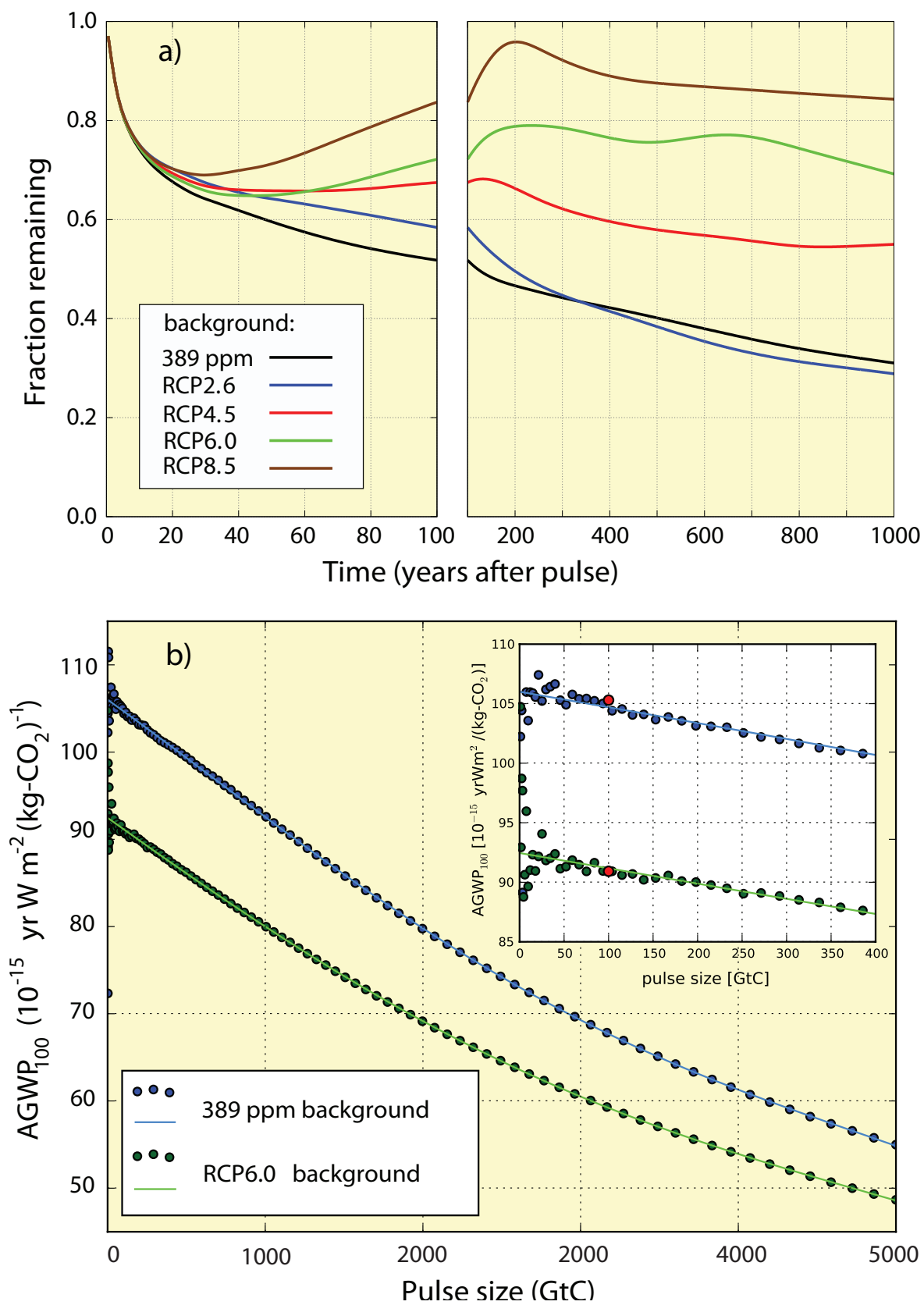

Fig. 5. (a) $\mathrm{IRF}_{\mathrm{CO}_{2}}$ for different background conditions as simulated with the Bern3D-LPJ model (reference). Carbon emissions and emissions of other agents, and land use maps are prescribed following those of the Representative Concentration Pathways. In the runs without pulse, atmospheric $\mathrm{CO}_{2}$ is projected to reach $421,538,670,936 \mathrm{ppm}$ by 2100 and 360, 543, 752, 1962 ppm by year 3000 and for RCP2.6, RCP4.5, RCP6, and RCP8.5 respectively. The $\mathrm{IRF}_{\mathrm{CO}_{2}}$ for the standard setup with a constant $\mathrm{CO}_{2}$ background of 389 ppm is shown by the black line. (b) $\mathrm{AGWP}_{\mathrm{CO}_{2}}$ versus pulse size for two different background conditions. Circles represent results from individual simulations and the lines fits through the results. The standard pulse size of $100 \mathrm{GtC}$ is indicated by red circles.

efficiency (Eq. 3) more than compensates for the larger timeintegrated $\mathrm{IRF}_{\mathrm{CO}_{2}}$ in PI5000 than PI100.

Next, the influence of the pulse size on the Absolute Global Warming Potential of $\mathrm{CO}_{2}$ at year 100 is investigated in more detail (Fig. 5b). Specifically, we ask how representative is the $\mathrm{AGWP}_{\mathrm{CO}_{2}}$ as determined with a pulse in- put of $100 \mathrm{GtC}$ in our standard setup for the limiting case of an infinitely small pulse. The pulse size was varied between $1 \mathrm{GtC}$ and $5000 \mathrm{GtC}$ in the Bern3D-LPJ both for constant background conditions of $389 \mathrm{ppm}$ as well as for the RCP6.0 case. $\mathrm{AGWP}_{\mathrm{CO}_{2}}(t=100 \mathrm{yr})$ is plotted versus pulse size in Fig. 5b. A polynomial fit through the data points yields 
a continuous relationship between pulse size and AGWP over the range from 0 to $5000 \mathrm{GtC}$. The results show that $\mathrm{AGWP}_{\mathrm{CO}_{2}}(t=100 \mathrm{yr})$ for an infinitely small pulse is only about $1.2 \%$ higher than for a pulse size of $100 \mathrm{GtC}$. Results also show that internal climate variability affect the computed $\mathrm{AGWP}_{\mathrm{CO}_{2}}$ significantly for small pulses of a few $\mathrm{GtC}$ only in the Bern3D-LPJ. This is evidenced by the scatter in results for small pulses. In conclusion, the $\mathrm{AGWP}_{\mathrm{CO}_{2}}$ values tabulated in Table 4 are a good approximation for the limiting case of infinitely small carbon additions or removals to the atmosphere.

\subsubsection{Carbon cycle-climate feedbacks}

The influence of the carbon cycle-climate feedbacks is investigated with the Bern3D-LPJ model for emission pulses of 100 and $5000 \mathrm{GtC}$ added to preindustrial conditions (Fig. 7). Results are compared between a setup where climate varies in response to an emission pulse and a setup where climate is kept invariant at preindustrial conditions and for a range of pulse sizes. The time-integrated $\mathrm{IRF}_{\mathrm{CO}_{2}}$ at year 20, 50, 100,500 , and 1000 is $5 \%, 10 \%, 13 \%, 13 \%, 8 \%$ lower for the 100 and $4 \%, 9 \%, 15 \%, 33 \%, 40 \%$ lower for the $5000 \mathrm{GtC}$ pulses if the carbon cycle-climate feedback is suppressed. The reductions in the time-integrated $\mathrm{IRF}_{\mathrm{CO}_{2}}$ due to the carbon cycle-climate feedback are similar to the effects of reducing the pulse size from $5000 \mathrm{GtC}$ to about $2000 \mathrm{GtC}$ and from $100 \mathrm{GtC}$ to $10 \mathrm{GtC}$, respectively (Fig. 7).

In summary, $\mathrm{IRF}_{\mathrm{CO}_{2}}$ and its time integral is lower for preindustrial than present day background conditions and for smaller compared to larger emission pulses. On the other hand, the ocean uptake per unit emission decreases with increasing background $\mathrm{CO}_{2}$ concentrations (and related warmer climate conditions) and increasing pulse sizes. The responses in SAT, ocean heat content and steric sea level rise show little differences between the two $100 \mathrm{GtC}$ cases and a smaller response per unit emission for larger pulse sizes. The time-integrated $\mathrm{IRF}_{\mathrm{CO}_{2}}$ and thus the AGWP depend also on the carbon cycle-climate feedback. However, the most important factor that determines the time-integrated $\mathrm{IRF}_{\mathrm{CO}_{2}}$ and AGWP is the choice of time horizon.

\section{Discussion and conclusion}

We have reassessed the response of the coupled carbon cycleclimate system to an emission pulse of carbon for present day $\mathrm{CO}_{2}$ and climate conditions using a suite of models of various complexity. The multi-model mean response in atmospheric $\mathrm{CO}_{2}$ was fitted by an analytical function (sum of exponentials) for easy use by others. A novel element of the study is a thorough assessment of uncertainties in the simulated responses based on the spread of the multi-model ensemble and of three ensembles with individual models as well as using a linear programming approach constrained by
Table 9. Sensitivity of GWP on the time horizon TH and the perturbation life time of a gas.

\begin{tabular}{lr|rrrrr}
\hline Gas/TH & & $20 \mathrm{yr}$ & $50 \mathrm{yr}$ & $100 \mathrm{yr}$ & $500 \mathrm{yr}$ & $1000 \mathrm{yr}$ \\
\hline & life time (yr) & \multicolumn{5}{|c}{ ratio of GWP(TH) to GWP(TH=100) } \\
\cline { 2 - 7 } $\mathrm{CH}_{4}$ & 12 & 2.98 & 1.71 & 1.00 & 0.28 & 0.17 \\
$\mathrm{~N}_{2} \mathrm{O}$ & 114 & 1.01 & 1.05 & 1.00 & 0.48 & 0.29 \\
$\mathrm{SF}_{6}$ & 3200 & 0.74 & 0.87 & 1.00 & 1.33 & 1.48 \\
\hline
\end{tabular}

observations. These different approaches to estimate the uncertainty in the integrated $\mathrm{IRF}_{\mathrm{CO}_{2}}$ yield comparable results. We also quantified the sensitivity of the responses to the magnitude of the emission pulse and the atmospheric and climatic background conditions. The influence of the climate-carbon cycle feedback on results was investigated within one model. A recent study investigates how differences among the IRFs impact the estimates of GWP and GTP (Olivie and Peters, 2012).

It is important to update the AGWP and AGTP of $\mathrm{CO}_{2}$ and to assess their uncertainty since $\mathrm{CO}_{2}$ is the reference gas in GWP and GTP calculations. It therefore exerts a significant control on the GWP and GTP of any other gas. We find that that the absolute global warming potential (AGWP) of $\mathrm{CO}_{2}$ for a time horizon of $100 \mathrm{yr}$ is $92.5 \times 10^{-15} \mathrm{yr} \mathrm{W} \mathrm{m}^{-2}$ per $\mathrm{kg}-\mathrm{CO}_{2}$ with a 5 to $95 \%$ confidence range of (68 to 117) $\times 10^{-15} \mathrm{yr} \mathrm{W} \mathrm{m}^{-2}$ per kg-CO $\mathrm{CO}_{2}$ (Table 4). Although, the ocean absorbs most of the emission pulse, the uncertainty in the perturbation of the land carbon inventory (in absolute units) is larger than for the perturbation in the ocean carbon inventory. This is related to different responses of the land biosphere models to changes in atmospheric $\mathrm{CO}_{2}$ and climate and reflects our incomplete knowledge on these terrestrial processes.

There are also uncertainties related to the experimental setup. The time-integrated $\mathrm{CO}_{2}$ impulse response at year 100 is about twice as large for an emission pulse of $5000 \mathrm{GtC}$ compared to our standard pulse size of $100 \mathrm{GtC}$. An emission of $5000 \mathrm{GtC}$ is an extreme case in the context of Global Warming Potential (GWP), though within reach when burning all fossil resources. Such large pulses are also used in other studies to assess the evolution in the $\mathrm{CO}_{2}$ perturbation over several centuries and up to $10000 \mathrm{yr}$ (Archer et al., 2009; Eby et al., 2009). These studies also find a long-lasting perturbation in atmospheric $\mathrm{CO}_{2}$. A more modest increase of the pulse size from $100 \mathrm{GtC}$ to $1000 \mathrm{GtC}$ yields an increase in the time-integrated $\mathrm{CO}_{2}$ impulse response, used to compute AGWP and GWP, by one third. The influence of the carboncycle climate feedback is found to be of order $10 \%$ to $20 \%$ on the time integrated $\mathrm{CO}_{2}$ impulse response and the AGWP of $\mathrm{CO}_{2}$. The magnitude of this effect varies across models (Friedlingstein et al., 2006; Gillett and Matthews, 2010). The carbon-cycle climate feedback was not included in the IRF of $\mathrm{CO}_{2}$ derived with the Bern-SAR model, but is included in the 

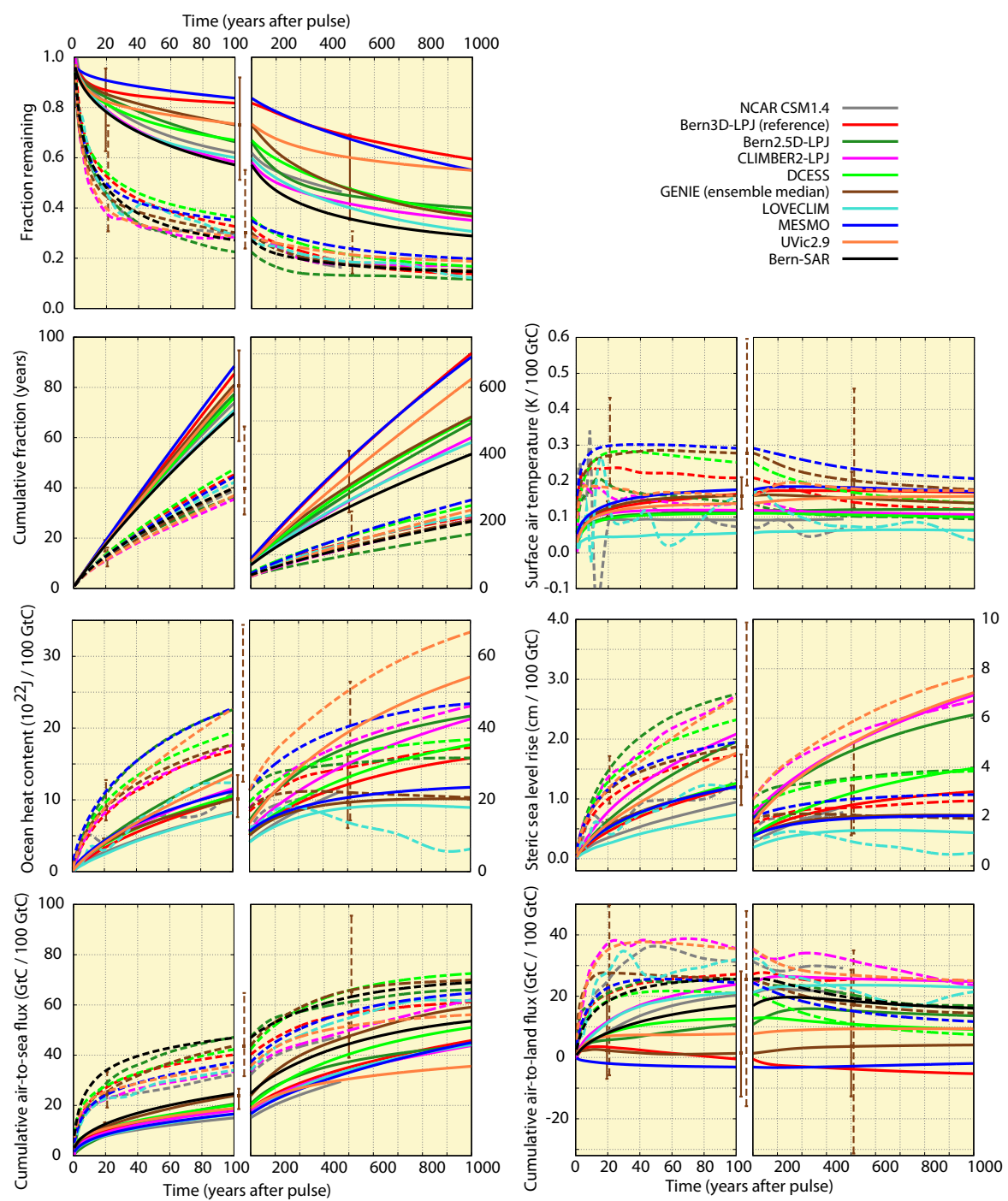

Fig. 6. Response of the carbon cycle-climate system to a pulse emission of $5000 \mathrm{GtC}$ (solid, PI5000) and 100 GtC (dashed, PI100) added to the atmosphere under preindustrial conditions. The responses in surface air temperature, ocean heat content, steric sea level rise, and in carbon fluxes for PI5000 are scaled by a factor of 50 for a better comparison with the $100 \mathrm{GtC}$ pulse.

Bern model versions as used in the TAR and AR4 and corresponding IRFs. A potential inconsistency in GWP can arise if climate feedbacks are included in the calculation of $\mathrm{IRF}_{\mathrm{CO}_{2}}$ and $\mathrm{AGWP}_{\mathrm{CO}_{2}}$, but not in the calculation of the gas under consideration. Although, choices in pulse size, background concentration, and model lead to considerable uncertainties in AGWP and GWP, the most important variable is the time horizon (Table 9).

The subjective choice of the time horizon has a much larger influence on the range in absolute global warming potential of $\mathrm{CO}_{2}$ and in the global warming potential of most other agents than uncertainties associated with the computation of these values for a given time horizon. The uncertainty in AGWP (in units of $\mathrm{yr} \mathrm{W} \mathrm{m}{ }^{-2}$ per kg- $\mathrm{CO}_{2}$ ) can be mapped to a rangein the time horizon (in units of year). For a time horizon of $100 \mathrm{yr}$, the lower and upper bound of the $5-95 \%$ confidence range of the AGWP for $\mathrm{CO}_{2}$ correspond to the multi-model mean value of AGWP evaluated at the time horizon of $68 \mathrm{yr}$ and $135 \mathrm{yr}$. This range of $67 \mathrm{yr}$, steming from uncertainties in the carbon cycle-climate model response, is much smaller than the differences resulting from the subjective choice of alternative time horizons; in the AR4 IPCC report (Table 2.14, p. 212 in Forster et al., 2007) GWP are tabulated for illustrative time horizons of 20,100 , and $500 \mathrm{yr}$. Table 9 illustrates how the GWP of methane, nitrous oxide, and sulphur hexafluoride calculated with a single efold decay of $12 \mathrm{yr}, 114 \mathrm{yr}$ and $3200 \mathrm{yr}$ changes with the choice of time horizon. For example, one could select a time horizon of $1000 \mathrm{yr}$ instead of $100 \mathrm{yr}$ in the UNFCCC process and thereby account somewhat more explicitly for the 

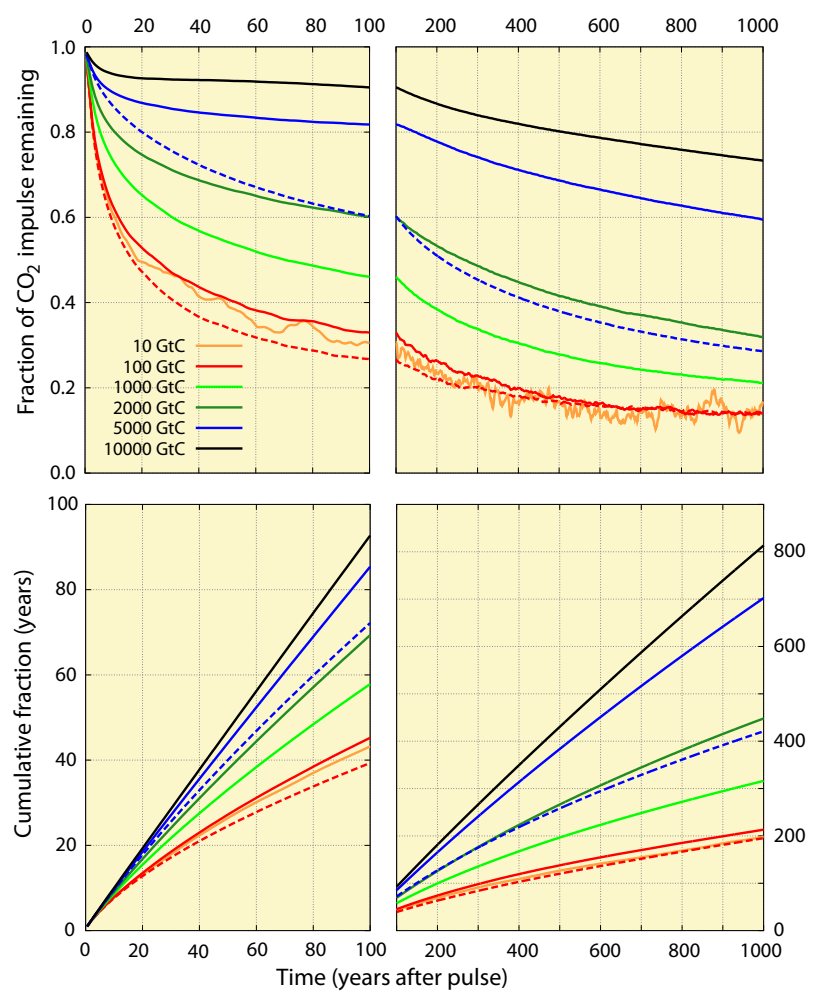

Fig. 7. Influence of pulse size and climate-carbon cycle feedback on the response in atmospheric $\mathrm{CO}_{2}$ and the time-integrated $\mathrm{IRF}_{\mathrm{CO}_{2}}$ as simulated with the Bern3D-LPJ model (standard setup). Pulse emissions, ranging from 10 to $10000 \mathrm{GtC}$ in the individual simulations, are added to the atmosphere under preindustrial conditions. Dashed lines represent simulations where climate was kept constant in the model.

long timescales involved in the Earth System. In this case, the GWP for methane would be more than 5 times smaller and only $17 \%$ (13 to $24 \%$; 5 to $95 \%$ confidence range considering uncertainty in $\mathrm{IRF}_{\mathrm{CO}_{2}}$ only) of that for $100 \mathrm{yr}$. The GWP for $\mathrm{N}_{2} \mathrm{O}$ would be more than 3 times smaller and only $29 \%$ (23 to $41 \%$ ) of that for $100 \mathrm{yr}$, whereas the GWP for $\mathrm{SF}_{6}$ would be about $48 \%$ (15\% to $\left.110 \%\right)$ larger than that for a time horizon of $100 \mathrm{yr}$. On the other hand, selecting a time horizon of $20 \mathrm{yr}$ instead of $100 \mathrm{yr}$ yields a three times larger GWP for methane. A strong influence of the time horizon is also found for GTP and time-integrated GTP (Peters et al., 2011).

The IPCC presented impulse response functions of $\mathrm{CO}_{2}$, $\mathrm{IRF}_{\mathrm{CO}_{2}}$, in its major assessment reports. Figure 8 shows how $\mathrm{IRF}_{\mathrm{CO}_{2}}$ has changed from the IPCC First Assessement Report (FAR), to the Second Assessment Report (SAR), to the Fourth Assessement Report (AR4) and compares these responses with the results of this study. $\mathrm{IRF}_{\mathrm{CO}_{2}}$ was not updated in the Third Assessment Report. Differences in the $\mathrm{IRF}_{\mathrm{CO}_{2}}$ are relatively small. The higher initial airborne fraction published in the FAR is related to the application of an atmosphere-ocean model with a neutral land biosphere, whereas in subsequent reports the land biosphere model absorbs a considerable fraction of the initial emission pulse during the first few decades. The responses published in the SAR and the AR4 are lower than the multi-model model mean response of this study. This is predominantly due to the smaller pulse size and lower $\mathrm{CO}_{2}$ background in the SAR and AR4 setup. The time-integrated $\mathrm{IRF}_{\mathrm{CO}_{2}}$ for the AR4 (Bern2.5DLPJ) and SAR (Bern-SAR) models under the setup of this study (Table 4) are with 49 and 51 yr only slightly lower than the multi-model mean of $52 \mathrm{yr}$ at year 100 . We do not find indications that there are systematic differences in $\mathrm{IRF}_{\mathrm{CO}_{2}}$ between models of different complexities such as EMICs and comprehensive Earth System Models.

In addition to the Absolute Global Warming Potential, we have also quantified the Absolute Global Temperature change Potential and corresponding responses in ocean heat content and steric sea level rise by directly applying the suite of carbon cycle-climate models. The uncertainty in these responses is much larger than the uncertainty in the $\mathrm{IRF}_{\mathrm{CO}_{2}}$ and the AGWP of $\mathrm{CO}_{2}$. This is mainly a consequence of the large range in the climate sensitivity of the different models (Table 2) and their ocean heat uptake efficiency. More general, uncertainties increase along the cause-effect chain from emissions to atmospheric abundance to radiative forcing to climate change. In addition, it is difficult to extract the temperature signal from a relatively small $\mathrm{CO}_{2}$ emission pulse from results of comprehensive ESM as these models feature considerable interannual-to-decadal temperature variability. Larger pulse sizes and/or running ensembles instead of single simulations would improve signal-to-noise ratio. Intercomparison studies that look into the responses of non- $\mathrm{CO}_{2}$ agents might further improve the quantification of metrics and their uncertainties. Yet fundamental issues will remain. Different forcing agents are distinct and any simple metric intended to compare forcing agents relies on subjective choices.

$\mathrm{CO}_{2}$ continues to dominate anthropogenic warming. For the current crop of emission scenarios from the integrated assessment community (Weyant et al., 2006; Van Vuuren et al., 2008), the contribution of $\mathrm{CO}_{2}$ to the anthropogenic warming by 2100 is estimated using an emission-driven climate model to be 58 to $76 \%$ of that of all greenhouse gases together (Strassmann et al., 2009). Independent from the choice of emission metric, the long life time of the anthropogenic $\mathrm{CO}_{2}$ perturbation implies that anthropogenic emissions of $\mathrm{CO}_{2}$ must be reduced if greenhouse gas forcing and anthropogenic climate change are to be stabilized (Siegenthaler and Oeschger, 1978). 


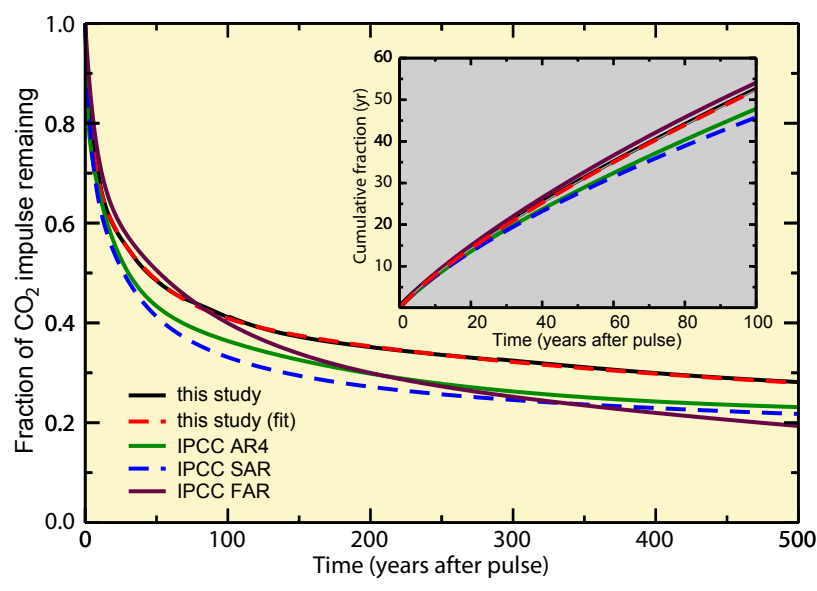

Fig. 8. The impulse response function for $\mathrm{CO}_{2}\left(\mathrm{IRF}_{\mathrm{CO}_{2}}\right)$ as used to compute GWP in the IPCC First (FAR), Second (SAR) and Fourth (AR4) Assessment Report and from this study. The red curve is a fit to the multi-model mean shown in black. The inset shows the time-integrated $\mathrm{IRF}_{\mathrm{CO}_{2}}$ for the first $100 \mathrm{yr}$ after the emission pulse.

\section{Appendix A}

\section{Model descriptions}

ACC2: the Aggregated Carbon Cycle, Atmospheric Chemistry and Climate model (ACC2) (Tanaka et al., 2007; Tanaka, 2008) consists of a box model of the global carbon cycle, simple parameterizations of the atmospheric chemistry, and a land-ocean energy balance model. Most relevant to this study is the carbon cycle component, which is a four-layer atmosphere-ocean box model coupled with a four-reservoir land biosphere box model (Sect. 2.1 of Tanaka, 2008). The saturation of the ocean $\mathrm{CO}_{2}$ uptake under rising atmospheric $\mathrm{CO}_{2}$ concentration is dynamically reproduced by the thermodynamic equilibrium for carbonate species. The $\mathrm{CO}_{2}$ fertilization effect is parameterized by the $\beta$ factor. The temperature sensitivity of the soil respiration is modeled through the $Q 10$ parameter. The land and ocean $\mathrm{CO}_{2}$ uptake is influenced by the temperature change. Values of uncertain parameters (including the $\beta$ factor and the $Q 10$ parameter) are estimated based on an inverse estimation setup (Sect. 3 of Tanaka, 2008), in which a large number of parameters are simultaneously optimized by using associated historical observations and prior parameter estimates including their uncertainties from year 1750 to 2000 (Tables 3.1 and 3.2 of Tanaka, 2008). Parameter values estimated through the inverse estimation are consistently used in projections beyond 2000. The simplified process representations in ACC2 allow one to perform a sensitivity analysis for the $\mathrm{CO}_{2}$ response under various sets of assumptions. ACC 2 has been applied to several studies (Tanaka et al., 2009a, b, 2012).

Bern-SAR: this model was applied to calculate the $\mathrm{CO}_{2}$ impulse response function as used for the Global Warming
Potentials of IPCC 1994 report on Radiative Forcing, the IPCC Second Assessment Report and the Kyoto Protocol. The Bern model (Siegenthaler and Joos, 1992; Joos et al., 1996) is designed to compute the uptake of anthropogenic carbon by land and ocean. It links a well-mixed atmosphere with the High-Latitude Exchange/Interior DiffusionAdvection(HILDA) ocean model and a 4-box representation of the land biosphere (Siegenthaler and Oeschger, 1987). Model parameters of the box-diffusion-type ocean model were determined such that the model reproduces the oceanic distribution of natural and bomb-produced radiocarbon. Net primary production on land increases with the natural logarithm of $\mathrm{CO}_{2}$ and the scaling factor $(\beta=0.27)$ was chosen in order to close the atmospheric $\mathrm{CO}_{2}$ budget in the early nineties.

Bern2.5D-LPJ: this model was used to calculate the $\mathrm{CO}_{2}$ impulse response function for the IPCC AR4 report (Forster et al., 2007, p. 213). Here, the same code version as in the AR4 was used and subsequent updates of the land biosphere component (LPJ) are not included. The Bern2.5DLPJ (or Bern2.5CC in Plattner et al., 2008) reduced complexity climate model includes components describing (1) the physical climate system, (2) the cycling of carbon and related elements, and (3) a module to calculate concentrations of non- $\mathrm{CO}_{2}$ greenhouse gases and radiative forcing by atmospheric $\mathrm{CO}_{2}$, non- $\mathrm{CO}_{2}$ greenhouse gases, and aerosols (Plattner et al., 2008). The ocean physical component is the zonally averaged, three-basin circulation model of Stocker et al. (1992), coupled to a zonally and vertically averaged atmospheric energy balance model, including an active hydrological cycle (Schmittner and Stocker, 1999). The ocean biogeochemical component includes a simple prognostic description of the cycles of carbon, carbon isotopes, oxygen, and carbon-related tracers (Marchal et al., 1998; Joos et al., 1999; Plattner et al., 2001). The terrestrial biosphere component is the Lund-Potsdam-Jena (LPJ) dynamic global vegetation model at $3.75^{\circ} \times 2.5^{\circ}$ resolution as used by Joos et al. (2001); Gerber et al. (2003) and described in detail by Sitch et al. (2003). Vegetation is represented by nine plant functional types. Fertilization of plants by increasing atmospheric $\mathrm{CO}_{2}$ concentrations is modeled according to a modified Farquhar scheme (Farquhar et al., 1980; Haxeltine and Prentice, 1996). The module designed to calculate radiative forcing by atmospheric $\mathrm{CO}_{2}$, non- $\mathrm{CO}_{2}$ greenhouse gases, and aerosols is based on work summarized in Fuglestvedt and Berntsen (1999) and Joos et al. (2001). The climate sensitivity is $3.2 \mathrm{~K}$ for a nominal doubling of $\mathrm{CO}_{2}$.

Bern3D-LPJ: Bern3D-LPJ is an Earth System Model of Intermediate Complexity with a fully coupled carbon cycle and components that represent the ocean and sea ice, ocean sediments, the atmosphere, and the terrestrial biosphere. The ocean component is a seasonally forced three-dimensional frictional geostrophic global ocean model (Edwards et al., 1998) with a resolution of $36 \times 36$ boxes in the horizontal direction and 32 vertical layers (Müller et al., 2006). Marine 
biogeochemical cycles are implemented following OCMIP2 (Najjar and Orr, 1999; Orr et al., 1999; Najjar et al., 2007) with the addition of prognostic formulations for biological productivity and the cycling of iron, silica, ${ }^{13} \mathrm{C}$ and ${ }^{14} \mathrm{C}$ (Parekh et al., 2008; Tschumi et al., 2008), as well as a sedimentary component (Tschumi et al., 2011; Gehlen et al., 2006; Heinze et al., 1999). The atmosphere is represented by a single-layer energy and moisture balance model with the same horizontal resolution as the ocean component (Ritz et al., 2011). The $\mathrm{CO}_{2}$ forcing is calculated after (Myhre et al., 1998) and the model is tuned to simulate an equilibrium climate sensitivity of $3{ }^{\circ} \mathrm{C}$. Other greenhouse gases and volcanic aerosols are prescribed as global radiative forcing, while tropospheric sulphate aerosols are taken into account by changing the surface albedo locally (Steinacher, 2011; Reader and Boer, 1998). The climate sensitivity is $3 \mathrm{~K}$ for a nominal doubling of $\mathrm{CO}_{2}$. The terrestrial biosphere component is based on the Lund-Potsdam-Jena (LPJ) Dynamic Global Vegetation Model at $3.75^{\circ} \times 2.5^{\circ}$ resolution (Joos et al., 2001; Sitch et al., 2003). Vegetation is represented by 12 plant functional types and $\mathrm{CO}_{2}$ fertilization is modeled according to the modified Farquhar scheme (Farquhar et al., 1980; Haxeltine and Prentice, 1996). The model has recently been extended with modules to account for land use (Strassmann et al., 2008; Stocker et al., 2011), peatlands and permafrost dynamics (Gerten et al., 2004; Wania et al., 2009a, b), and land surface albedo (Steinacher, 2011). The LPJ component is driven by global mean $\mathrm{CO}_{2}$ concentrations and changes in surface air temperature relative to a reference period by scaling global mean surface temperature change simulated by the Bern3D with spatial patterns of precipitation and temperature (Steinacher, 2011; Stocker et al., 2011).

CLIMBER2-LPJmL: CLIMBER2-LPJml (Kleinen et al., 2010) consists of the Earth System Model of Intermediate Complexity (EMIC) CLIMBER2, coupled to the dynamic global vegetation model (DGVM) LPJmL. CLIMBER2 (Petoukhov et al., 2005) consists of a 2.5dimensional statistical-dynamical atmosphere with a resolution of roughly $51^{\circ}$ (longitude) by $10^{\circ}$ (latitude), a zonally averaged ocean resolving three basins with a latitudinal resolution of $2.5^{\circ}$, and a sea ice model. CLIMBER2 also contains oceanic biogeochemistry, a model for marine biota, and a sediment model (Archer, 1996; Brovkin et al., 2002, 2007). Weathering rates scale to runoff from the land surface. To this EMIC we have coupled the DGVM LPJmL (Sitch et al., 2003; Bondeau et al., 2007; Fader et al., 2010; Portmann et al., 2008) in order to investigate land surface processes at a significantly higher resolution of $0.5 \times 0.5^{\circ}$. Agricultural land use is included in this version of LPJ. Monthly anomalies from the climatology of the climate fields are passed to LPJ, where they are added to climate patterns based on the Climatic Research Unit CRU-TS climate data set (New et al., 2000). The carbon flux between atmosphere and land surface is determined from the annual change in the LPJ carbon pools, and employed in CLIMBER2 to de- termine the $\mathrm{CO}_{2}$ concentration. Biogeochemical feedbacks are thus determined by the combination of CLIMBER 2 and LPJmL, while biogeophysical effects are solely determined by CLIMBER2. The climate sensitivity is $3 \mathrm{~K}$.

DCESS: the DCESS model consists of fully coupled modules for the atmosphere, ocean, ocean sediment, land biosphere and lithosphere (Shaffer et al., 2008). The model geometry consists of one hemisphere, divided into two $360^{\circ} \times$ $52^{\circ}$ zones. Long term climate sensitivity has been calibrated to $3{ }^{\circ} \mathrm{C}$. The atmosphere component considers radiation balance, heat and gas exchanges with other modules, and meridional transport of heat and water vapor between low-mid latitude and high latitude zones. The ocean component is $270^{\circ}$ wide and extends from the equator to $70^{\circ}$ latitude. Both ocean sectors are divided into 55 layers with $100 \mathrm{~m}$ vertical resolution. Each layer is assigned an ocean sediment section, with width determined from observed ocean depth distributions. Sea ice and snow cover are diagnosed from estimated atmospheric temperature profiles. Circulation and mixing are prescribed, with values calibrated from observations as in the HILDA model (Shaffer and Sarmiento, 1995). Biogenic production of particulate organic matter in the ocean surface layer depends on phosphate availability but with lower efficiency in the high latitude zone. The calcite to organic carbon rain ratio depends on surface layer temperature. The ocean sediment component considers calcium carbonate dissolution as well as oxic-anoxic organic matter remineralisation. The land biosphere component includes leaves, wood, litter and soil. Here, it has been modified to include prescribed land use change carbon losses, distributed in proportion to the initial inventory sizes of the module components. With this change, the model $\mathrm{CO}_{2}$ fertilization factor, originally 0.65 , has been recalibrated to 0.37 . Finally, the lithosphere component considers outgassing and climate-dependent weathering of carbonate and silicate rocks, as well as rocks containing old organic carbon and phosphorus. The atmospheric methane module was not used here.

GENIE: the GENIE-1 physical model comprises the 3D frictional geostrophic ocean model GOLDSTEIN, with a resolution of $36 \times 36$ boxes in the horizontal direction and 16 vertical levels, coupled to a 2-D energy moisture balance atmosphere and a thermodynamic-dynamic sea-ice model (Edwards and Marsh, 2005). Recent developments (Marsh et al., 2011) include the incorporation of stratification-dependent mixing, a more general equation of state through a parameterization of thermobaricity, and improvements to the representation of fixed wind forcing. The land surface component is ENTS, a dynamic model of terrestrial carbon storage (Williamson et al., 2006) with a relatively simple implementation of spatiotemporal land use change. Ocean chemistry is modeled with BIOGEM (Ridgwell et al., 2007), including iron limitation (Annan and Hargreaves, 2010), and is coupled to the sediment model SEDGEM with fixed weathering, diagnosed during the model spin-up to simulated observed ocean alkalinity (Ridgwell and Hargreaves, 2007). All GE- 
NIE results are derived from ensembles applying the same 20-member parameter set. The selected parameters were filtered from a 100-member, 28-parameter pre-calibrated ensemble, constrained for plausible present-day $\mathrm{CO}_{2}$ concentrations.

HadGEM2-ES: HadGEM2-ES (Collins et al., 2011) couples interactive ocean biogeochemistry, terrestrial biogeochemistry and dust, interactive tropospheric chemistry and aerosol components into an update of the physical model HadGEM1. The physical model contains a 40 level $1 \times 1$ degree, moving to $1 / 3$ rd degree at the equator ocean, and a 38 level $1.875 \times 1.25$ atmosphere (The HadGEM2 Development Team, 2011). HadGEM2-ES has been set-up and used to perform all of the CMIP5 simulations as described by Jones et al. (2011). The ocean biogeochemistry uses the DiatHadOCC model an update of HadOCC (Palmer and Totterdell, 2001), now simulating diatom and non-diatom phytoplankton functional types, a single zooplankton, and cycling of nitrogen, silica and iron. Diat-HadOCC is coupled to other earth system components through the model's physics, iron supplied through dust, air-sea exchange of $\mathrm{CO}_{2}$ and oceanic emission of dimethylsulphide. The terrestrial carbon cycle is represented by the MOSES2 land surface scheme (Essery et al., 2003) which simulates exchange of water, energy and carbon between the land surface and the atmosphere, and the TRIFFID dynamic global vegetation model (Cox, 2001) which simulates the coverage and competition between 5 plant functional types (broadleaf tree, needleleaf tree, C3 and $\mathrm{C} 4$ grass and shrub) and 4 non-vegetated surface types (bare soil, urban, lakes and land-ice).

LOVECLIM: the Earth system model of intermediate complexity LOVECLIM (version 1.1) (Menviel et al., 2008) links the ECBilt atmosphere, the CLIO sea-ice ocean model and a bucket model for land hydrology with the VECODE dynamic vegetation model and the LOCH ocean carbon model. The atmosphere model (ECBilt) is a spectral T21 model, based on quasigeostrophic equations with 3 vertical levels and a horizontal resolution of about $5.625 \times 5.625$ degree. Ageostrophic forcing terms are estimated from the vertical motion field and added to the prognostic vorticity equation and thermodynamic equation.

The sea ice-ocean component (CLIO) (Goosse et al., 1999) consists of a primitive equation ocean general circulation model with $3 \times 3$ degree resolution on a partly rotated grid in the North Atlantic. CLIO uses a free surface and is coupled to a thermodynamic-dynamic sea ice model (Fichefet and Maqueda, 1997). In the vertical there are 20 unevenly spaced levels. Mixing along isopycnals, diapycnal mixing, as well as the effect of mesoscale eddies on transports and mixing and downsloping currents at the bottom of continental shelves are parameterized (Goosse et al., 2010). The ocean, atmosphere and sea ice components model are coupled by exchange of momentum, heat and freshwater fluxes. The hydrological cycle over land is closed by a bucket model for soil moisture and simple river runoff scheme. The global dynamic terres- trial vegetation is modeled using VECODE (Brovkin et al., 1997). Annual mean values of precipitation and temperature are communicated to the vegetation from the atmospheric model. On the basis of these mean values the evolution of the vegetation cover described as a fractional distribution of desert, tree, and grass in each land grid cell is calculated once a year. In the current version, only land albedo (as seen by the atmospheric model) outside the ice sheets is changed by VECODE. LOCH is a three-dimensional global model of the oceanic carbon cycle with prognostic equations for dissolved inorganic carbon, total alkalinity, phosphate, dissolved and particulate organic matter, oxygen and silicates (Goosse et al., 2010; Menviel et al., 2008). The phytoplankton growth is a function of temperature, light and phosphate concentration. The sink term depends on grazing and mortality. Although phytoplankton biomass is a prognostic variable it is not subject to advective transports. Remineralization below the euphotic zone $(0-120 \mathrm{~m})$ is a function of oxygen concentrations. Anoxic remineralization can occur in oxygen-depleted areas but is less efficient. The export production is accompanied by the export of opal assuming a constant silicate-tophosphate ratio. Furthermore $\mathrm{CaCO}_{3}$ (calcite and aragonite) shells are formed as a function of phytoplankton growth. The dissolution of shells occurs in the deepest ocean layer. LOCH is coupled to CLIO, using the same time step. Biogeochemical tracers that are subject to advection and mixing are advected and mixed using the same circulation field and mixing parameters respectively as in CLIO.

MAGICC6: MAGICC is a reduced-complexity climate model with an upwelling-diffusive-entrainment ocean and is coupled to a simple carbon cycle model including $\mathrm{CO}_{2}$ fertilization and temperature feedback parameterizations of the terrestrial biosphere and oceanic uptake. MAGICC version 6 has been calibrated to AOGCMs (Meehl et al., 2007) and carbon cycle models (Friedlingstein et al., 2006) used in the Fourth IPCC Assessment Report (see Meinshausen et al., 2011a and b for details). Varying the parameters in MAGICC to emulate AOGCM/C4MIP model combinations allows to explore the climate response space in terms of concentrations, radiative forcing, and hemispheric land/ocean surface air temperatures spanned by the range of complex climate models. This version of MAGICC6 was also used to produce harmonized GHG concentrations for the new set of Representative Concentration Pathways (Meinshausen et al., 2011b). For this intercomparison, we used a set of 19 AOGCM calibrations and 9 coupled climate-carbon cycle model calibrations.

MESMO: MESMO version 1 (Matsumoto et al., 2008) is based on the C-GOLDSTEIN ocean model (Edwards and Marsh, 2005). It consists of a frictional geostrophic 3-D ocean circulation model coupled to a dynamicthermodynamic sea ice model and atmospheric model of energy and moisture balance. Ocean production is based on prognostic nutrient uptake kinetics of phosphate and nitrate with dependence on light, mixed layer depth, 
temperature, and biomass. Interior ocean ventilation is well calibrated against natural radiocarbon on centennial timescale and against transient anthropogenic tracers on decadal timescales. Here MESMO1 is coupled to a simple prognostic land biosphere model (Williamson et al., 2006) that calculates energy, moisture, and carbon exchanges between the land and the atmosphere. Prognostic variables include vegetation and soil carbon as well as land surface albedo and temperature.

MPI-ESM: the fully comprehensive Earth System Model MPI-ESM of the Max-Planck-Institute for Meteorology in Hamburg, Germany consists of the atmospheric model ECHAM6 (here in T63L47 resolution) with land surface model JSBACH (Raddatz et al., 2007). Each land grid cell is divided into tiles covered with 8 natural and 4 anthropogenic PFTs; vegetation model in JSBACH includes an efficient module for vegetation dynamics (Brovkin et al., 2009). Anthropogenic land use is predetermined. The physical ocean model is MPIOM, which further includes a sea-ice model (Marsland et al., 2003) on a nominal $1.5^{\circ}$ grid with higher resolution in the North Atlantic. Marine biogeochemistry is represented by the Hamburg Ocean carbon cycle HAMOCC 5.1 which operates on the same grid as MPIOM and includes the full carbonate chemistry and a NPZD type model of the biological pump (Maier-Reimer et al., 2005; Maier-Reimer, 1993). MPI-ESM is used here in the same version that is employed for the CMIP5 experiments "MPI-ESM-LR". $\mathrm{CO}_{2}$ is allowed to float freely between the model's carbon reservoirs (i.e., atmosphere, land, and ocean) depending on the state of the compartments and climate-carbon cycle feedbacks are simulated by the model.

NCAR CSM1.4: the physical core of the Climate System Model of the National Centre for Atmospheric Research (NCAR CSM1.4-carbon) (Doney et al., 2006; Fung et al., $2005)$ is a modified version of the NCAR CSM1.4 coupled physical model, consisting of ocean, atmosphere, land and sea ice components integrated via a flux coupler without flux adjustments. Atmospheric $\mathrm{CO}_{2}$ is treated as a prognostic variable whose balance is determined by exchange fluxes with the land and ocean. The ocean model includes a derivate of the OCMIP-2 (Ocean Carbon-Cycle Model Intercomparison Project Phase 2) ocean biogeochemistry model (Najjar et al., 2007) with prognostic formulations for marine biological production. The main processes of the organic and inorganic carbon cycle within the ocean and airsea $\mathrm{CO}_{2}$ flux are included. A parameterization of the marine iron cycle (Doney et al., 2006) considers atmospheric dust deposition/iron dissolution, biological uptake, vertical particle transport and scavenging. Prognostic variables in the ocean include phosphate, dissolved inorganic carbon, alkalinity, oxygen, and dissolved organic phosphorus. The land carbon module combines the NCAR Land Surface Model with a modified version of the terrestrial biogeochemical Carnegie-Ames-Stanford Approach (CASA; Randerson et al., 1997) providing full coupling of energy (via dynamic leaf phenology and hence albedo), water (via transpiration), and carbon cycles of the atmosphere and land. CASA follows the life cycles of plant functional types from carbon assimilation via photosynthesis, to mortality and decomposition, and the return of $\mathrm{CO}_{2}$ to the atmosphere via respiration. NPP is allocated to leafs, roots, and wood with preferred allocation to roots during water-limited conditions and to wood/leaves during light-limited conditions. There are nine soil carbon pools. The transfer rates between them and to the atmosphere are sensitive to soil temperature and soil moisture saturation. The land model does not include other land surface processes that affect atmosphere-biosphere interactions such as an explicit nitrogen cycle, fires and other disturbances, herbivory, dynamic vegetation cover, or anthropogenic land cover change.

TOTEM2: TOTEM2 (Ver et al., 1999; Mackenzie et al., 2011) is a global biogeochemical model of the life-essential elements carbon, nitrogen, and phosphorus. The model comprises thirteen reservoirs: the atmosphere; six terrestrial reservoirs (living biota, humus, inorganic soil, continental soilwater, shallow groundwater, and lakes); three coastalzone reservoirs (organic matter, water, and sediments); and three open ocean reservoirs (organic matter, surface water, and deep water). The coupling of the individual cycles is achieved by the average $\mathrm{C}: \mathrm{N}: \mathrm{P}$ ratios associated with oceanic and terrestrial photosynthesis (Redfield ratios), autorespiration on land and in ocean waters, humus formation, and sedimentation of organic matter in the coastal zone and open ocean. We make a simplifying assumption that these biologically mediated coupling processes apply over many different species and environments, and occur with the same global mean elemental ratios on the decadal to century timescale. All the transfer processes between the model reservoirs are represented by linear or nonlinear equations describing reaction mechanisms and physical transport processes. The model has been shown to reproduce well the atmospheric $\mathrm{CO}_{2}$ concentration for the past $300 \mathrm{yr}$ (Ver et al., 1999).

UVic ESCM: the UVic ESCM version 2.9 (Eby et al., 2009) consists of a primitive equation 3 -D ocean general circulation model coupled to a dynamic-thermodynamic sea-ice model and an atmospheric energy-moisture balance model with dynamical feedbacks (Weaver et al., 2001). The model conserves heat, moisture, and carbon between components to machine precision without flux adjustments. The land surface and terrestrial vegetation components are represented by a simplified version of the Hadley Centre's MOSES landsurface scheme coupled to the dynamic vegetation model TRIFFID (Meissner et al., 2003). Land carbon fluxes are calculated within MOSES and are allocated to vegetation and soil carbon pools (Matthews et al., 2004). Ocean carbon is simulated by means of an OCMIP-type inorganic carboncycle model and a NPZD marine ecosystem model with two nutrients $\left(\mathrm{PO}_{4}\right.$ and $\left.\mathrm{NO}_{3}\right)$, two phytoplankton classes, and prognostic denitrification (Schmittner and Galbraith, 2008). Sediment processes are represented using an oxic- 
only model of sediment respiration (Archer, 1996). Terrestrial weathering is diagnosed from the net sediment flux during spin-up and held fixed at the steady state pre-industrial value for transient simulations. The model was spun up with boundary conditions from the year 1800 for more than $10000 \mathrm{yr}$.

\section{Supplementary material related to this article is available online at: http://www.atmos-chem-phys.net/13/ 2793/2013/acp-13-2793-2013-supplement.pdf.}

Acknowledgements. This project was funded by the Swiss National Science Foundation and the EU FP7 project CARBOCHANGE "Changes in carbon uptake and emissions by oceans in a changing climate" which received funding from the European Community's Seventh Framework Programme under grant agreement no. 264879. Met Office authors were supported by the Joint DECC/Defra Met Office Hadley Centre Climate Programme (GA01101). K. Tanaka is supported by the Marie Curie Intra-European Fellowship within the seventh European Community. NRE and PBH acknowledge support from EU FP7 ERMITAGE grant no. 265170. T. F. and A. T. are grateful to Anne Mouchet for providing the $\mathrm{LOCH}$ carbon cycle component for the LOVECLIM model. TLF is supported by the Carbon Mitigation Initiative (CMI) project at Princeton University, sponsored by BP.

Edited by: M. Heimann

\section{References}

Aamaas, B., Peters, G. P., and Fuglestvedt, J. S.: A synthesis of climate-based emission metrics with applications, Earth Syst. Dynam. Discuss., 3, 871-934, doi:10.5194/esdd-3-871-2012, 2012.

Annan, J. D. and Hargreaves, J. C.: Efficient identification of ocean thermodynamics in a physical/biogeochemical ocean model with an iterative Importance Sampling method, Ocean Modell., 32, 205-215, doi:10.1016/j.ocemod.2010.02.003, 2010.

Archer, D.: A data-driven model of the global calcite lysocline, Global Biogeochem. Cy., 10, 511-526, doi:10.1029/96gb01521, 1996.

Archer, D., Eby, M., Brovkin, V., Ridgwell, A., Cao, L., Mikolajewicz, U., Caldeira, K., Matsumoto, K., Munhoven, G., Montenegro, A., and Tokos, K.: Atmospheric Lifetime of Fossil Fuel Carbon Dioxide, Annu. Rev. Earth Planet. Sci., 37, 117-134, doi:10.1146/annurev.earth.031208.100206, 2009.

Azar, C. and Johansson, D. J. A.: On the relationship between metrics to compare greenhouse gases - the case of IGTP, GWP and SGTP, Earth Syst. Dynam., 3, 139-147, doi:10.5194/esd-3-1392012, 2012.

Bondeau, A., Smith, P. C., Zaehle, S., Schaphoff, S., Lucht, W., Cramer, W., Gerten, D., Lotze-Campen, H., MÜLler, C., Reichstein, M., and Smith, B.: Modelling the role of agriculture for the 20th century global terrestrial carbon balance, Glob. Change Biol., 13, 679-706, 2007.
Boucher, O.: Comparison of physically- and economically-based $\mathrm{CO}_{2}$-equivalences for methane, Earth Syst. Dynam., 3, 49-61, doi:10.5194/esd-3-49-2012, 2012.

Boucher, O. and Reddy, M. S.: Climate trade-off between black carbon and carbon dioxide emissions, Energy Policy, 36, 193-200, 2008.

Broecker, W. S., Peng, T.-H., and Engh, R.: Modelling the carbon system, Radiocarbon, 22, 565-598, 1980.

Brovkin, V., Ganopolski, A., and Svirezhev, Y.: A continuous climate-vegetation classification for use in climate-biosphere studies, Ecol. Modell., 101, 251-261, doi:10.1016/s03043800(97)00049-5, 1997.

Brovkin, V., Bendtsen, J., Claussen, M., Ganopolski, A., Kubatzki, C., Petoukhov, V., and Andreev, A.: Carbon cycle, vegetation, and climate dynamics in the Holocene: Experiments with the CLIMBER-2 model, Global Biogeochem. Cy., 16, 1139, 11311113, doi:10.1029/2001GB001662, 2002.

Brovkin, V., Ganopolski, A., Archer, D., and Rahmstorf, S.: Lowering of glacial atmospheric $\mathrm{CO}_{2}$ in response to changes in oceanic circulation and marine biogeochemistry, Paleoceanography, 22, PA4202, doi:10.1029/2006pa001380, 2007.

Brovkin, V., Raddatz, T., Reick, C. H., Claussen, M., and Gayler, V.: Global biogeophysical interactions between forest and climate, Geophys. Res. Lett., 36, L07405, doi:10.1029/2009g1037543, 2009.

Caldeira, K. and Kasting, J. F.: Insensitivity of global warming potentials to carbon dioxide emission scenarios, Nature, 366, 251253, 1993.

Cao, L., Eby, M., Ridgwell, A., Caldeira, K., Archer, D., Ishida, A., Joos, F., Matsumoto, K., Mikolajewicz, U., Mouchet, A., Orr, J. C., Plattner, G.-K., Schlitzer, R., Tokos, K., Totterdell, I., Tschumi, T., Yamanaka, Y., and Yool, A.: The role of ocean transport in the uptake of anthropogenic $\mathrm{CO}_{2}$, Biogeosciences, 6, 375-390, doi:10.5194/bg-6-375-2009, 2009.

Collins, W. J., Bellouin, N., Doutriaux-Boucher, M., Gedney, N., Halloran, P., Hinton, T., Hughes, J., Jones, C. D., Joshi, M., Liddicoat, S., Martin, G., O'Connor, F., Rae, J., Senior, C., Sitch, S., Totterdell, I., Wiltshire, A., and Woodward, S.: Development and evaluation of an Earth-System model - HadGEM2, Geosci. Model Dev., 4, 1051-1075, doi:10.5194/gmd-4-10512011, 2011.

Conway, T. and Tans, P. P.: Globally averaged marine surface annual mean data, NOAA/ESRL www.esrl.noaa.gov/gmd/ccgg/trends/, 2012.

Cox, P. M.: Description of the TRIFFID dynamic global vegetation model, Met Office, UK, 2001.

Denman, K. L., Brasseur, G., Chidthaisong, A., Ciais, P., Cox , P., Dickinson, R. E., Hauglustaine, D., Heinze, C., Holland, E., Jacob, D., Lohmann, U., Ramachandra, S., da Silva Dias, P. L., Wofsy, S., and Zhang, X.: Couplings between changes in the climate system and biogeochemistry, in: Climate Change 2007: The Physical Science Basis. Contribution of Working Group I to the Fourth Assessment Report of the Intergovernmental Panel on Climate Change, edited by: Solomon, S., Qin, D., Manning, M., Chen, Z., Marquis, M., Averyt, K. B., Tignor, M., and Miller, H. L., Cambridge University Press, Cambridge United Kingdom and New York, NY, USA, 498-587, 2007.

Doney, S. C., Lindsay, K., Fung, I., and John, J.: Natural variability in a stable, 1000-year global coupled climate-carbon cycle 
simulation, J. Climate, 19, 3033-3054, 2006.

Eby, M., Zickfeld, K., Montenegro, A., Archer, D., Meissner, K. J., and Weaver, A. J.: Lifetime of Anthropogenic Climate Change: Millennial Time Scales of Potential $\mathrm{CO}_{2}$ and Surface Temperature Perturbations, J. Climate, 22, 2501-2511, doi:10.1175/2008jcli2554.1, 2009.

Eby, M., Weaver, A. J., Alexander, K., Zickfeld, K., Abe-Ouchi, A., Cimatoribus, A. A., Crespin, E., Drijfhout, S. S., Edwards, N. R., Eliseev, A. V., Feulner, G., Fichefet, T., Forest, C. E., Goosse, H., Holden, P. B., Joos, F., Kawamiya, M., Kicklighter, D., Kienert, H., Matsumoto, K., Mokhov, I. I., Monier, E., Olsen, S. M., Pedersen, J. O. P., Perrette, M., Philippon-Berthier, G., Ridgwell, A., Schlosser, A., Schneider von Deimling, T., Shaffer, G., Smith, R. S., Spahni, R., Sokolov, A. P., Steinacher, M., Tachiiri, K., Tokos, K., Yoshimori, M., Zeng, N., and Zhao, F.: Historical and idealized climate model experiments: an EMIC intercomparison, Clim. Past Discuss., 8, 4121-4181, doi:10.5194/cpd-84121-2012, 2012.

Edwards, N. R. and Marsh, R.: Uncertainties due to transportparameter sensitivity in an efficient 3-D ocean-climate model, Clim. Dynam., 24, 415-433, doi:10.1007/s00382-004-0508-8, 2005.

Edwards, N. R., Willmott, A. J., and Killworth, P. D.: On the role of topography and wind stress on the stability of the thermohaline circulation, J. Phys. Oceanogr., 28, 756-778, 1998.

Enting, I. G.: On the use of smoothing splines to filter $\mathrm{CO}_{2}$ data, J. Geophys. Res., 92, 10977-10984, 1987.

Enting, I. G.: Ambiguities in the calibration of carbon cycle models, Inverse Problems, 6, L39-L46, 1990.

Enting, I. G. and Mansbridge, J. V.: The incompatibility of ice-core $\mathrm{CO}_{2}$ data with reconstructions of biotic $\mathrm{CO}_{2}$ sources, Tellus, 39B, 318-325, 1987.

Enting, I. G., Wigley, T. M. L., and Heimann, M.: Future Emissions and Concentrations of Carbon Dioxide: Key Ocean/Atmosphere/Land analyses, CSIRO, Division of Atmospheric Research, 1-118, 1994.

Enting, I. G., Rayner, P. J., and Ciais, P.: Carbon Cycle Uncertainty in REgional Carbon Cycle Assessment and Processes (RECCAP), Biogeosciences, 9, 2889-2904, doi:10.5194/bg-9-28892012, 2012.

Essery, R. L. H., Best, M. J., Betts, R. A., Cox, P. M., and Taylor, C. M.: Explicit representation of subgrid heterogeneity in a GCM land-surface scheme, J. Hydrometeorol., 43, 530-543, 2003.

Fader, M., Rost, S., Müller, C., Bondeau, A., and Gerten, D.: Virtual water content of temperate cereals and maize: Present and potential future patterns, J. Hydrol., 384, 218-231, doi:10.1016/j.jhydrol.2009.12.011, 2010.

Farquhar, G. D., von Caemmerer, S., and Berry, J. A.: A biochemical model of photosynthetic $\mathrm{CO}_{2}$ assimilation in leaves of $\mathrm{C} 3$ species, Planta, 149, 78-90, 1980.

Fichefet, T. and Maqueda, M. A. M.: Sensitivity of a global sea ice model to the treatment of ice thermodynamics and dynamics, J. Geophys. Res., 102, 12609-12646, doi:10.1029/97jc00480, 1997.

Forster, P., Ramaswamy, V., Artaxo, P., Berntsen, T., Betts, R., Fahey, D. W., Haywood, J., Lean, J., Lowe, D. C., Myhre, G., Nganga, J., Prinn, R., Raga, G., Schulz, M., and Van Doorland, R.: Changes in Atmospheric Constitutents and in Radiative Forcing, in: Climate Change 2007: The Physical Science Ba- sis. Contribution of Working Group I to Fourth Assessment Report of the Intergovernmental Panel on Climate Change, edited by: Solomon, S., Qin, D., Manning, M., Chen, Z., Marquis, M., Averyt, K. B., Tignor, M., and Miller, H. L., Cambridge United Kingdom and New York, NY, USA, New York, NY, USA, 129234, 2007.

Friedlingstein, P., Cox, P., Betts, R., Bopp, L., von Bloh, W., Brovkin, V., Doney, S., Eby, M., Fung, I., Govindasamy, B., John, J., Jones, C., Joos, F., Kato, T., Kawamiya, M., Knorr, W., Lindsay, K., Matthews, H. D., Raddatz, T., Rayner, R., Reick, C., Roeckner, E., Schnitzler, K.-G., Schnur, R., Strassmann, K., Thompson, S., Weaver, A. J., Yoshikawa, C., and Zeng, N.: Climate-carbon cycle feedback analysis, results from the C4MIP model intercomparison, J. Climate, 19, 3337-3353, 2006.

Friedrich, T., Timmermann, A., Abe-Ouchi, A., Bates, N. R., Chikamoto, M. O., Church, M. J., Dore, J. E., Gledhill, D. K., Gonzalez-Davila, M., Heinemann, M., Ilyina, T., Jungclaus, J. H., McLeod, E., Mouchet, A., and Santana-Casiano, J. M.: Detecting regional anthropogenic trends in ocean acidification against natural variability, Nature Clim. Change, 2, 167-171, 2012.

Fuglestvedt, J. S. and Berntsen, T.: A simple model for scenario studies of changes in global climate, Working Paper, Center for International Climate and Environmental Research, Oslo, 1999:2, 1999.

Fuglestvedt, J., Berntsen, T., Godal, O., and Sausen, R.: Metrics of climate change: Assessing radiative forcing and emission indices, Climatic Change, 267-331, 2003.

Fuglestvedt, J. S., Shine, K. P., Berntsen, T., Cook, J., Lee, D. S., Stenke, A., Skeie, R. B., Velders, G. J. M., and Waitz, I. A.: Transport impacts on atmosphere and climate: Metrics, Atmos. Environ., 44, 4648-4677, doi:10.1016/j.atmosenv.2009.04.044, 2010.

Fung, I., Doney, S. C., Lindsay, K., and John, J.: Evolution of carbon sinks in a changing climate, P. Natl. Acad. Sci., 102, 1120111206, 2005.

Gattuso, J. P., Bijma, J., Gehlen, M., Riebesell, U., and Turley, C.: Ocean acidification: knowns, unknowns, and perspectives, in: Ocean Acidification, edited by: Gattuso, J. P. and Hansson, L., Oxford University Press, Oxford, 291-311, 2011.

Gehlen, M., Bopp, L., Emprin, N., Aumont, O., Heinze, C., and Ragueneau, O.: Reconciling surface ocean productivity, export fluxes and sediment composition in a global biogeochemical ocean model, Biogeosciences, 3, 521-537, doi:10.5194/bg-3521-2006, 2006.

Gerber, S., Joos, F., Brugger, P., Stocker, T. F., Mann, M. E., Sitch, S., and Scholze, M.: Constraining temperature variations over the last millennium by comparing simulated and observed atmospheric $\mathrm{CO}_{2}$, Clim. Dynam., 20, 281-299, 2003.

Gerten, D., Schaphoff, S., Haberlandt, U., Lucht, W., and Sitch, S.: Terrestrial vegetation and water balance - hydrological evaluation of a dynamic global vegetation model, J. Hydrol., 286, 249270, 2004.

Gillett, N. P. and Matthews, H. D.: Accounting for carbon cycle feedbacks in a comparison of the global warming effects of greenhouse gases, Environ. Res. Lett., 5, 1-6, doi:10.1088/17489326/5/3/034011, 2010.

Goosse, H., Deleersnijder, E., Fichefet, T., and England, M. H.: Sensitivity of a global coupled ocean-sea ice model to the 
parameterization of vertical mixing, J. Geophys. Res., 104, 13681-13695, doi:10.1029/1999jc900099, 1999.

Goosse, H., Brovkin, V., Fichefet, T., Haarsma, R., Huybrechts, P., Jongma, J., Mouchet, A., Selten, F., Barriat, P.-Y., Campin, J.M., Deleersnijder, E., Driesschaert, E., Goelzer, H., Janssens, I., Loutre, M.-F., Morales Maqueda, M. A., Opsteegh, T., Mathieu, P.-P., Munhoven, G., Pettersson, E. J., Renssen, H., Roche, D. M., Schaeffer, M., Tartinville, B., Timmermann, A., and Weber, S. L.: Description of the Earth system model of intermediate complexity LOVECLIM version 1.2, Geosci. Model Dev., 3, 603-633, doi:10.5194/gmd-3-603-2010, 2010.

Haxeltine, A. and Prentice, I. C.: A general model for the light use efficiency of primary production, Funct. Ecol., 10, 551-561, 1996.

Heinze, C., Maier-Reimer, E., Winguth, A. M. E., and Archer, D.: A global oceanic sediment model for long-term climate studies, Global Biogeochem. Cy., 13, 221-250, 1999.

Holden, P. B., Edwards, N. R., Gerten, D., and Schaphoff, S.: A model-based constraint on $\mathrm{CO}_{2}$ fertilisation, Biogeosciences, 10 , 339-355, doi:10.5194/bg-10-339-2013, 2013.

Hurtt, G. C., Chini, L. P., Frolking, S., Betts, R. A., Feddema, J., Fischer, G., Fisk, J. P., Hibbard, K., Houghton, R. A., Janetos, A., Jones, C. D., Kindermann, G., Kinoshita, T., Klein Goldewijk, K., Riahi, K., Shevliakova, E., Smith, S., Stehfest, E., Thomson, A., Thornton, P., Vuuren, D. P., and Wang, Y. P.: Harmonization of land-use scenarios for the period 1500-2100: 600 years of global gridded annual land-use transitions, wood harvest, and resulting secondary lands, Climatic Change, 109, 117161, doi:10.1007/s10584-011-0153-2, 2011.

Johansson, D.: Economics- and physical-based metrics for comparing greenhouse gases, Climatic Change, 110, 123-141, doi:10.1007/s10584-011-0072-2, 2012.

Jones, C. D., Hughes, J. K., Bellouin, N., Hardiman, S. C., Jones, G. S., Knight, J., Liddicoat, S., O'Connor, F. M., Andres, R. J., Bell, C., Boo, K.-O., Bozzo, A., Butchart, N., Cadule, P., Corbin, K. D., Doutriaux-Boucher, M., Friedlingstein, P., Gornall, J., Gray, L., Halloran, P. R., Hurtt, G., Ingram, W. J., Lamarque, J.-F., Law, R. M., Meinshausen, M., Osprey, S., Palin, E. J., Parsons Chini, L., Raddatz, T., Sanderson, M. G., Sellar, A. A., Schurer, A., Valdes, P., Wood, N., Woodward, S., Yoshioka, M., and Zerroukat, M.: The HadGEM2-ES implementation of CMIP5 centennial simulations, Geosci. Model Dev., 4, 543-570, doi:10.5194/gmd-4-543-2011, 2011.

Joos, F., Bruno, M., Fink, R., Siegenthaler, U., Stocker, T. F., and LeQuere, C.: An efficient and accurate representation of complex oceanic and biospheric models of anthropogenic carbon uptake, Tellus B, 48, 397-417, 1996.

Joos, F., Plattner, G. K., Stocker, T. F., Marchal, O., and Schmittner, A.: Global warming and marine carbon cycle feedbacks an future atmospheric $\mathrm{CO}_{2}$, Science, 284, 464-467, 1999.

Joos, F., Prentice, I. C., Sitch, S., Meyer, R., Hooss, G., Plattner, G. K., Gerber, S., and Hasselmann, K.: Global warming feedbacks on terrestrial carbon uptake under the Intergovernmental Panel on Climate Change (IPCC) emission scenarios, Global Biogeochem. Cy., 15, 891-908, 2001.

Joos, F., Frölicher, T. L., Steinacher, M., and Plattner, G.-K.: Impact of climate change mitigation on ocean acidification projections, in: Ocean Acidification, edited by: Gattuso, J. P., and Hansson, L., Oxford University Press, Oxford, 273-289, 2011.
Joos, F., Roth, R. Fuglestvedt, J. S., and Peters, G. P.:CO $\mathrm{CO}_{2}$ pulse response function for the calculation of Global Warming Potentials: a multi-model analysis: http://www.climate.unibe.ch/ 〜 joos/IRF_Intercomparison/ (last access: July 2012), 2012.

Kandlikar, M.: The relative role of trace gas emissions in greenhouse abatement policies, Energy Policy, 23, 879-883, 1995.

Key, R. M., Kozyr, A., Sabine, C. L., Lee, K., Wanninkhof, R., Bullister, J. L., Feely, R. A., Millero, F. J., Mordy, C., and Peng, T. H.: A global ocean carbon climatology: Results from Global Data Analysis Project (GLODAP), Global Biogeochem. Cy., 18, GB4031, doi:10.1029/2004GB002247, 2004.

Kleinen, T., Brovkin, V., von Bloh, W., Archer, D., and Munhoven, G.: Holocene carbon cycle dynamics, Geophys. Res. Lett., 37, L02705, doi:10.1029/2009GL041391, 2010.

Mackenzie, F. T., De Carlo, E. H., and Lerman, A.: Coupled C, $\mathrm{N}, \mathrm{P}$, and $\mathrm{O}$ biogeochemical cycling at the land-ocean interface, in: Treatise on Estuarine and Coastal Science, edited by: Wolanski, E. and McLusky, D. S., Academic Press, Waltham, 317-342, 2011.

Maier-Reimer, E.: Geochemical cycles in an ocean general circulation model. Preindustrial tracer distributions, Global Biogeochem. Cy., 7, 645-677, doi:10.1029/93gb01355, 1993.

Maier-Reimer, E. and Hasselmann, K.: Transport and storage of $\mathrm{CO}_{2}$ in the ocean - an inorganic ocean-circulation carbon cycle model, Clim. Dynam., 2, 63-90, 1987.

Maier-Reimer, E., Kriest, I., Segschneider, J., and Wetzel, P.: The Hamburg ocean carbon cycle model HAMOCC5.1 Technical description, Release 1.1, Max-Planck-Institut für Meteorologie, Hamburg, 2005.

Manne, A. S. and Richels, R. G.: An alternative approach to establishing trade-offs among greenhouse gases, Nature, 410, 675677, 2001.

Marchal, O., Stocker, T. F., and Joos, F.: Impact of oceanic reorganizations on the ocean carbon cycle and atmospheric carbon dioxide content, Paleoceanography, 13, 225-244, 1998.

Marsh, R., Müller, S. A., Yool, A., and Edwards, N. R.: Incorporation of the C-GOLDSTEIN efficient climate model into the GENIE framework: "eb_go_gs" configurations of GENIE, Geosci. Model Dev., 4, 957-992, doi:10.5194/gmd-4-957-2011, 2011.

Marsland, S. J., Haak, H., Jungclaus, J. H., Latif, M., and Röske, F.: The Max-Planck-Institute global ocean/sea ice model with orthogonal curvilinear coordinates, Ocean Modell., 5, 91-127, doi:10.1016/s1463-5003(02)00015-x, 2003.

Matsumoto, K., Tokos, K. S., Price, A. R., and Cox, S. J.: First description of the Minnesota Earth System Model for Ocean biogeochemistry (MESMO 1.0), Geosci. Model Dev., 1, 1-15, doi:10.5194/gmd-1-1-2008, 2008.

Matthews, H. D., Weaver, A. J., Meissner, K. J., Gillett, N. P., and Eby, M.: Natural and anthropogenic climate change: incorporating historical land cover change, vegetation dynamics and the global carbon cycle, Clim. Dynam., 22, 461-479, doi:10.1007/s00382-004-0392-2, 2004.

Meehl, G. A., Stocker, T. F., Collins, W. D., Friedlingstein, P., Gaye, A. T., Gregory, J. M., Kitoh, A., Knutti, R., Murphy, J. M., Noda, A., Raper, S. C. B., Watterson, I. G., J., W. A., and Zhao, Z.-C.: Global Climate Projections, in: Climate Change 2007: The Physical Science Basis. Contribution of Working Group I to Fourth Assessment Report of the Intergovernmental Panel on Climate Change, edited by: Solomon, S., Qin, D., Manning, M., Chen, Z., 
Marquis, M., Averyt, K. B., Tignor, M., and Miller, H. L., Cambridge United Kingdom and New York, NY, USA, New York, NY, USA, 747-845, 2007.

Meinshausen, M., Raper, S. C. B., and Wigley, T. M. L.: Emulating coupled atmosphere-ocean and carbon cycle models with a simpler model, MAGICC6 - Part 1: Model description and calibration, Atmos. Chem. Phys., 11, 1417-1456, doi:10.5194/acp11-1417-2011, 2011a.

Meinshausen, M., Smith, S. J., Calvin, K., Daniel, J. S., Kainuma, M. L. T., Lamarque, J.-F., Matsumoto, K., Montzka, S. A., Raper, S. C. B., Riahi, K., Thomson, A., Velders, G. J. M., and van Vuuren, D. P. P.: The RCP greenhouse gas concentrations and their extensions from 1765 to 2300, Climatic Change, 109, 213-241, doi:10.1007/s10584-011-0156-z, 2011b.

Meissner, K. J., Weaver, A. J., Matthews, H. D., and Cox, P. M.: The role of land surface dynamics in glacial inception: a study with the UVic Earth System Model, Clim. Dynam., 21, 515-537, doi:10.1007/s00382-003-0352-2, 2003.

Menviel, L., Timmermann, A., Mouchet, A., and Timm, O.: Climate and marine carbon cycle response to changes in the strength of the Southern Hemispheric westerlies, Paleoceanography, 23, PA4201, doi:10.1029/2008pa001604, 2008.

Meyer, R., Joos, F., Esser, G., Heimann, M., Hooss, G., Kohlmaier, G., Sauf, W., Voss, R., and Wittenberg, U.: The substitution of high-resolution terrestrial biosphere models and carbon sequestration in response to changing $\mathrm{CO}_{2}$ and climate, Global Biogeochem. Cy., 13, 785-802, 1999.

Müller, S. A., Joos, F., Edwards, N. R., and Stocker, T. F.: Water mass distribution and ventilation time scales in a costefficient, three-dimensional ocean model, J. Climate, 19 54795499, doi:10.1175/JCLI3911.1, 2006.

Myhre, G., Highwood, E. J., Shine, K. P., and Stordal, F.: New estimates of radiative forcing due to well mixed greenhouse gases, Geophys. Res. Lett., 25, 2715-1718, 1998.

Najjar, R. G. and Orr, J. C.: OCMIP-2 Biotic-HOWTO: http://www. ipsl.jussieu.fr/OCMIP/, 1999.

Najjar, R. G., Jin, X., Louanchi, F., Aumont, O., Caldeira, K., Doney, S. C., Dutay, J. C., Follows, M., Gruber, N., Joos, F., Lindsay, K., Maier-Reimer, E., Matear, R. J., Matsumoto, K., Monfray, P., Mouchet, A., Orr, J. C., Plattner, G. K., Sarmiento, J. L., Schlitzer, R., Slater, R. D., Weirig, M. F., Yamanaka, Y., and Yool, A.: Impact of circulation on export production, dissolved organic matter, and dissolved oxygen in the ocean: Results from Phase II of the Ocean Carbon-cycle Model Intercomparison Project (OCMIP-2), Global Biogeochem. Cy., 21, GB3007, doi:10.1029/2006GB002857, 2007.

New, M., Hulme, M., and Jones, P.: Representing TwentiethCentury Space-Time Climate Variability. Part II: Development of 1901-96 Monthly Grids of Terrestrial Surface Climate, J. Climate, 13, 2217-2238, doi:10.1175/15200442(2000)013;2217:rtcstc $; 2.0 . c 0 ; 2,2000$.

O'Neill, B. C.: The Jury is Still Out on Global Warming Potentials, Climatic Change, 44, 427-443, doi:10.1023/a:1005582929198, 2000.

Oeschger, H., Siegenthaler, U., Schotterer, U., and Gugelmann, A.: A box diffusion model to study the carbon dioxide exchange in nature, Tellus, 27, 170-192, 1975.

Olivié, D. J. L. and Peters, G. P.: The impact of model variation in $\mathrm{CO}_{2}$ and temperature impulse response functions on emission metrics, Earth Syst. Dynam. Discuss., 3, 935-977, doi:10.5194/esdd-3-935-2012, 2012.

Orr, J. C., Najjar, R. G., Sabine, C., and Joos, F.: OCMIP2 Abiotic-HOWTO: http://www.ipsl.jussieu.fr/OCMIP/phase2/ simulations/Abiotic/HOWTO-Abiotic.html (last access: July 2012), 1999.

Orr, J. C., Fabry, V. J., Aumont, O., Bopp, L., Doney, S. C., Feely, R. A., Gnanadesikan, A., Gruber, N., Ishida, A., Joos, F., Key, R. M., Lindsay, K., Maier-Reimer, E., Matear, R., Monfray, P., Mouchet, A., Najjar, R. G., Plattner, G. K., Rodgers, K. B., Sabine, C. L., Sarmiento, J. L., Schlitzer, R., Slater, R. D., Totterdell, I. J., Weirig, M. F., Yamanaka, Y., and Yool, A.: Anthropogenic ocean acidification over the twenty-first century and its impact on calcifying organisms, Nature, 437, 681-686, 2005.

Palmer, J. R. and Totterdell, I. J.: Production and export in a global ocean ecosystem model, Deep Sea Res. I, 48, 1169-1198, 2001.

Parekh, P., Joos, F., and Müller, S. A.: A modeling assessment of the interplay between aeolian iron fluxes and iron-binding ligands in controlling carbon dioxide fluctuations during Antarctic warm events, Paleoceanography, 23, PA4202, 4201-4214, doi:10.1029/2007PA001531, 2008.

Peters, G. P., Aamaas, B., Berntsen, T., and Fuglestvedt, J. S.: The integrated global temperature change potential (iGTP) and relationships between emission metrics, Environ. Res. Lett., 6, 044021, doi:10.1088/1748-9326/6/4/044021, 2011.

Petoukhov, V., Claussen, M., Berger, A., Crucifix, M., Eby, M., Eliseev, A. V., Fichefet, T., Ganopolski, A., Goosse, H., Kamenkovich, I., Mokhov, I. I., Montoya, M., Mysak, L. A., Sokolov, A., Stone, P., Wang, Z., and Weaver, A. J.: EMIC Intercomparison Project (EMIP-CO ${ }_{2}$ ): comparative analysis of EMIC simulations of climate, and of equilibrium and transient responses to atmospheric $\mathrm{CO}_{2}$ doubling, Clim. Dynam., 25, 363385, doi:10.1007/s00382-005-0042-3, 2005.

Plattner, G. K., Joos, F., Stocker, T. F., and Marchal, O.: Feedback mechanisms and sensitivities of ocean carbon uptake under global warming, Tellus B, 53, 564-592, 2001.

Plattner, G.-K., Knutti, R., Joos, F., Stocker, T. F., von Bloh, W., Brovkin, V., Cameron, D., Driesschaert, E., Dutkiewicz, S., Eby, M., Edwards, N. R., Fichefet, T., Hargreaves, J. C., Jones, C. D., Loutre, M. F., Matthews, H. D., Mouchet, A., Mueller, S. A., Nawrath, S., Price, A., Sokolov, A., Strassmann, K. M., and Weaver, A. J.: Long-term climate commitments projected with climate - carbon cycle models, J. Climate, 21, 2721-2751, 2008.

Plattner, G.-K., Stocker, T., Midgley, P., and Tignor, M.: IPCC Expert Meeting on the Science of Alternative Metrics: Meeting Report, IPCC Working Group I, Technical Support Unit, Bern, Switzerland, 2009.

Portmann, F., Siebert, S., Bauer, C., and Döll, P.: Global Data Set of Monthly Growing Areas of 26 Irrigated Crops, Institute of Physical Geography, University of Frankfurt, Frankfurt am Main, Germany, 2008.

Prather, M. J.: Lifetimes and time-scales in atmospheric chemistry, Philos. T. Roy. Soc. A, 365, 1705-1726, 2007.

Prather, M. J. and Hsu, J.: Coupling of Nitrous Oxide and Methane by Global Atmospheric Chemistry, Science, 330, 952-954, 2010.

Prather, M. J., Penner, J. E., Fuglestvedt, J. S., Kurosawa, A., Lowe, J. A., Höhne, N., Jain, A. K., Andronova, N., Pinguelli, L., Pires de Campos, C., Raper, S. C. B., Skeie, R. B., Stott, P. A., van Aardenne, J., and Wagner, F.: Tracking uncertainties in the causal 
chain from human activities to climate, Geophys. Res. Lett., 36, L05707, doi:10.1029/2008g1036474, 2009.

Prather, M. J., Holmes, C. D., and Hsu, J.: Reactive greenhouse gas scenarios: Systematic exploration of uncertainties and the role of atmospheric chemistry, Geophys. Res. Lett., 39, L09803, doi:10.1029/2012g1051440, 2012.

Prentice, I. C., Farquhar, G. D., Fasham, M. J., Goulden, M. I., Heimann, M., Jaramillo, V. J., Kheshgi, H. S., LeQuéré, C., Scholes, R. J., and Wallace, D. W. R.: The carbon cycle and atmospheric $\mathrm{CO}_{2}$, in: Climate Change 2001: The Scientific Basis, Contribution of Working Group I to the Third Assessment Report of the Intergovernmental Panel on Climate Change, edited by: Houghton, J. T., Ding, Y., Griggs, D. J., Noguer, M., van der Linden, P. J., Dai, X., Maskell, K., and Johnson, C. A., Cambridge University Press, Cambridge, United Kingdom and New York, NY, USA, 183-237, 2001.

Press, W. H., Teukolsky, S. A., Vetterling, W. T., and Flannery, B. P.: Numerical Recipes, Cambridge University Press, Cambridge UK, 1986.

Raddatz, T., Reick, C., Knorr, W., Kattge, J., Roeckner, E., Schnur, R., Schnitzler, K. G., Wetzel, P., and Jungclaus, J.: Will the tropical land biosphere dominate the climate-carbon cycle feedback during the twenty-first century?, Clim. Dynam., 29, 565-574, doi:10.1007/s00382-007-0247-8, 2007.

Randerson, J. T., Thompson, M. V., Conway, T. J., Fung, I. Y., and Field, C. B.: The contribution of terrestrial sources and sinks to trends in the seasonal cycle of atmospheric carbon dioxide, Global Biogeochem. Cy., 11, 535-560, 1997.

Reader, M. C. and Boer, G. J.: The modification of greenhouse gas warming by the direct effect of sulphate aerosols, Clim. Dynam., 14, 593-607, doi:10.1007/s003820050243, 1998.

Reisinger, A., Meinshausen, M., Manning, M., and Bodeker, G.: Uncertainties of global warming metrics: $\mathrm{CO}_{2}$ and $\mathrm{CH}_{4}$, Geophys. Res. Lett., 37, L14707, doi:10.1029/2010GL043803, 2010.

Reisinger, A., Meinshausen, M., and Manning, M.: Future changes in global warming potentials under representative concentration pathways, Environ. Res. Lett., 6, 024020, doi:10.1088/17489326/6/2/024020, 2011.

Ridgwell, A. and Hargreaves, J. C.: Regulation of atmospheric $\mathrm{CO}_{2}$ by deep-sea sediments in an Earth system model, Global Biogeochem. Cy., 21, GB2008, doi:10.1029/2006gb002764, 2007.

Ridgwell, A., Hargreaves, J. C., Edwards, N. R., Annan, J. D., Lenton, T. M., Marsh, R., Yool, A., and Watson, A.: Marine geochemical data assimilation in an efficient Earth System Model of global biogeochemical cycling, Biogeosciences, 4, 87-104, doi:10.5194/bg-4-87-2007, 2007.

Ritz, S. P., Stocker, T. F., and Joos, F.: A coupled dynamical oceanenergy balance atmosphere model for paleoclimate studies, J. Climate, 24, 349-375, 2011.

Roy, T., Bopp, L., Gehlen, M., Schneider, B., Cadule, P., Frölicher, T., Segschneider, J., Tjiputra, J., Heinze, C., and Joos, F.: Regional impacts of climate change and atmospheric $\mathrm{CO}_{2}$ on future ocean carbon uptake:A multi-model linear feedback analysis, J. Climate, 24, 2300-2318, doi:10.1175/2010JCLI3787.1, 2011.

Sarmiento, J. L., Orr, J. C., and Siegenthaler, U.: A perturbation simulation of $\mathrm{CO}_{2}$ uptake in an ocean general circulation model, J. Geophys. Res., 97, 3621-3645, 1992.

Sarmiento, J. L., Hughes, T. M. C., Stouffer, R. J., and Manabe, S.: Simulated response of the ocean carbon cycle to anthropogenic climate warming, Nature, 393, 245-249, 1998.

Schimel, D., Alves, D., Enting, I. G., Heimann, M., Joos, F., Raynaud, D., Wigley, T. M. L., Prather, M., Derwent, R., Ehhalt, D., Fraser, P., Sanhueza, E., Zhou, X., Jonas, P., Charlson, R., Rhode, H., Sadasivan, S., Shine, K. P., Fouquart, Y., Ramaswamy, V., Solomon, S., Srinivasan, J., Albritton, D., Derwent, R., Isaksen, I., Lal, M., and Wuebbles, D.: Radiative Forcing of Climate Change, in: Climate Change 1995: The Science of Climate Change. Contribution of WGI to the Second Assessment Report of the Intergovernmental Panel on Climate Change, edited by: Houghton, J. T., Meira Filho, L. G., Callander, B. A., Harris, N., Kattenberg, A., and Maskell, K., Cambridge University Press, New York, 65-131, 1996.

Schmittner, A. and Galbraith, E. D.: Glacial greenhouse gas fluctuations controlled by ocean circulation changes, Nature, 456, 373-376, doi:10.1038/nature07531, 2008.

Schmittner, A. and Stocker, T. F.: The stability of the thermohaline circulation in global warming experiments, J. Climate, 12, 11171133, 1999.

Shaffer, G. and Sarmiento, J. L.: Biogeochemical cycling in the global ocean 1. A new, analytical model with continuous vertical resolution and high-latitude dynamics, J. Geophys. Res., 100, 2659-2672, doi:10.1029/94jc01167, 1995.

Shaffer, G., Malskær Olsen, S., and Pepke Pedersen, J. O.: Presentation, calibration and validation of the low-order, DCESS Earth System Model (Version 1), Geosci. Model Dev., 1, 17-51, doi:10.5194/gmd-1-17-2008, 2008.

Shine, K.: The global warming potential-the need for an interdisciplinary retrial, Climatic Change, 467-472, 2009.

Shine, K., Fuglestvedt, J., Hailemariam, K., and Stuber, N.: Alternatives to the Global Warming Potential for Comparing Climate Impacts of Emissions of Greenhouse Gases, Climatic Change, 68, 281-302, doi:10.1007/s10584-005-1146-9, 2005.

Shine, K. P., Derwent, R. G., Wuebbles, D. J., and Morcrette, J.J.: Radiative Forcing of Climate, in: Climate Change: The IPCC Scientific Assessment, edited by: Houghton, J. T., Jenkins, G. J., and Ephraums, J. J., Cambridge University Press, Cambridge, United Kingdom and New York, NY, USA, 41-68, 1990.

Siegenthaler, U. and Joos, F.: Use of a Simple-Model for Studying Oceanic Tracer Distributions and the Global Carbon-Cycle, Tellus B, 44, 186-207, 1992.

Siegenthaler, U. and Oeschger, H.: Predicting future atmospheric carbon dioxide levels, Science, 199, 388-395, 1978.

Siegenthaler, U. and Oeschger, H.: Biospheric $\mathrm{CO}_{2}$ emissions during the past 200 years reconstructed by deconvolution of ice core data, Tellus, 46B, 103-142, 1987.

Sitch, S., Smith, B., Prentice, I. C., Arneth, A., Bondeau, A., Cramer, W., Kaplan, J. O., Levis, S., Lucht, W., Sykes, M. T., Thonicke, K., and Venevsky, S.: Evaluation of ecosystem dynamics, plant geography and terrestrial carbon cycling in the LPJ dynamic global vegetation model, Glob. Change Biol., 9, 161-185, 2003.

Solomon, S., Qin, D., Manning, M., Alley, R., Berntsen, T., Bindoff, N. L., Chen, Z., Chidthaisong, A., Gregory, J., Hegerl, G., Heimann, M., Hewitson, B., Hoskins, B., Joos, F., Jouzel, J., Kattsov, V., Lohmann, U., Matsuno, T., Molina, M., Nicholls, N., Overpeck, J., Raga, G., Ramaswamy, V., Ren, J., Rusticucci, M., Somerville, R., Stocker, T. F., Stouffer, R. J., Whetton, P., Wood, R. A., and Wratt, D.: Technical Summary, in: 
Climate Change 2007: The Physical Science Basis, Contribution of Working Group I to the Fourth Assessment Report of the Intergovernmental Panel on Climate Change, edited by: Solomon, S., Qin, D., Manning, M., Chen, Z., Marquis, M., Averyt, K. B., Tignor, M., and Miller, H. L., Cambridge University Press, Cambridge United Kingdom and New York, NY, USA, 19-91, 2007.

Steinacher, M.: Modeling changes in the global carbon cycleclimate system, $\mathrm{PhD}$, Philosophisch-naturwissenschaftliche Fakultät, University of Bern, Bern, 212 pp., 2011.

Stocker, B. D., Strassmann, K., and Joos, F.: Sensitivity of Holocene atmospheric $\mathrm{CO}_{2}$ and the modern carbon budget to early human land use: analyses with a process-based model, Biogeosciences, 8, 69-88, doi:10.5194/bg-8-69-2011, 2011.

Stocker, T. F., Wright, D. G., and Mysak, L. A.: A Zonally Averaged, Coupled Ocean Atmosphere Model for Paleoclimate Studies, J. Climate, 5, 773-797, 1992.

Strassmann, K. M., Joos, F., and Fischer, G.: Simulating effects of land use changes on carbon fluxes: past contributions to atmospheric $\mathrm{CO}_{2}$ increases and future commitments due to losses of terrestrial sink capacity, Tellus B, 60B, 583-603, 2008.

Strassmann, K. M., Plattner, G. K., and Joos, F.: $\mathrm{CO}_{2}$ and non- $\mathrm{CO}_{2}$ radiative forcing agents in twenty-first century climate change mitigation scenarios, Clim. Dynam., 33, 737-749, 2009.

Tanaka, K.: Inverse Estimation for the Simple Earth System Model ACC2 and Its Applications, Ph.D., Universität Hamburg, Hamburg, 296 pp., 2008.

Tanaka, K., Kriegler, E., Bruckner, T., Hooss, G., Knorr, W., and Raddatz, T.: Aggregated Carbon Cycle, Atmospheric Chemistry, and Climate Model (ACC2) - description of the forward and inverse modes, Max Planck Institute for Meteorology, Hamburg, $188,2007$.

Tanaka, K., O’Neill, B., Rokityanskiy, D., Obersteiner, M., and Tol, R.: Evaluating Global Warming Potentials with historical temperature, Climatic Change, 96, 443-466, doi:10.1007/s10584009-9566-6, 2009a.

Tanaka, K., Raddatz, T., O'Neill, B. C., and Reick, C. H. I.: Insufficient forcing uncertainty underestimates the risk of high climate sensitivity, Geophys. Res. Lett., 36, L16709, doi:10.1029/2009GL039642, 2009b.

Tanaka, K., Peters, G. P., and Fuglestvedt, J. S.: Policy Update: Multicomponent climate policy: why do emission metrics matter?, Carbon Management, 1, 191-197, doi:10.4155/cmt.10.28, 2010.

Tanaka, K., Berntsen, T., Fuglestvedt, J. S., and Rypdal, K.: Climate Effects of Emission Standards: The Case for Gasoline and Diesel Cars, Environ. Sci. Technol., 46, 5205-5213, doi:10.1021/es204190w, 2012.

Tarnocai, C., Canadell, J. G., Schuur, E. A. G., Kuhry, P., Mayhitova, G., and Zimov, S.: Soil organic carbon pools in the northern circumpolar permafrost region, Global Biogeochem. Cy., 23, 1-11, 2009.

The HadGEM2 Development Team: Martin, G. M., Bellouin, N., Collins, W. J., Culverwell, I. D., Halloran, P. R., Hardiman, S. C., Hinton, T. J., Jones, C. D., McDonald, R. E., McLaren, A. J., O'Connor, F. M., Roberts, M. J., Rodriguez, J. M., Woodward, S., Best, M. J., Brooks, M. E., Brown, A. R., Butchart, N., Dearden, C., Derbyshire, S. H., Dharssi, I., Doutriaux-Boucher, M., Edwards, J. M., Falloon, P. D., Gedney, N., Gray, L. J., Hewitt, H. T., Hobson, M., Huddleston, M. R., Hughes, J., Ineson, S., Ingram, W. J., James, P. M., Johns, T. C., Johnson, C. E., Jones, A.,
Jones, C. P., Joshi, M. M., Keen, A. B., Liddicoat, S., Lock, A. P., Maidens, A. V., Manners, J. C., Milton, S. F., Rae, J. G. L., Ridley, J. K., Sellar, A., Senior, C. A., Totterdell, I. J., Verhoef, A., Vidale, P. L., and Wiltshire, A.: The HadGEM2 family of Met Office Unified Model climate configurations, Geosci. Model Dev., 4, 723-757, doi:10.5194/gmd-4-723-2011, 2011.

Tol, R., Berntsen, T., O’Neill, B. C., Fuglestvedt, J. S., and Shine, K. P.: A unifying framework for metrics for aggregating the climate effect of different emissions, Environ. Res. Lett., 7, 1-8, 10.1088/1748-9326/7/4/044006, 2012.

Tschumi, T., Joos, F., and Parekh, P.: How important are Southern Hemisphere wind changes for low glacial carbon dioxide? A model study, Paleoceanography, 23, PA4208, doi:10.1029/2008PA001592, 2008.

Tschumi, T., Joos, F., Gehlen, M., and Heinze, C.: Deep ocean ventilation, carbon isotopes, marine sedimentation and the deglacial $\mathrm{CO}_{2}$ rise, Clim. Past, 7, 771-800, doi:10.5194/cp-7-771-2011, 2011.

UNFCCC, FCCC/CP/1997/7 decision 4/CP.5, Guidelines for the preparation of national communications from Parties included in Annex I to the Convention. Secretary of the United Nations Framework Convention on Climate Change, Bonn, Germany: http://unfccc.int/resource/docs/cop5/07.pdf, 1997.

UNFCCC, FCCC/CP/1997/7/Add.1, Methodological issues related to the Kyoto Protocol, Secretary of the United Nations Framework Convention on Climate Change, Bonn, Germany: http: //unfccc.int/resource/docs/cop3/07a01.pdf, 1998.

UNFCCC, FCCC/CP/2002/7/Add.2 Decision 17/CP.8, Guidelines for the preparation of national communications from Parties not included in Annex I to the Convention. Secretary of the United Nations Framework Convention on Climate Change, Bonn, Germany: http://unfccc.int/resource/docs/cop8/ 07a02.pdf\#page=2, 2002.

UNFCCC, FCCC/CP/2011/9/Add.2, Decision 15/CP.17, Revision of the UNFCCC reporting guidelines on annual inventories for Parties included in Annex I to the Convention. Secretary of the United Nations Framework Convention on Climate Change, Bonn, Germany: http://unfccc.int/resource/docs/2011/ cop17/eng/09a02.pdf\#page=23, 2011 a.

UNFCCC, FCCC/KP/CMP/2011/10/Add.1, decision 4/CMP.7, Greenhouse gases, sectors and source categories, common metrics to calculate the carbon dioxide equivalence of anthropogenic emissions by sources and removals by sinks, and other methodological issues. Secretary of the United Nations Framework Convention on Climate Change, Bonn, Germany: http://unfccc.int/ resource/docs/2011/cmp7/eng/10a01.pdf\#page=23, $2011 \mathrm{~b}$.

Van Vuuren, D. P., Meinshausen, M., Plattner, G.-K., Joos, F., Strassmann, K. M., Smith, S. J., Wigley, T. M. L., Raper, S. C. B., Riahi, K., de la Chesnaye, F., den Elzen, M., Fujino, J., Jiang, K., Nakicenovic, N., Paltsev, S., and Reilly, J. M.: Temperature increase of 21 st century mitigation scenarios, P. Natl. Acad. Sci. USA, 105, 15258-15262, 2008.

Ver, L. M. B., Mackenzie, F. T., and Lerman, A.: Biogeochemical responses of the carbon cycle to natural and human perturbations; past, present, and future, American Journal of Science, 299, 762801, 1999.

Wania, R., Ross, I., and Prentice, I. C.: Integrating peatlands and permafrost into a dynamic global vegetation model: 1. Evaluation and sensitivity of physical land surface processes, Global 
Biogeochem. Cy., 23, GB3014, doi:10.1029/2008gb003412, 2009a.

Wania, R., Ross, I., and Prentice, I. C.: Integrating peatlands and permafrost into a dynamic global vegetation model: 2. Evaluation and sensitivity of vegetation and carbon cycle processes, Global Biogeochem. Cy., 23, GB3015, doi:10.1029/2008gb003413, 2009b.

Weaver, A. J., Eby, M., Wiebe, E. C., Bitz, C. M., Duffy, P. B., Ewen, T. L., Fanning, A. F., Holland, M. M., MacFadyen, A., Matthews, H. D., Meissner, K. J., Saenko, O., Schmittner, A. H. W., and Yoshimori, M.: The UVic Earth System Climate Model: Model description, climatology and application to past, present and future climates, Atmos.-Ocean, 39, 361-428, 2001.

Weaver, A. J., Sedlácek, J., Eby, M., Alexander, K., Crespin, E., Fichefet, T., Philippon-Berthier, G., Joos, F., Kawamiya, M., Matsumoto, K., Steinacher, M., Tachiiri, K., Tokos, K., Yoshimori, M., and Zickfeld, K.: Stability of the Atlantic meridional overturning circulation: A model intercomparison, Geophys. Res. Lett., 39, L20709, doi:10.1029/2012g1053763, 2012.
Weyant, J. R., de la Chesnaye, F. C., and Blanford, G. J.: Overview of emf-21: Multigas mitigation and climate policy, Energy Journal, 27, 1-32, 2006.

Williamson, M. S., Lenton, T. M., Shepherd, J. G., and Edwards, N. R.: An efficient numerical terrestrial scheme (ENTS) for Earth system modelling, Ecol. Modell., 198, 362-374, doi:10.1016/j.ecolmodel.2006.05.027, 2006.

Wuebbles, D. J., Jain, A. K., Patten, K. O., and Grant, K. E.: Sensitivity of direct global warming potentials to key uncertainties, Climatic Change, 29, 265-297, 1995.

Zickfeld, K., Eby, M., Weaver, A. J., Crespin, E., Fichefet, T., Goosse, H., Edwards, N. R., Holden, P. B., Eliseev, A. V., Mokhov, I. I., Feulner, G., Kienert, H., Perrette, M., Schneider von Deimling, T., Forest, C. E., Joos, F., Spahni, R., Steinacher, M., Kawamiya, M., Tachiiri, K., Kicklighter, D., Monier, E., Schlosser, A., Sokolov, A. P., Matsumoto, K., Tokos, K., Olsen, S. M., Pedersen, J. O. P., Shaffer, G., Ridgwell, A., Zeng, N., and Zhao, F.: Long-term Climate Change Commitment and Reversibility: An EMIC Intercomparison, J. Climate, in press, 2012. 